\title{
ENSAIOS ENZIMÁTICOS DE PROTEASES DE HIV-1 DE SUBTIPOS BRASILEIROS
}

NÁDIA HELENA MARTINS

Dissertação apresentada ao Instituto de Física de São Carlos, da Universidade de São Paulo, para a obtenção do título de Mestre em Ciências: Física Aplicada opção Física Biomolecular

Orientador: Prof. Dr. Igor Polikarpov 
Martins, Nádia Helena

Ensaios enzimáticos de proteases de HIV-1 de subtipos brasileiros / Nadia Helena Martins; orientador Igor Polikarpov.-- São Carlos, 2007.

$119 \mathrm{f}$.

Dissertação (Mestrado em Física Aplicada - Área de concentração: Física Biomolecular ) - Instituto de Física de São Carlos da Universidade de São Paulo.

1. Protease de HIV. 2. Inibidores de protease. 3. Constante de inibição. I. Título. 
Para mãe, vó e vô 


\section{Agradecimentos}

A Deus.

À minha mãe, por todo seu amor, que sempre se mostrou mais forte nos momentos mais necessários. À minha vó, por desempenhar tão brilhantemente o papel de avó! Ao meu avô, pelo maior exemplo de força que conheço. Obrigada por alicerçarem minha vida!

Ao Prof. Igor Polikarpov, pela oportunidade de fazer parte de seu grupo de pesquisa. A todos os funcionários e professores do Instituto de Física de São Carlos.

Ao apoio financeiro concedido pela FAPESP.

Ao Mario Sanches, um dos maiores culpados pelo meu apego a ciência.

A Sandra Krauchenco, grande amiga e responsável pela realização desse trabalho.

A Paula Amaral, IC dedicadíssima, muito importante nos últimos dias de laboratório.

A todos os professores, funcionários e colegas de trabalho do grupo de Cristalografia de Proteínas.

Às amigas Amanda e Ana Letícia (somos um mulherão!!), Liviasaura (sócia no café errado), Carol Figueira (companheiríssima!!), Carol Hoff (minha irmãzinha loira), Carol Guzzi, Lú e especialmente à Maria (mainha!!)

Aos amigos Wanius, João, Fernando, Napoleão, Lucas, Caqui, Niko, Rodrigo, Maurício. Obrigada por todo carinho e apoio no melhores e piores momentos.

A todos os amigos, porque simplesmente estavam lá! Sem nem perceberem o quanto estavam sendo importantes... 


\section{Resumo}

MARTINS, N. H. Ensaios enzimáticos de proteases de HIV-1 de subtipos brasileiros. 2007. 119f. Dissertação (Mestrado) - Instituto de Física de São Carlos, Universidade de São Paulo, São Carlos, 2007.

Mesmo com o grande número de estudos relacionados à proteases do subtipo $\mathrm{B}$ e de como suas mutações podem interferir na estrutura, na resistência a inibidores e na eficiência catalítica da enzima, existe ainda uma lacuna de como as mudanças polimórficas de proteases de HIV de outros subtipos de HIV-1 interferem nesses fatores. Nesse contexto insere-se esse trabalho, que utilizou proteases de HIV-1 isoladas de pacientes brasileiros HIV-1 infectados com o subtipo F, e outros dois mutantes, sendo que um do subtipo $\mathrm{F}$ e outro do subtipo B para ensaios frente a seis inibidores comercialmente disponíveis: amprenavir, indinavir, lopinavir, nelfinavir, ritonavir e saquinavir. Nossos resultados experimentais revelam que os seis inibidores comerciais estudados são significantemente menos ativos para o subtipo F e para as mutantes quando comparados ao subtipo B. Além disso, os valores de vitalidade dessas proteases também são considerados maiores que os obtidos para a proteína selvagem do subtipo B. O acúmulo de mutações comumente detectadas e o polimorfismo natural tornam a protease selvagem do subtipo F cataliticamente suficiente para manter a viabilidade do vírus e garantir alto grau de resistência cruzada frente a todos os inibidores estudados.

Palavras chave: Protease de HIV, inibidores de protease, constante de inibição. 


\section{Abstract}

MARTINS, N. H. Enzimatic assays of HIV-1 proteases from brazilian subtypes. 2007. 119f. Dissertação (Master Degree) - Instituto de Física de São Carlos, Universidade de São Paulo, São Carlos, 2007.

Despite years of intense research around the world, HIV continues to represent considerable therapeutical challenge. In order to gain more insights into resistance of polymorphic mutations of existing HIV subtypes toward commercially available pharmaceutics, we studied inhibition of subtypes B and F HIV proteases (PRs) [native and two mutant enzymes clinically identified in Brazilian patients] by six commercial inhibitors (amprenavir, indinavir, lopinavir, nelfinavir, ritonavir and saquinavir). Our results show that all these inhibitors have significantly higher $\mathrm{K}_{\mathrm{i}}$ values for the subtype F HIV PR $(F w t)$ and both mutant enzymes than that for the B subtype HIV PR (Bwt). Furthermore, the biochemical fitnesses of these proteases, or their vitalities, are also considerably higher than that of Bwt. The accumulation of commonly detected resistant mutations in HIV PRs with natural polymorphisms turns $F w t$ sufficiently catalytically active to guarantee the virus viability and confers it a large degree of cross resistance against all studied inhibitors.

Keywords: HIV protease, protease inhibitor, inhibition constant. 


\section{Lista de Figuras}

01 A) Organização do genoma do vírus HIV-1. B) Diagrama do vírus HIV 15 maduro.

02 Ciclo de replicação do HIV. 17

03 Representação da estrutura tridimensional da protease de HIV-1. 20

04 Mudança conformacional provocada pela presença do inibidor no sítio 21 ativo.

05 Distribuição dos diferentes subtipos de HIV-1. 23

06 Mutações de resistência e inibidores de protease. 24

07 Alinhamento das seqüências de aminoácidos das proteases de HIV. 28

08 Representação estrutural dos inibidores utilizados nos ensaios de 29 atividade.

09 Mecanismos de clivagem do substrato. 30

10 Digestão com enzima de restrição. 42

11 Gel SDS-Poliacrilamida 16\% - referente às lavagens 43

12 Cromatografia da purificação da protease Fmut em coluna de troca 44 aniônica QHP..

13 Cromatograma da purificação da protease Fmut em coluna de troca 44 catiônica SPHP.

14 Gel SDS-Poliacrilamida 16\% - referente à purificação. 45

15 Gráfico da curva de calibração com EDANS. 45

16 Gráfico do ensaio de inibição da protease Bmut com o inibidor 47 amprenavir.

17 Gráfico Vi/Vo para Bmut versus concentração de amprenavir. 48

18 Gráfico da conversão do substrato para Bmut. 50

19 Gráfico de barras representando os valores de vitalidade . 52

20 Representação da estrutura tridimensional das proteases de HIV-1. 55

21 Mudanças conformacionais observadas na região do flap. 56

23 Correspondência estrutural entre L90M e L89M. 56

24 Mudanças conformacionais devido à mutação V82A. 57 


\section{Lista de Tabelas}

01 Constantes de inibição para subtipos diferentes de HIV-1 protease 46

02 Eficiência catalítica para subtipos de HIV-1 protease 


\section{Lista de Abreviaturas}

$\begin{array}{ll}\text { AIDS } & \text { Síndrome da Imunodeficiência Adquirida } \\ \text { APV } & \text { Inibidor de protease amprenavir } \\ \text { Bmut } & \text { Protease de HIV do subtipo B mutante } \\ \text { Bwt } & \text { Protease de HIV do subtipo B selvagem } \\ \text { DABCYL } & \text { (4'-dimetilaminoazobenzeno-4-carboxilato) } \\ \text { EDANS } & \text { [5-(2-aminoetilamino)-1-sulfonato de naftaleno] } \\ \text { Fmut } & \text { Protease de HIV do subtipo F mutante } \\ \text { Fwt } & \text { Protease de HIV do subtipo F selvagem } \\ \text { HIV } & \text { Vírus da Imunodeficiência Humana } \\ \text { IDV } & \text { Inibidor de protease indinavir } \\ \text { LPV } & \text { Inibidor de protease lopinavir } \\ \text { NFV } & \text { Inibidor de protease nelfinavir } \\ \text { PPT } & \text { Inibidor de protease pepstatina } \\ \text { RTV } & \text { Inibidor de protease ritonavir } \\ \text { SQV } & \text { Inibidor de protease saquinavir }\end{array}$




\section{Sumário}

Introdução

1-Síndrome da Imunodeficiência Adquirida

12

2-HIV - Vírus da Imunodeficiência Humana 13

3-Alvos e Tratamento Disponível contra a AIDS 18

4-Protease de HIV 19

5-Subtipos e Mutações 21

Material e Métodos $\quad 26$

MATERIAL

1-Proteases de HIV-1 estudadas nesse projeto 27

2-Inibidores de Protease utilizados 28

3-Substrato fluorescente $\quad 30$

MÉTODOS

1-Método para obtenção de células E.coli competentes 31

2-Transformação de bactérias por choque térmico 32

3-Mini-preparação de DNA plasmidial e análise 32

4-Produção heteróloga das proteases Bwt, Bmut, Fwt e Fmut 33

4.1-Expressão 33

4.2-Lavagens dos corpos de inclusão 34

4.3-Cromatografia de troca iônica 34

4.4-Cromatografia de troca aniônica 35

4.5-Reenovelamento 35

5-Ensaios enzimáticos $\quad 36$

5.1-Condições experimentais 36 
5.2-Calibração com EDANS

5.3-Ensaios de Inibição 38

5.4-Eficiência catalítica e KM 39

$\begin{array}{ll}\text { Resultados } & 41\end{array}$

1-Produção heteróloga das proteases Bwt, Bmut, Fwt e Fmut 42

2-Ensaios enzimáticos $\quad 45$

2.1-Calibração com EDANS 45

2.2-Ensaios de Inibição $\quad 46$

2.3-Eficiência catalítica $\quad 49$

2.4-Adaptação bioquímica ou vitalidade 51

Discussão 53

Conclusões e Perspectivas 63

Referências $\quad 66$

Anexo A: Gráficos de inibição para as proteases de HIV-1

Anexo B: Gráficos de conversão do substrato para as proteases de HIV Apêndice A: Manuscrito: Effectiveness of Six FDA-Approved Inhibitors against Subtype F HIV-1 Protease and Two Drug-Resistant Mutants. 


\section{Introdução}

$\mathrm{Na}$ introdução trataremos de aspectos gerais da AIDS e especificamente do vírus HIV com ênfase em sua protease aspártica, objeto de estudo desse trabalho.

"Há quem fale que a vida da gente é um nada no mundo, é uma gota no tempo, que nem dá um segundo..." 


\section{1-Síndrome da Imunodeficiência Adquirida}

A AIDS (Síndrome da Imunodeficiência Adquirida) é um complexo de sintomas e doenças que se manifestam após a infecção do organismo humano pelo HIV (Vírus da Imunodeficiência Humana). Os primeiros casos surgiram nos Estados Unidos, Haiti, e África Central em meados da década de 70, mas foram caracterizados como AIDS em 1982. Em 1983 o vírus HIV foi identificado como causador da AIDS (Barré-Sinoussi, 1983; Galo, 1984). Embora inicialmente essa tenha sido uma síndrome restrita aos homossexuais e usuários de drogas injetáveis, não demorou muito até que atingisse também homens e mulheres heterossexuais e crianças nascidas de mães infectadas (Kummerle, 1996). Dez anos depois da AIDS ser identificada, já existia mais de 10 milhões de pessoas infectadas pelo HIV no mundo.

O principal dano causado pela infecção por HIV é a destruição progressiva do sistema imune celular. O HIV infecta as células do sistema imunológico, especialmente linfócitos T do tipo CD4+, levando a uma severa imunodepressão e tornando a pessoa mais suscetível a doenças infecciosas. Na tentativa de combater a infecção o corpo produz algo em torno de 10 bilhões de novos linfócitos por dia, no entanto, 10 bilhões de novas cópias de HIV também são produzidas. Esta batalha entre a produção viral e a resposta imune ocorre por muitos anos até que os danos ao sistema imune sejam irreparáveis (Kummerle, 1996).

Assim, quando uma pessoa tem AIDS, significa que o vírus já causou danos suficientes ao seu sistema imunológico, permitindo que infecções e alguns tipos de cânceres se desenvolvam. Entre as condições clínicas que afetam as pessoas em estágio avançado da infecção pelo HIV, as mais graves e de maior freqüência são as infecções oportunistas. Os sintomas determinados por elas vão desde tosse até coma, dependendo 
do agente causador ou do estágio de evolução. A AIDS também torna as pessoas particularmente suscetíveis ao desenvolvimento de diversos tipos de cânceres, especialmente os causados por vírus, como o câncer de colo de útero e o sarcoma de Kaposi. Além disso, existem registros de ocorrências de alguns tipos de cânceres do sistema imunológico, conhecidos como linfomas. Nas crianças aidéticas, as infecções oportunistas surgem como formas severas de infecções bacterianas comuns a toda criança como: conjuntivite, infecções de ouvido e amigdalite.

De acordo com os dados de dezembro de 2006 do Programa das Nações Unidas para HIV/AIDS - UNAIDS (UNAIDS, 2006), o número estimado de infectados com o vírus HIV em todo mundo era de aproximadamente 39,5 milhões de pessoas, sendo 2,3 milhões de crianças com menos de 15 anos. No ano de 2006 o número de novas infecções chegou a 4,3 milhões e ocorreram cerca de 3 milhões de mortes. A região mais atingida pelo HIV é a África sub-sahariana, onde o número de infectados chega a 25 milhões com mais de 2 milhões de mortes registradas por ano. Já na América Latina vivem cerca de 1.7 milhões de portadores do vírus HIV, dentre esses, mais de 430 mil foram notificados no Brasil até junho de 2006 onde a região sudeste é responsável por 62,3\% dos casos seguida pela região sul com 17,9\% (Boletim Epidemiológico, 2006).

\section{2-HIV - Vírus da Imunodeficiência Humana}

O Vírus da Imunodeficiência Humana, HIV, pertence ao gênero lentivirus, o qual inclui retrovírus que possuem genomas complexos e possuem um interior capsídico em forma de cone, por exemplo, o vírus da imunodeficiência símia (SIV) e o vírus da anemia infecciosa equina (EIAV) (Vaishnav, 1991). Como em todos os retrovírus, o genoma do HIV é codificado por duas moléculas idênticas de RNA com $9,2 \mathrm{~Kb}$, que é transcrito 
reversamente para uma molécula de DNA viral pela transcriptase reversa quando ocorre a infecção em novas células hospedeiras.

Os vírus maduros exibem morfologia esférica de 100-120nm de diâmetro, e consistem em uma bicamada lipídica derivada da membrana da célula hospedeira, que também contém diversas proteínas celulares de membrana derivadas da célula hospedeira, incluindo principalmente antígenos histocompatíveis, actina e ubiqüitina (Figura 1) (Sierra, 2005).

O vírus HIV possui 15 proteínas divididas em estruturais, enzimas e de acessório (Frankel, 1998). As proteínas estruturais são codificadas pelos genes gag e env (Figura 1) e são: matriz (MA ou p17), capsídeo (CA ou p24), núcleo-capsídeo (NC ou p7), p6, superfície ou gp120 (SU) e transmembrana ou gp41 (TM). As glicoproteínas expostas na superfície, SU, estão ancoradas no vírus por interações com as proteínas transmembrana (TM). Uma parede matricial formada por aproximadamente 2000 cópias da proteína de matriz (MA ou p17) preenche o espaço entre a superfície interna da membrana viral e uma partícula capsídica cônica formada por cerca de 2000 cópias da proteína de capsídeo (CA ou p24) que está localizada no centro do vírus. A partícula capsídica encapsula duas cópias do genoma viral não ligado, o qual é estabilizado como um complexo ribonucleoprotéico com cerca de 2000 cópias da proteína nucleocapsídica (NC ou p7) (Turner \& Summers, 1999).

$\mathrm{O}$ gene pol codifica as três enzimas: protease (PR), relacionada com a clivagem de poliproteínas virais, transcriptase reversa (RT), com a função de transcrever reversamente RNA em DNA e integrase (IN) que integra o DNA viral no genoma da célula hospedeira. 
Quanto às seis proteínas de acessório, três são encapsuladas na partícula viral: Vif, Vpr e Nef e as outras três, Tat, Rev e Vpu são produzidas somente na célula infectada, local onde atuam (Frankel, 1998).

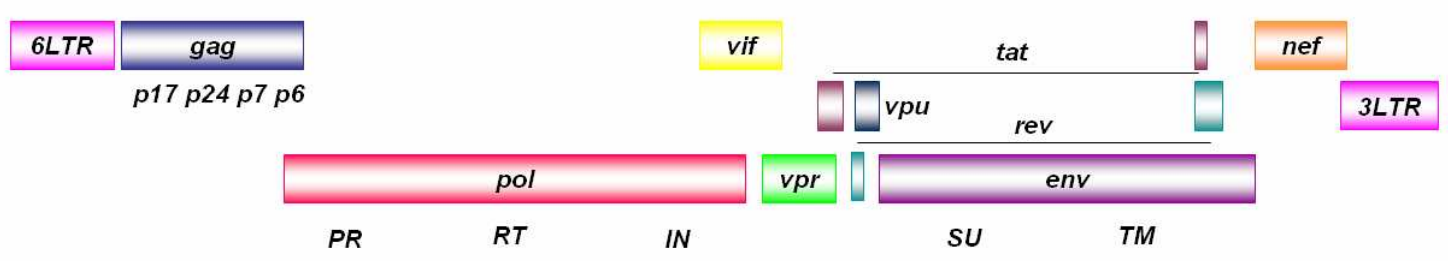

A)

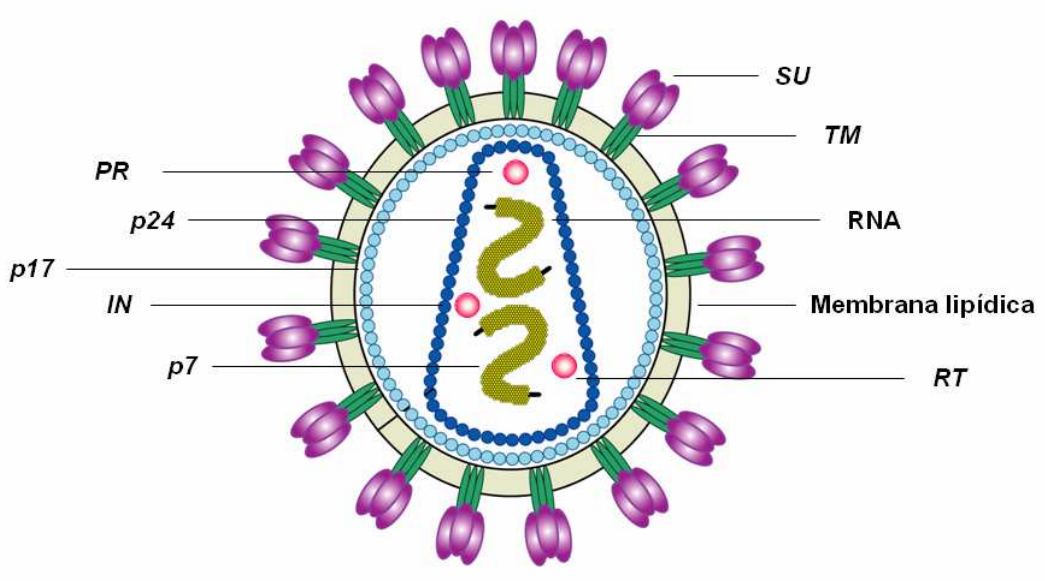

Figura 1: A) Organização do genoma do vírus HIV-1: Os éxons tat e rev estão conectados por linhas. Quatro regiões podem ser distinguidas no genoma: (1) LTR: regiões regulatórias localizadas nas extremidades. (2) o gene gag-pol que codifica duas poliproteínas precursoras, sendo que a poliproteina Gag inclui proteínas do nucleocapsídio e a Gag-Pol compreende algumas proteínas estruturais e as três enzimas virais: protease (PR), integrase (IN) e transcriptase reversa (RT). (3) O gene env codifica a proteína de superfície $\mathrm{SU}$ e a transmembrana TM. (4) Genes acessórios: tat, rev, nef, vif, vpr e vpu. B) Diagrama do vírus HIV maduro: A membrana lipídica é oriunda da célula hospedeira, e possui além de proteínas celulares, glicoproteínas do vírus (SU) e proteínas transmembrana (TM). A principal proteína estrutural a formar a matriz do vírus é a p17 (MA), a p24 (CA) é a responsável pela formação do capsídio, p7 (NC) atua na estabilização do RNA genômico. As enzimas protease, transcriptaase reversa e a integrase estão presentes no interior do capsídio (Sierra, 2005; Turner \& Summers, 1999).

A entrada do vírus na célula é iniciada através de interações entre as glicoproteínas de superfície do vírus e receptores CD4 encontrados principalmente na 
superfície de linfócitos T. O ciclo de replicação tem duas fases, a inicial e a tardia,

\section{Figura 2.}

A fase inicial começa com o reconhecimento da célula alvo pelo vírus maduro e consiste do reconhecimento e ligação das proteínas de superfície do HIV (SU) a receptores CD4 da célula alvo. No passo seguinte, ocorre à fusão e a penetração do vírus na célula hospedeira, quando o material genético, as enzimas e as proteínas acessórias são liberadas no citosol. Nesta ocasião, tem-se à transcrição reversa do RNA catalisada pela RT e a formação de um complexo pré-integração, que inclui as proteínas virais IN, MA, RT e vpr, responsável pelo transporte do material genético viral até o núcleo. Dentro do núcleo, o DNA viral é finalmente integrado covalentemente ao cromossomo via proteína IN (Turner \& Summers, 1999).

A fase tardia começa com a regulação da expressão, por intermédio das proteínas virais acessórias, envolvendo todos os seus processos que vai desde o desenvolvimento inicial do vírus até sua maturação. Inicialmente ocorre a síntese de RNAs mensageiros processados e não processados, que são transportados para fora do núcleo para serem traduzidos. Durante a tradução, primeiramente são sintetizadas as proteínas regulatórias, tat, rev, nef. A proteína tat é um ativador de transcrição essencial, enquanto nef é um fator que sinaliza a degradação de moléculas CD4 celulares pelo endossomo. O RNA não processado é reconhecido pela rev que auxilia na regulação da produção das poliproteínas Gag e Gag-Pol. Já a proteína precursora referente ao gene env é sintetizada no retículo endoplasmático, após o processamento no complexo de Golgi ela forma um complexo não covalentemente ligado: TM-SU, que é transportado para a membrana celular para a montagem do vírus. Cópias de Gag e Gag-Pol são transportadas para a membrana junto com duas moléculas do RNA viral para a montagem do capsídio imaturo, que brota da célula hospedeira. Após o brotamento 
começa a fase de maturação que ocorre com a clivagem das poliproteínas Gag, permitindo que as proteínas estruturais formem o nucleocapsídio, e Gag-Pol para a liberação das enzimas IN e RT. Essa clivagem é feita pela protease, que sofre autoclivagem da poliproteína, vale ressaltar que a inibição da protease leva a formação de partículas virais imaturas e não infectantes. (Turner \& Summers, 1999).

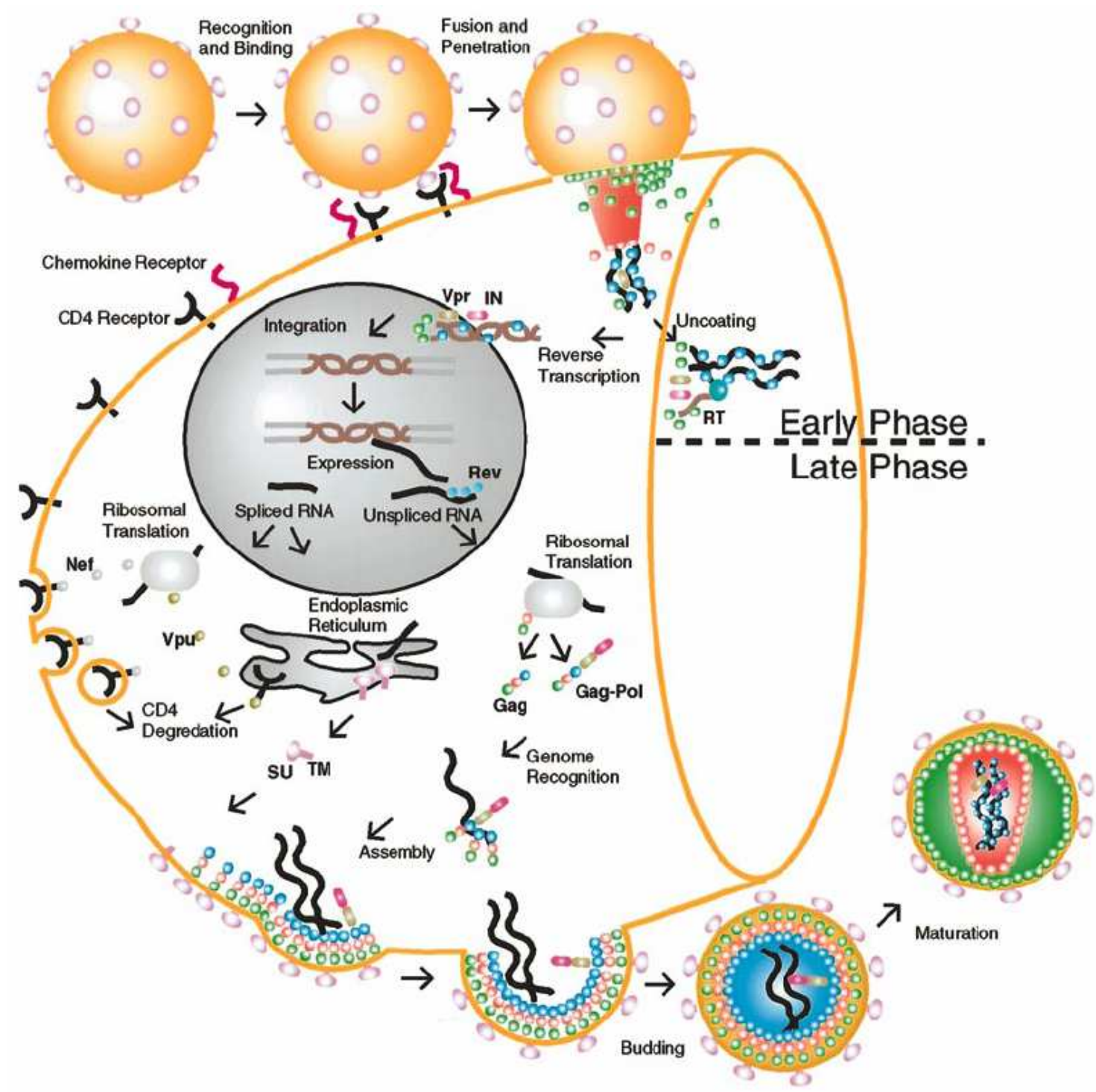

Figura 2: Ciclo de Replicação do HIV. Fase inicial: O ciclo de replicação tem duas fases, a inicial (Early Phase) e a tardia (Late Phase). A inicial começa com o reconhecimento da célula alvo pelo vírus maduro e envolve todos os processos até a integração do DNA viral, pela ação da integrase, dentro do cromossomo da célula hospedeira. A fase tardia começa com a regulação da expressão, por intermédio das proteínas virais acessórias, produção das poliproteínas Gag e Gag-Pol, do complexo SU-TM. Desenvolvimento inicial do vírus até o brotamento e a maturação da partícula viral, que se dá através da clivagem das poliproteínas pela protease. Reproduzido de Turner \& Summers, 1999. 


\section{3-Alvos e Tratamento Disponível contra a AIDS}

Os alvos terapêuticos para os quais existem fármacos disponíveis no mercado são as enzimas transcriptase reversa, protease e a proteína estrutural SU ou gp41. Esses compostos inibem a função dessas proteínas, impedindo o fechamento do ciclo de replicação do vírus. No caso da transcriptase reversa existem inibidores análogos e não análogos de nucleotídeos, impedindo a transformação do RNA viral em DNA que pode ser integrado ao genoma celular, atualmente existem mais de 10 inibidores aprovados. Para as proteases estão disponíveis inibidores peptídeos-miméticos e não peptídeos miméticos, que impedem a maturação do vírus formado. Já a SU é alvo do inibidor de fusão enfurvitide da partícula viral nas células CD4 (US-Food and Drug Administration, 2006). O tratamento utilizado atualmente em paciente com AIDS, chamado HAART (Highly Active Antiretroviral Therapy), utiliza dois inibidores de transcriptase reversa, nucleosídicos ou não; e um ou mais inibidores de protease. Este tratamento pode reduzir a carga viral no plasma para níveis indetectáveis, fornecendo benefícios clínicos duradouros. No entanto, não são todos os pacientes que respondem à HAART e o desenvolvimento de resistência permanece um dos problemas mais sérios na supressão da infecção pelo HIV (Caride, 2001).

A integrase é um outro alvo terapêutico interessante e sua inibição impediria a integração do DNA viral ao genoma celular. Ainda não existem fármacos comercialmente disponíveis para essa enzima, embora estudos nesta direção já estejam em fases avançadas (Hazuda, 2000). 


\section{4-Protease de HIV}

Baseado em sua sequiência de aminoácidos, inibição por pepstatina e estrutura cristalina, a protease de HIV-1 tem sido classificada como uma protease aspártica (Roberts, 1990). No ciclo de replicação viral essa proteína está envolvida na maturação do vírus, logo após o brotamento, para formar a partícula infecciosa. Seguindo-se ao brotamento ocorre a clivagem das poliproteínas Gag e Gag-Pol pela protease para produzir as outras enzimas RT e IN, assim como as proteínas estruturais p24 ou MA, p17 ou CA e p7 ou NC. Dessa maneira, a inibição completa da protease levaria à formação de partículas virais imaturas e, portanto, não infecciosas.

As primeiras estruturas cristalográficas dessa proteína foram resolvidas no fim da década de 80 (Wlodawer, 1989; Navia, 1989; Blundell, 1990). Trata-se de um homodímero com simetria C2 e 99 aminoácidos por monômero. Cada subunidade é composta majoritariamente por folhas- $\beta$. São 9 fitas- $\beta$ e apenas uma $\alpha$-hélice, como pode ser visto na Figura 3. O sítio catalítico é composto por uma tríade de aminoácidos (Asp-25, Thr-26, Gly-27), localizado num loop interno, na interface dimérica. A estrutura desse loop é estabilizada por pontes de hidrogênio, padrão característico de proteases aspárticas. 


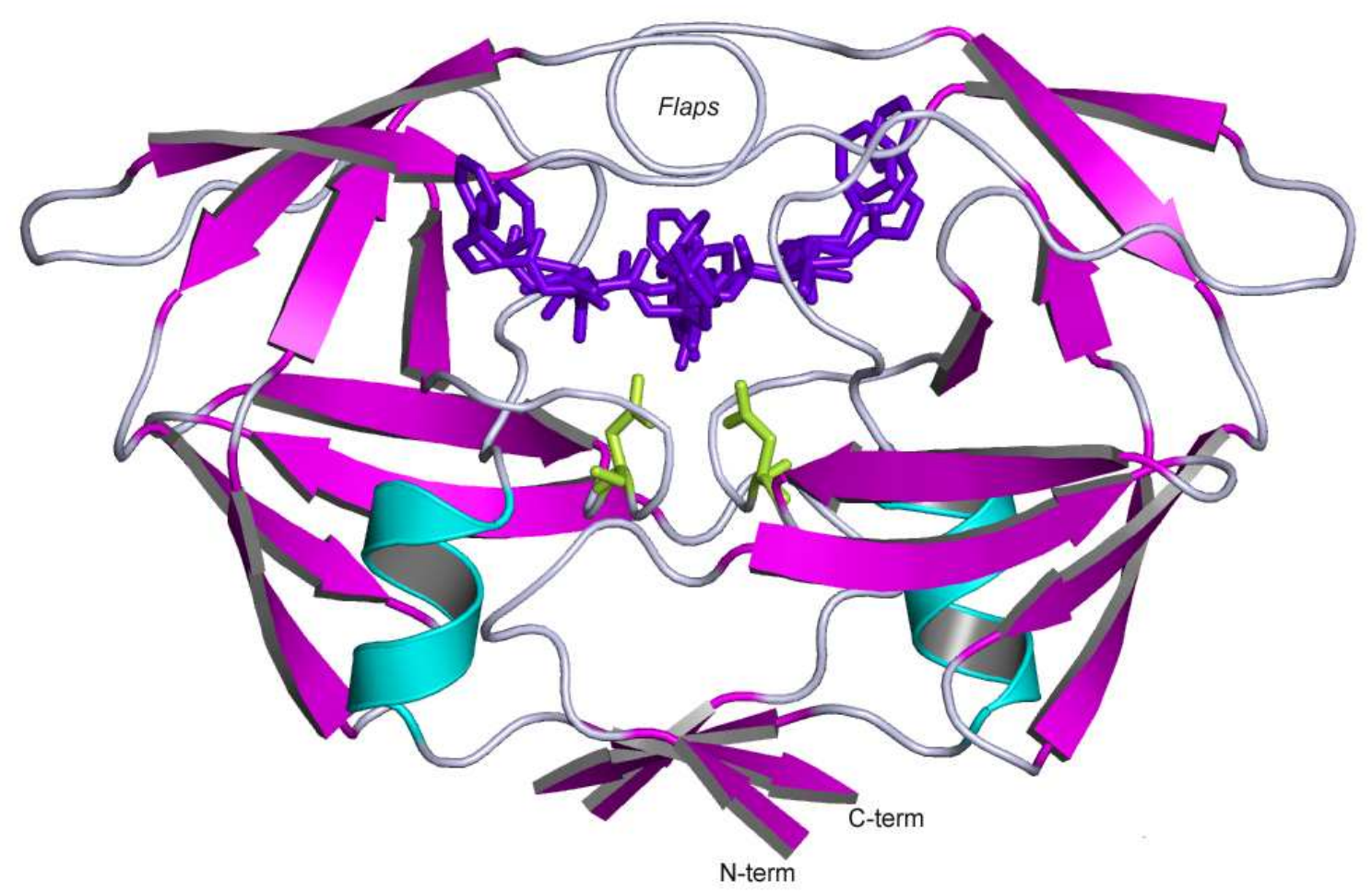

Figura 3: Representação da estrutura tridimensional da protease de HIV-1. O desenho mostra a estrutura cristalográfica da protease Fmut complexada com o inibidor TL-3 (em violeta) no sítio ativo. Os resíduos Asp 25 estão mostrados em verde. Em magenta as fitas $\beta$, em azul claro as hélices- $\alpha$, e os loops em cinza (Sanches, 2007).

Nessa mesma Figura 3, pode ser visto um flap representado logo acima do sítio ativo, onde se encontra o inibidor. Esse flap funciona como uma espécie de tampa, fechando-se quando existe um substrato no sítio ativo.

O primeiro inibidor de protease de HIV-1 descoberto foi a pepstatina, um inibidor de pepsina, que também é uma protease aspártica. Atualmente existem oito inibidores de protease de HIV aprovados pela FDA comercialmente disponíveis. São eles: amprenavir (Agenerase), saquinavir (Invirase), ritonavir (Norvir), lopinavir/ritonavir (Kaletra), indinavir (Crixivan), nelfinavir (Viracept), atazanavir (Reyataz), tipranavir (Aptivus), fosamprenavir (Lexiva) e darunavir (Prezista). A Figura 4 mostra a mudança conformacional provocada pela presença do inibidor no sítio ativo da proteína. 

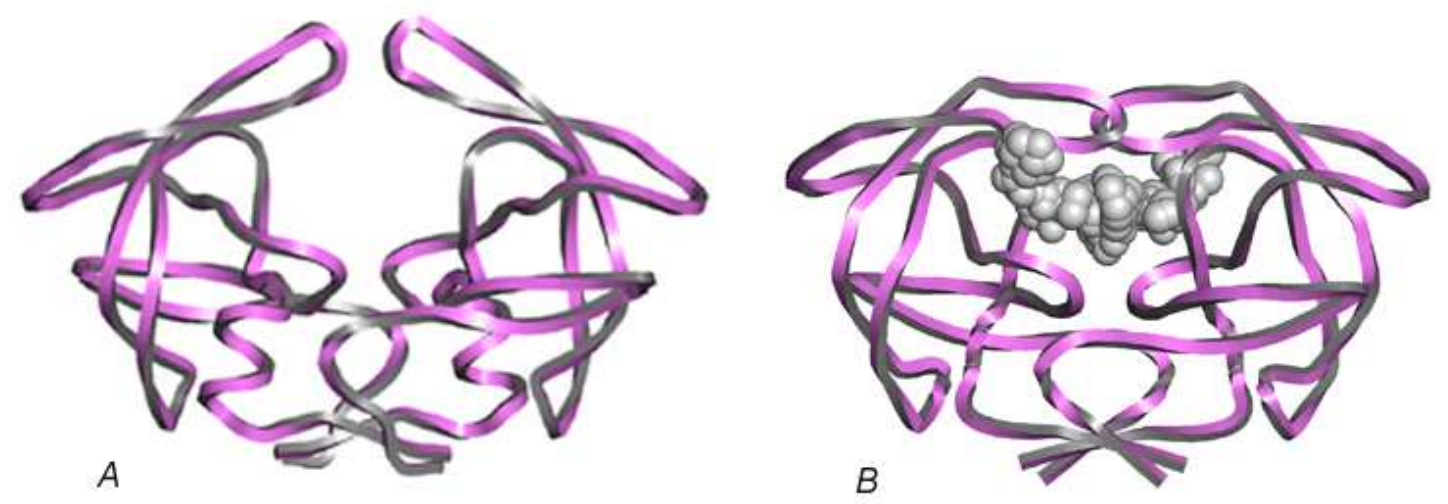

Figura 4: Mudança conformacional provocada pela presença do inibidor no sitio ativo. (A) protease de HIV-1 na forma livre e em (B) o complexo com inibidor. A ligação do inibidor induz uma mudança conformacional na qual os flaps se fecham sobre o sítio ativo.

\section{5-Subtipos e Mutações}

O HIV-1 é um vírus com alta taxa de mutação. Uma das formas de se estudar a variabilidade genética do vírus é através da análise filogenética. A partir dos dados de seqüenciamento dos genes env e gag o HIV-1 foi dividido em três grupos: M (Major), O (outlier) e N (New ou Non-M, Non-O) (Robertson, 1999). O grupo M é mundialmente distribuído, possuindo os subtipos $\mathrm{A}-\mathrm{K}$, que juntos representam a maior parte das infecções por HIV-1. O grupo O é aparentemente endêmico da República dos Camarões, bem como o grupo N (Kantor, 2004).

O subtipo B é mundialmente distribuído e é responsável por $70 \%$ das infecções do HIV, seguido pelos subtipos A e C que englobam 7\% das infecções cada um. Na América do Sul o subtipo B ainda prevalece, seguido de uma forma recombinante BF, com $66 \%$ e $12 \%$ das infecções respectivamente. No Brasil, além do subtipo B, com $76 \%$ de prevalência, são encontrados os subtipos C, D e F, sendo que o F é o principal não-B 
com mais de $7 \%$ das infecções notificadas como mostrado na Figura 5 http://www.hiv.lanl.gov/content/hiv-db/geography/map_right.html..

A maioria dos estudos relativos ao HIV-1 foi e vêem sendo realizados em países onde o subtipo B é praticamente único, porém outros subtipos ainda pouco estudados estruturalmente são responsáveis por grande parte das infecções por HIV relatadas. Os inibidores de protease utilizados atualmente foram desenvolvidos baseados em estruturas da protease HIV-1 subtipo B, e pouco se sabe qual a eficiência para outros subtipos.

Além das diferenças entre os subtipos existem algumas mutações que podem levar a resistência a inibidores. Essa resistência é uma consequiência inevitável da supressão incompleta da replicação do HIV. A rápida taxa de replicação e a inerente variação genética levam a identificação de linhagens virais que exibem susceptibilidade a medicamentos diferentes. Até 2004 já haviam sido notificadas mais de 790 mutações nucleotídicas relacionadas com combinações de medicamentos: 320 para o gene da transcriptase reversa; 253 mutações para a protease, que geraram 70 mutações na sua seqüência protéica; e outras mutações que foram relacionadas à integrase e às poliproteínas Gag e Env (Parikh, 2004).

A Figura 6 ilustra mutações de aminoácidos para a protease de HIV-1 do grupo M, que apresentaram mudança na susceptibilidade a determinados inibidores. 


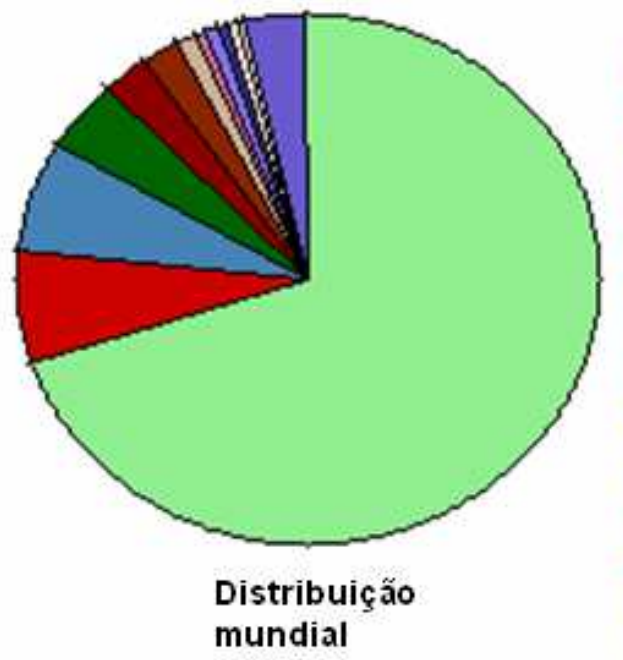

mundial

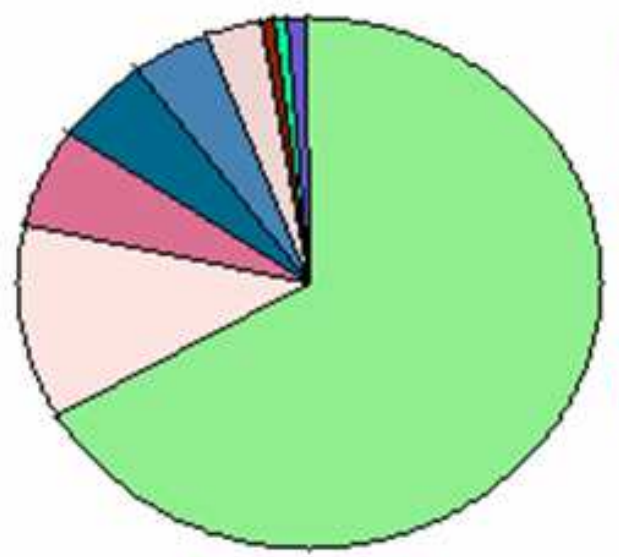

América do sul

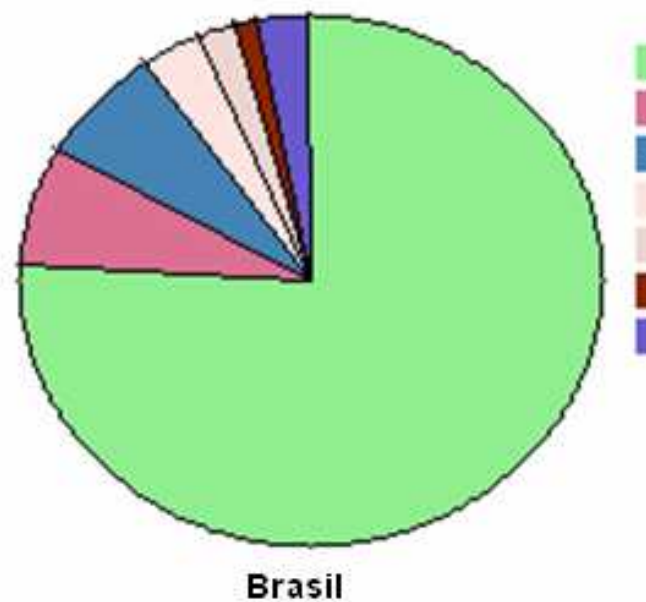

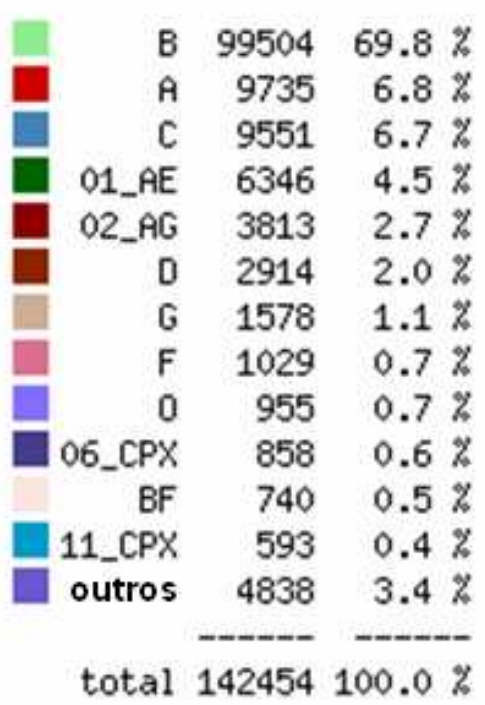
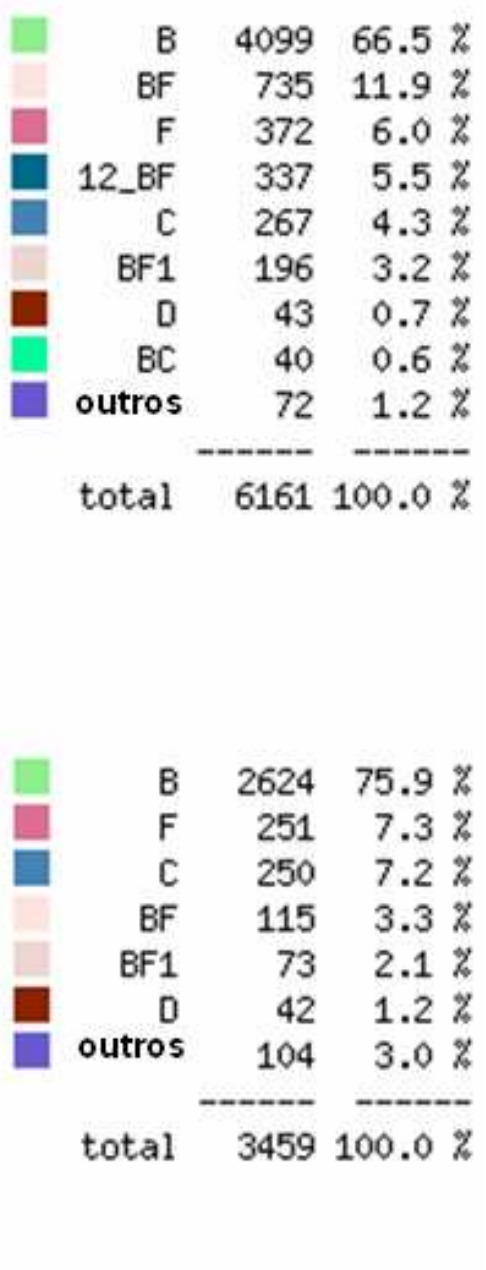

Figura 5: Distribuição dos diferentes subtipos de HIV-1. O primeiro gráfico mostra a distribuição mundial, o segundo na América do Sul e o terceiro no Brasil. Vale ressaltar que o subtipo $\mathrm{F}$ é responsável por mais de $7 \%$ das infecções notificadas no Brasil (adaptado de http://www.hiv.lanl.gov/content/hiv-db/geography/map_right.html) 


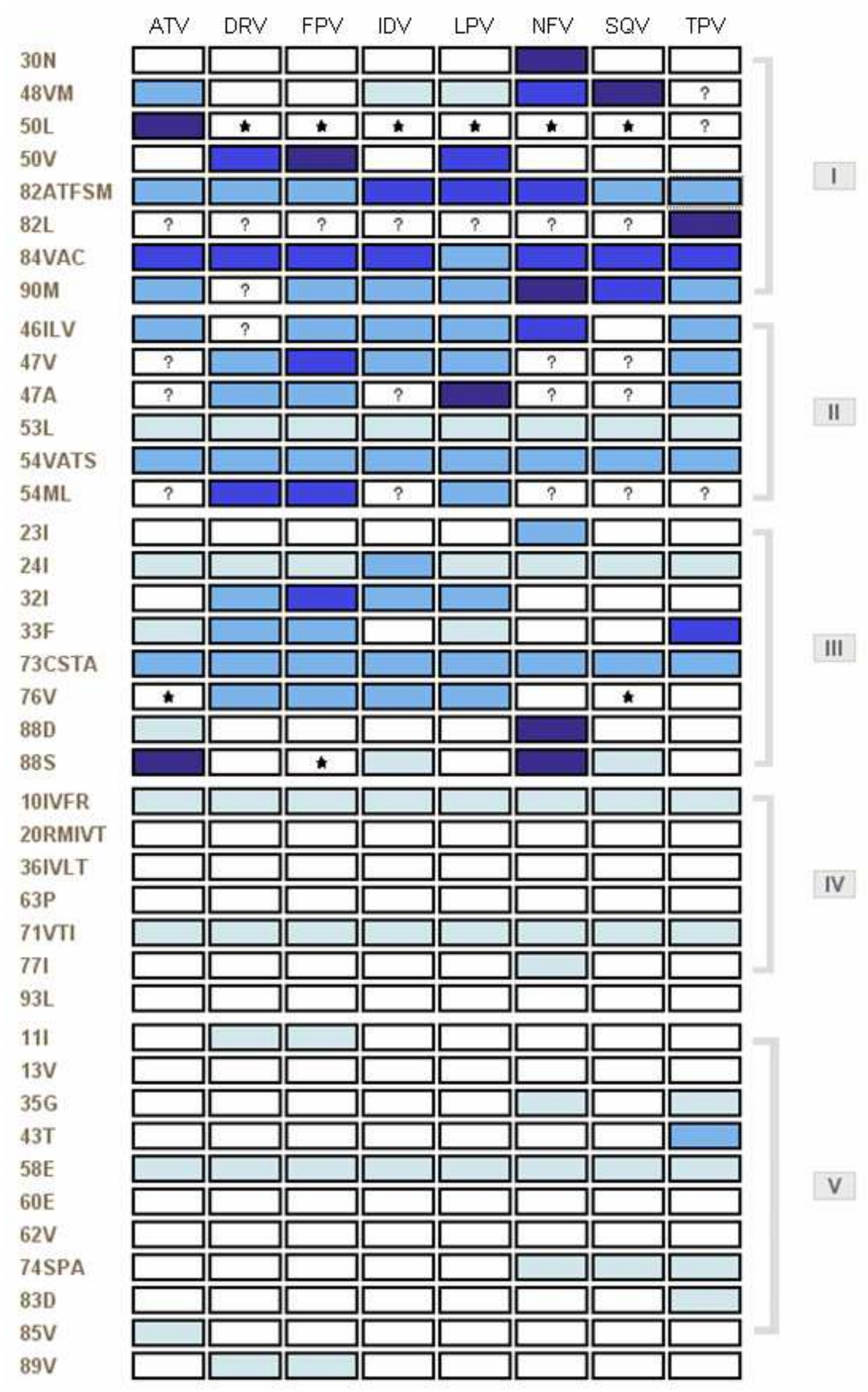




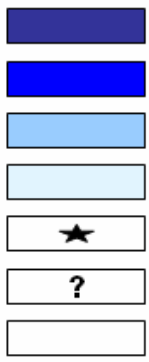

Alto grau de resistência

Resistência intermediária

Baixo grau de resistência

Contribui para a resistência

Hipersusceptibilidade

Desconhecido

Sem resistência

Figura 6: Mutações de resistência e inibidores de protease. ATV: atazanavir, DRV: duranavir, FPV: fosamprenavir, IDV: indinavir, LPV: lopinavir, NFV: nelfinavir, RTV: ritonavir, SQV: saquinavir, TPV: tipranavir. A contribuição de uma mutação para a resistência é dada pela intensidade dos retângulos azuis. O primeiro bloco (I) consiste em mutações primárias; o segundo bloco (II) contém um conjunto de mutações importantes na região dos flaps; o terceiro bloco (III) contém mutações não-polimórficas menos importantes que as dos flaps; o quarto bloco (IV) consiste de posições polimórficas que contribuem para a resistência quando em combinação com outras mutações de resistência e por último o quinto bloco (V), está relacionado a mutações reportadas recentemente, e que vêm sendo relacionadas aos inibidores ATV, TPV e DRV. Reproduzido de http://hivdb.stanford.edu/cgi-bin/PIResiNote.cgi .

\section{6-Objetivos}

$O$ trabalho teve como objetivo principal caracterizar as proteases de HIV-1 de linhagens encontradas em pacientes brasileiros segundo sua eficiência catalítica e inibição por fármacos comerciais. 


\title{
Material
}

\author{
e \\ Métodos
}

Os protocolos para a produção heteróloga das proteases

foram previamente estabelecidos em nosso grupo pelo

Dr. Mario Sanches e a metodologia aplicada nos ensaios

enzimáticos foi estabelecida pela $\operatorname{Dr}^{\mathrm{a}}$ Sandra

Krauchenco.

Ela é uma doce ilusão? Mas e a vida? Ela é maravilha ou é sofrimento? Ela é alegria ou lamento? 


\section{MATERIAL}

\section{1-Proteases de HIV-1 estudadas nesse projeto}

Nesse projeto foram utilizadas 4 proteases de HIV diferentes: uma selvagem $(B w t)$ e uma mutante $(B m u t)$ do subtipo B e selvagem $(F w t)$ e mutante $(F m u t)$ do subtipo F. Com exceção da $B w t$, as outras proteases tiveram suas seqüências codificadoras obtidas a partir de amostras de cDNA viral de crianças infectadas verticalmente, ou seja, com mães soropositivas. Essas crianças receberam tratamento com inibidores para protease ritonavir e nelfinavir e os inibidores para transcriptase reversa amivudina, stavudina e zidovudina e apresentaram falhas terapêuticas (Brindeiro, 2002).

O alinhamento seqüencial das proteases pode ser observado na figura7. Bwt é a seqüência consenso para o subtipo B (Benson, 1998) e foi utilizada como controle durante a padronização dos protocolos utilizados. Bmut possui 8 mutações com relação a Bwt: S37N, R41K, K45R, I54V, L63P, A71V, V82A e L90M, Fwt difere em 12 posições I15V, E35D, M36I, S37N, R41K, R57K, D60E, Q61N, I62V, L63S, I64L e L89M e Fmut possui 20 mutações com relação à seqüência consenso L10I, I15V, G16E, K20R, E35D, M36I, S37N, P39S, R41K, M46I, G51R, I54V, R57K, D60E, Q61D, K70R, I72V, T74A, V82A e L89M. Além disso, todas as proteases possuem a mutação Q7K que confere proteção à autólise, sem afetar sua atividade enzimática, aumentando assim sua estabilidade para a produção heteróloga (Rose, 1993; Mildner, 1994).

As proteases $B w t, B m u t, F w t$, e $F m u t$ já haviam sido previamente subclonadas em pET11a nos sítios para enzimas de restrição NdeI (extremidade sense) e BamHI (extremidade antisense). O vetor de expressão confere resistência a ampicilina e é induzido por IPTG. Para a produção heteróloga utilizamos células competentes de $E$. 
coli BL21(DE3) para Bwt e BL21(DE3)-RIL (Códon Plus) para Bmut, Fwt, e Fmut (esta cepa produz tRNA para códons raros arginina, isoleucina e leucina e é resistente a cloranfenicol). Essa escolha foi feita, pois se observou que nas sequiências dessas proteases encontram-se códons raros para E. coli, quanto a esses aminoácidos.

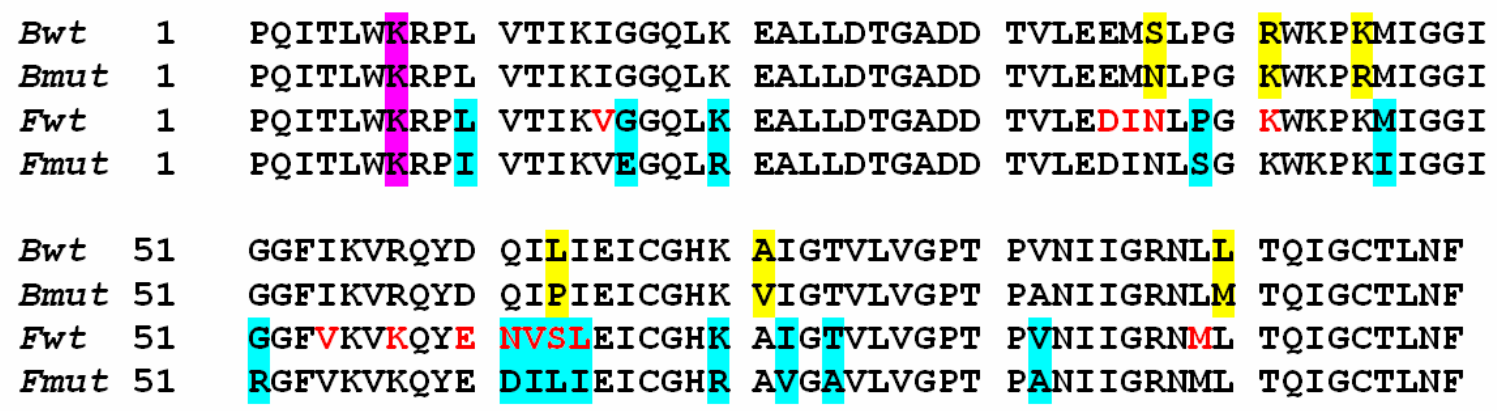

Figura 7: Alinhamento das sequiências de aminoácidos das proteases de HIV. Em letras vermelhas: diferenças entre $B w t$ e $F w t$, em destaque amarelo: diferenças entre $B w t$ e $B m u t$, em destaque azul: diferenças entre $F w t$ e $F m u t$. Em rosa, a mutação Q7K, que confere proteção a autólise.

\section{2-Inibidores de Protease utilizados}

Os ensaios de atividade foram realizados para seis inibidores comerciais, amprenavir, indinavir, lopinavir, nelfinavir, ritonavir e saquinavir e outros dois inibidores de proteases aspárticas, pepstatina e TL-3 (Li, 2000) (Figura 8). Os inibidores comerciais foram gentilmente fornecidos pela Far-Manguinhos/ Fiocruz, e o inibidor TL-3 (Li, 2000), fornecido pelo Dr. Alexander Wlodawer. Os inibidores foram solubilizados em concentrações próximas de $1 \mathrm{mM}$, sendo que para amprenavir e saquinavir utilizamos DMSO e DMF na proporção de 1:1, para indinavir, lopinavir e ritonavir apenas DMF e para nelfinavir, TL-3 e pepstatina apenas DMSO. 
<smiles>CCC(C)CC(C)CC(C)CC(C)C</smiles><smiles>Cc1cccc(C)c1OCC(=O)N[C@H](Cc1ccccc1)[C@H](O)C[C@@H](Cc1ccccc1)NC(=O)C(C(C)C)N1CCCNC1=O</smiles>

Lopinavir<smiles>CC(C)c1nc(CN(C)C(=O)N[C@H](C(=O)N[C@H](Cc2ccccc2)C[C@@H](O)[C@H](Cc2ccccc2)NC(=O)OCc2cncs2)C(C)C)cs1</smiles>

Ritonavir<smiles>CC(C)(C)NC(=O)[C@@H]1CN(Cc2cccnc2)CCN1C[C@H](O)C[C@H](Cc1ccccc1)C(=O)N[C@H]1c2ccccc2C[C@H]1O</smiles>
Indinavir<smiles>Cc1c(O)cccc1C(=O)N[C@H](CSc1ccccc1)[C@H](O)CN1C[C@@H](C(=O)NC(C)(C)C)C[C@@H]2CCCC[C@@H]21</smiles>

Neltınavir<smiles>CC(C)(C)NC(=O)[C@@H]1C[C@H]2CCCC[C@H]2CN1C[C@H](O)[C@H](Cc1ccccc1)NC(=O)[C@H](CC(N)=O)NC(=O)c1ccc2ccccc2n1</smiles>

Saquinavir

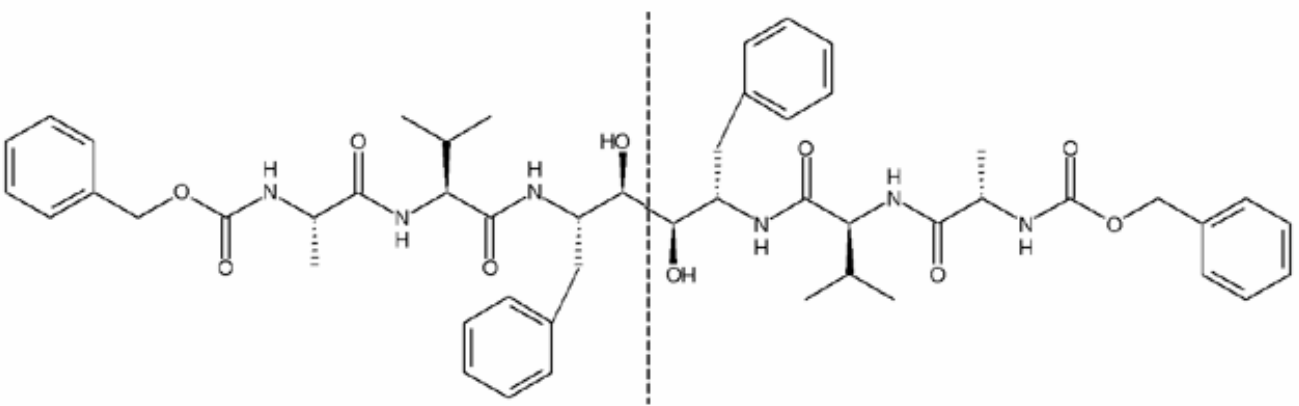

TL-3<smiles>CC(=O)NC(C(=O)N[C@H](C(=O)N[C@H](CC(C)C)[C@@H](O)CC(=O)N[C@H](C)C(=O)N[C@@H](CC(C)C)[C@@H](O)CC(=O)O)C(C)C)C(C)C</smiles>

Pepstatin

Figura 8: Representação estrutural dos inibidores utilizados nos ensaios de atividade. Os inibidores amprenavir, indinavir, lopinavir, nelfinavir, ritonavir e saquinavir são inibidores comercialmente disponíveis para o tratamento antiretroviral. 


\section{3-Substrato fluorescente}

A atividade enzimática das proteases foi medida com o substrato ArgGlu(EDANS)-Ser-Gln-Asn-Tyr-Pro-Ile-Val-Gln-Lys(DABCYL)-Arg (HIV protease substrate-1, SIGMA) que contém o sítio de clivagem tirosina-prolina, encontrado entre a proteína de matriz p17 e a de capsídio p24 na poliproteína precursora Gag, bem como dois aminoácidos covalentemente modificados para a detecção da clivagem. Uma das modificações consiste na adição de um fluoróforo no ácido glutâmico C-terminal, EDANS [5-(2-aminoetilamino)-1-sulfonato de naftaleno], e a outra na adição de um aceptor cromofórico em uma lisina N-terminal, o DABCYL (4'dimetilaminoazobenzeno-4-carboxilato). A figura 9 representa o mecanismo do substrato.

$$
\begin{gathered}
\text { Arg-Glu EDANS }- \text { Ser-GIn-Asn-Tyr-Pro-lle-Val GIn-Lys DABCYL -Arg } \\
\qquad \begin{array}{l}
\text { Clivagem promovida } \\
\text { pela HIV protease }
\end{array}
\end{gathered}
$$

\section{Arg-Glu EDANS -Ser-GIn-Asn-Tyr + Pro-Ile-Val GIn-Lys DABCYL -Arg}

Figura 9: Mecanismo de clivagem do substrato. O esquema mostra a clivagem proteolítica do substrato no sítio Tyr-Pro. Com a clivagem em dois fragmentos, a fluorescência de EDANS que estava inibida pela presença de DABCYL no peptídeo intacto é recuperada e pode ser monitorada por fluorimetria.

O EDANS possui pico de absorção a 340nm e de emissão a 490nm, enquanto o DABCYL absorve a 490nm, assim a sobreposição da absorbância do DABCYL com a emissão do EDANS permitem transferência da energia de ressonância entre os dois, fazendo com que a fluorescência intrínseca do EDANS a 490nm não seja observada. Esse fenômeno se torna insignificante a distancia maiores que 100 Á. Sabendo que os aminoácidos modificados estão em lados opostos do sítio de clivagem, quando o 
peptídeo é clivado, o grupo DABCYL se distancia do EDANS e a emissão a 490nm pode ser monitorada.

\section{MÉTODOS}

\section{1-Método para obtenção de células E.coli competentes}

Para a obtenção de células competentes, utilizamos o método de fragilização da parede celular por cloreto de cálcio. Nesse procedimento $5 \mathrm{~mL}$ de meio LB foi inoculado com uma amostra de E.coli e incubado durante 16 horas com agitação de 250rpm a $37^{\circ} \mathrm{C}$. Em seguida, $0,5 \mathrm{~mL}$ dessa cultura foi utilizado para o inoculo de $100 \mathrm{~mL}$ de $\mathrm{LB}$. A cultura foi incubada a $37^{\circ} \mathrm{C}$ com agitação de 250 rpm até atingir DO600 0,4. O material foi colocado em tubo de polipropileno pré-resfriado e autoclavado, e mantido em gelo por $15 \mathrm{~min}$, só depois centrifugado, sem freio, a $5 \mathrm{Krpm}, 4^{\circ} \mathrm{C}$, por $10 \mathrm{~min}$ num rotor previamente resfriado. A massa celular sedimentada ou pellet, foi ressuspendida cuidadosamente em $20 \mathrm{~mL}$ de solução de cloreto de cálcio $(60 \mathrm{mM} \mathrm{CaCl} 2,15 \%$ glicerol, 10mM de PIPES, água Milli-Q, pH 7,0, estéril por filtração e resfriada) e novamente centrifugada nas mesmas condições anteriores. Essa etapa foi repetida por mais duas vezes. Por fim, o pellet foi ressuspendido gentilmente em $8 \mathrm{~mL}$ de solução de cloreto de cálcio e então transferido em tubos plásticos de 1,5mL autoclavados e pré-resfriados. As alíquotas de $200 \mu \mathrm{L}$, foram por fim congeladas em nitrogênio líquido e armazenadas a $80^{\circ} \mathrm{C}$.

Foram utilizadas células competentes do tipo E.coli BL21(DE3) para a produção da protease Bwt e E.coli BL21(DE3)-RIL para Bmut, Fwt e Fmut. A linhagem DH5- $\alpha$ de E. coli foi necessária para a propagação do DNA plasmidial. O procedimento 
adotado foi basicamente o mesmo para todas as linhagens utilizadas, com exceção da E.coli BL21(DE3)-RIL, que possui resistência a cloranfenicol, o qual é adicionado nos meios de cultura utilizados na concentração de $35 \mu \mathrm{g} / \mathrm{mL}$.

\section{2-Transformação de bactérias por choque térmico}

Os plasmídeos contendo o gene das proteases em vetor de expressão foram construídos anteriormente a esse projeto pelo Dr. Mario Sanches, e foram utilizados na reação de transformação de células de E.coli BL21 e DH5- $\alpha$ competentes para expressão e propagação do DNA, respectivamente.

Para cada reação, aproximadamente 50ng de DNA foram adicionados a $100 \mu \mathrm{L}$ de células competentes mantidas em gelo durante $5 \mathrm{~min}$. A mistura foi incubada seqüencialmente em gelo por $10 \mathrm{~min}$, banho térmico a $42^{\circ} \mathrm{C}$ por 50 segundos e novamente em gelo por 10 minutos. Após esse choque térmico $200 \mu \mathrm{L}$ de meio LB líquido foi acrescentado, e a reação incubada a $250 \mathrm{rpm}$ por $1 \mathrm{~h}$ a $37^{\circ} \mathrm{C}$. Finalmente, o produto dessa reação foi inoculado em placas de Petri com $25 \mathrm{~mL}$ de meio LB sólido enriquecido com $100 \mu \mathrm{g} / \mathrm{mL}$ de ampicilina, quando a célula utilizada era BL21(DE3) ou DH5- $\alpha$, e também $35 \mu \mathrm{g} / \mathrm{mL}$ de cloranfenicol, para BL21(DE3)-RIL. As culturas foram incubadas a $37^{\circ} \mathrm{C}$, durante 16 horas.

\section{3-Mini-preparação de DNA plasmidial e análise}

Uma cultura com 5mL de células DH5- $\alpha$ transformadas e meio LB enriquecido com $100 \mu \mathrm{g} / \mathrm{mL}$ de ampicilina, foi incubada durante 16 horas em agitação de 250rpm a $37^{\circ} \mathrm{C}$. A cultura foi transferida para tubos de microcentrifuga de $1,5 \mathrm{~mL}$, e o DNA foi 
obtido através de kit comercial Wizard Plus SV minipreps - Promega, seguindo o protocolo do fabricante.

A análise da preparação de DNA foi feita através de reação de digestão com as enzimas de restrição $N d e$ I e BamHI onde o DNA plasmidial obtido foi clivado separando a seqüência codificadora da protease, confirmando assim, a presença deste no vetor.

\section{4-Produção heteróloga das proteases Bwt, Bmut, Fwt e Fmut}

\section{1-Expressão}

Para a expressão das proteases $B w t, F w t, B m u t$ e $F m u t$, foi utilizado meio LB (Luria Broth) acrescido de $1 \%$ de glucose, $0,01 \%$ de antiespumante, $100 \mu \mathrm{g} / \mathrm{mL}$ de ampicilina e para $F w t$, Bmut e Fmut $35 \mu \mathrm{g} / \mathrm{mL}$ cloranfenicol.

Em um experimento típico, foi feito um pré-inóculo em meio LB semelhante ao de expressão (1/20 do volume final da cultura). Esse pré-inóculo cresceu por aproximadamente $16 \mathrm{~h}$ sob agitação de $250 \mathrm{rpm}$ a $37^{\circ} \mathrm{C}$, após o qual foi adicionado ao meio de expressão, pré-aquecido, e deixado sob agitação de $250 \mathrm{rpm}$ a $37^{\circ} \mathrm{C}$. A absorbância da cultura foi monitorada a $600 \mathrm{~nm}$ até que atingisse $0,7 \mathrm{UA}$, sendo então adicionado IPTG, na concentração final de $1 \mathrm{mM}$. Após 4 horas de indução a cultura foi centrifugada a velocidade de 6000 rpm por 10 minutos a $4^{\circ} \mathrm{C}$. 


\section{2-Lavagens dos corpos de inclusão}

A protease é expressa em corpos de inclusão, que nesse caso foram obtidos através da lise celular seguido da lavagem dos mesmos. Esses procedimentos foram realizados em gelo ou a $4^{\circ} \mathrm{C}$.

Para a lise celular, ressuspendeu-se a massa celular em TLA (50mM Tris-HCL $\mathrm{pH} 8,0,5 \mathrm{mM}$ EDTA, $0,1 \% \quad \beta$-mercaptoetanol) com $100 \mu \mathrm{g}$ de lisozima/mL, na proporção de $1 \mathrm{~g}$ de célula para $20 \mathrm{~mL}$ de tampão. Essa mistura foi deixada sob agitação por 30 minutos, depois então sonicada para a quebra de DNA e lise celular (com 6 ciclos de 30s de sonicação e 1min de intervalo, na potência 6, sonicador Branson 450, sempre em gelo). A amostra foi então centrifugada a $15 \mathrm{Krpm}$ por 40 minutos. O precipitado foi ressuspendido em $80 \%$ do volume inicial de TLB (TLA + 2M uréia, $1 \%$ Triton X-100), e novamente centrifugado nas condições anteriores, iniciando assim a fase de lavagens dos corpos de inclusão. O precipitado foi novamente ressuspendido com TLA, e centrifugado nas mesmas condições. Esse último processo foi repetido, e desta vez os corpos de inclusão foram ressuspendidos em $20 \%$ do volume inicial de TLA, sendo esse então o volume final da amostra, e mantido a $4^{\circ}$ até o início da cromatografia de troca aniônica.

\section{3-Cromatografia de troca iônica}

Os corpos de inclusão foram centrifugados a $17 \mathrm{Krpm}$ à $4^{\circ} \mathrm{C}$ por 40 minutos. $\mathrm{O}$ precipitado resultante foi ressuspendido em tampão AE-A (50mM Tris- $\mathrm{HCl}$ pH 8,0, 5 mM EDTA, 8 M uréia, 0,1\% $\beta$-mercaptoetanol), na proporção de $1 \mathrm{~mL}$ para cada $10 \mathrm{~mL}$ da suspensão de corpos de inclusão, e centrifugado a $17 \mathrm{Krpm}$ durante 30 minutos a 
temperatura ambiente. A partir desse passo o procedimento foi realizado em temperatura ambiente para evitar a cristalização da uréia. $\mathrm{O}$ sobrenadante contendo a proteína solúvel foi injetado na coluna HiTrap Q-HP de 5mL, previamente equilibrada (5 volumes de coluna de água, 5 volumes de coluna de AE-B seguidos de 5 volumes de coluna de AE-A). Utilizou-se para a cromatografia o aparelho HPLC - ÄKTA (GE Healthcare). O fluxo mantido foi $\leq 1 \mathrm{~mL} / \mathrm{min}$. A amostra que não ligou na coluna contém a protease, e foi recolhida para a próxima cromatografia.

\section{4-Cromatografia de troca aniônica}

A amostra resultante do item 4.3 foi ajustada com acetato de sódio $(25 \mathrm{mM}) \mathrm{pH}$ 5,0 (com HCl), diluída 1x em tampão CE-A e injetada na coluna HiTrap SP-HP de 5 ou 1mL, pré-equilibrada com tampão CE-A (25mM acetato de sódio, 2mM EDTA, 8M de

uréia, $0,1 \% \beta$-mercaptoetanol, $\mathrm{pH}$ 5,0). A injeção foi feita através de uma bomba peristáltica ligada diretamente na coluna. Nesse ponto a protease liga-se na coluna, e se desliga com o aumento da força iônica, proporcionada por um gradiente feito entre CEA e CE-B (CE-A + 1M cloreto de sódio). O gradiente foi feito em 3 volumes de coluna até $30 \%$ de CE-B, quando foram coletadas frações de $1 \mathrm{~mL}$. As frações obtidas foram analisadas em SDS-PAGE, e combinadas de acordo com sua concentração e pureza.

\section{5-Reenovelamento}

Para reenovelar a protease desnaturada pela uréia foi feita uma diálise para a retirada gradual do agente desnaturante. Os procedimentos foram feitos à $4^{\circ} \mathrm{C}$. Utilizou- 
se membrana de diálise com corte de 6-8 KDa. As amostras encontravam-se na concentração aproximada de $0,2 \mathrm{mg} / \mathrm{mL}$ (método de Bradford).

As trocas de tampão se processaram da seguinte maneira: tampão de reenovelamento TR (20mM fosfato de sódio dibásico, $100 \mathrm{mM}$ de cloreto de sódio, 5mM EDTA, 0,1\% $\beta$-mercaptoetanol, $\mathrm{pH} 7,4$ ) com 4M de uréia durante 2h, TR com 2M de uréia por $2 \mathrm{~h}$, TR injetado em fluxo contínuo durante aproximadamente $14 \mathrm{~h}$ (com o auxílio de bomba peristáltica), TR novamente por mais 1h. Para os ensaios de atividade foi acrescentada mais uma troca de tampão, ainda a $4^{\circ} \mathrm{C}$, TE $(100 \mathrm{mM}$ acetato de sódio pH 4,7, 1 mM EDTA, 1.0 M NaCl, 1 mM DTT, 10\% v/v DMSO) sem DMSO por $2 \mathrm{~h}$.

Ao final da diálise, a amostra foi centrifugada a $43000 \mathrm{xg}$ a $4^{\circ} \mathrm{C}$, para eliminar proteínas precipitadas durante o processo, e mantida em gelo. A concentração foi feita a 1300xg, quando necessária, utilizando-se o concentrador Millipore - 10KDa. O processo de concentração foi monitorado através do método de Bradford.

\section{5-Ensaios enzimáticos}

Os ensaios enzimáticos foram padronizados pela $\mathrm{Dr}^{\mathrm{a}}$ Sandra Krauchenco com base nas informações contidas no artigo de Hoffman, 2003 Matayoshi, 1989, e componentes do kit comercial chamado "EnzoLyte ${ }^{\mathrm{TM}}$ HIV-1 Protease Assay Kit" comprado da empresa AnaSpec.

\section{1-Condições experimentais}

As medidas de fluorescência foram feitas no espectrofluorímetro Hitachi F-4000 PCI, com banho térmico acoplado para o controle de temperatura. Os comprimentos de 
ondas foram ajustados para $\lambda_{\mathrm{ex}}=340 \mathrm{~nm}$, excitação e $\lambda_{\mathrm{em}}=490 \mathrm{~nm}$, emissão. Utilizamos cubetas de quartzo de $500 \mu \mathrm{L}$, sendo que o volume final de cada reação foi de $300 \mu \mathrm{L}$. Os ensaios foram realizados a $37^{\circ} \mathrm{C}$, em tampão TE semelhante ao descrito por Matayoshi, 1989: $100 \mathrm{mM}$ acetato de sódio pH 4,7, $1 \mathrm{mM}$ EDTA, $1.0 \mathrm{M} \mathrm{NaCl}, 1 \mathrm{mM}$ DTT, 10\% v/v DMSO. O substrato foi adicionado na concentração final de $10 \mu \mathrm{M}$.

Utilizamos substrato SIGMA (HIV protease substrate 1), que foi ressuspenso em DMSO, de acordo com as especificações do fabricante. Durante os ensaios o substrato foi mantido em temperatura ambiente, em tubos de $1,5 \mathrm{~mL}$ protegidos da luz.

Todas as reações foram preparadas em tubos de $1,5 \mathrm{~mL}$ e incubadas em banho térmico a $37^{\circ} \mathrm{C}$ durante 3 minutos, antes da adição da protease.

\section{2-Calibração com EDANS}

Para analisar os dados, primeiro foi construída uma curva de calibração medindo-se o sinal de fluorescência (em unidades de fluorescência relativa ou UFR) para diferentes concentrações de EDANS em tampão de ensaio contendo o substrato. O EDANS foi utilizado nas seguintes concentrações, em nM: 500, 250, 125, 62.5, 31.25, $15.63,7.81$.

Esse padrão de referência foi usado para calibrar a variação de diferentes instrumentos e diferentes temperaturas usadas nos experimentos. A partir do gráfico construído foi feita uma regressão linear para a reta obtida e calculou-se o seu coeficiente angular. Com base nesta calibração, os dados de fluorescência medidos puderam ser convertidos em concentrações (nM). 


\section{3-Ensaios de Inibição}

Os experimentos de inibição foram realizados com seis inibidores comerciais: amprenavir (APV), indinavir (IDV), lopinavir (LPV), nelfinavir (NFV), ritonavir (RTV) e saquinavir (SQV). A taxa inicial de clivagem do substrato foi ajustada para 1020nM/min através da adição de proteína.

A partir daí foi feita uma curva de titulação com cada um dos inibidores, (tipicamente $0.0625,0.125,0.25,0.5,1,2,4,8,16$ e $32 \mathrm{nM}$ ). Esses resultados foram analisados segundo a equação geral para inibidores competitivos (Morrison, 1969 e Bieth, 1995), onde Vi para cada concentração de inibidor foi dividido pela taxa inicial Vo, esses resultados foram ajustados então na equação.

$$
\mathrm{V}_{\mathrm{i}} / \mathrm{V}_{0}=\left([\mathrm{Et}]-[\mathrm{It}]-\mathrm{K}_{\mathrm{i}, \text { app }}+\left\{\left([\mathrm{Et}]-[\mathrm{It}]-\mathrm{K}_{\mathrm{i}, \mathrm{app}}\right)^{2}+4[\mathrm{Et}] \mathrm{K}_{\mathrm{i}, \text { app }}\right\}^{1 / 2}\right) / 2[\mathrm{Et}]
$$

$\mathrm{V}_{\mathrm{i}}=$ velocidade de reação para cada concentração de inibidor, $\Delta$ [product] $\min ^{-1}$; $\mathrm{V}_{0}=$ velocidade de reação na ausência do inibidor, $\Delta$ [product $] \mathrm{min}^{-1}$;

$[E t]=$ concentração total de enzima (ligada ou não);

[It $]$ = concentração total de inibidor (ligado ou não);

$\mathrm{K}_{\mathrm{i}, \mathrm{app}}=$ constante de dissociação aparente para o complexo enzima:inibidor, dado pela concentração de substrato.

Quando tanto [Et] e $\mathrm{K}_{\mathrm{i} \text {,app }}$ são tratados como parâmetros variáveis, estimativas confiáveis para [Et], mas não para $\mathrm{K}_{\mathrm{i}, \mathrm{app}}$ são aproximadas em condições de quasetitulação ou seja $[\mathrm{Et}] / \mathrm{K}_{\mathrm{i}, \text { app }}>10$; por outro lado para $[\mathrm{Et}]<<\mathrm{K}_{\mathrm{i}, \text { app }}$ (praticamente $[\mathrm{Et}] / \mathrm{K}_{\mathrm{i}, \text { app }}$ 
<0.1) a equação (1) pode ser simplificada para a equação de inibição 'clássica' onde [Et] pode ser ignorado.

$$
\mathrm{V}_{\mathrm{i}} / \mathrm{V}_{0}=1 /\left(1+[\mathrm{It}] / \mathrm{K}_{\mathrm{i}, \mathrm{app}}\right)
$$

Para inibidores competitivos o $\mathrm{K}_{\mathrm{i}}$ real pode ser calculado a partir do $\mathrm{K}_{\mathrm{i} \text {,app }}$ usando a equação:

$$
\mathrm{K}_{\mathrm{i}}=\mathrm{K}_{\mathrm{i}, \mathrm{app}} /\left(1+[\mathrm{S}] / \mathrm{K}_{\mathrm{M}}\right)
$$

onde

$[S]=$ concentração de substrato

$\mathrm{K}_{\mathrm{M}}=$ constante Michaelis-Menten.

Nessas condições experimentais $[S]<K_{M}, K_{i, a p p}$ e $K_{i}$ são similares devido a competição praticamente nula entre inibidor e substrato, assim $\mathrm{K}_{\mathrm{i} \text {,app }}$ corresponde à $\mathrm{IC}_{50}$, ou seja a concentração de inibidor necessária para 50\% de inibição da atividade enzimática.

\section{4-Eficiência catalítica e $K M$}

Para definir a o tipo de inibição, clássica $\left([\mathrm{Et}] / \mathrm{K}_{\mathrm{i}}<0.1\right)$ ou "tight-binding" $(0.1<$ $\left.\left([E t] / K_{\mathrm{i}}\right)<10\right)$, de cada inibidor a concentração total de enzima foi estimada através da aproximação de condições de titulação da enzima pelo inibidor.

Para isso a taxa de conversão de substrato em produto na ausência de inibidor foi ajustada na faixa de 100 to $200 \mathrm{nM} \times \mathrm{min}^{-1}$ (Vo) e monitorada durante poucos minutos 
para minimizar o esgotamento do substrato. Os dados de $\left[\left(\mathrm{V}_{\mathrm{i}} / \mathrm{V}_{0}\right)\right.$ versus concentração correspondente de inibidor] desses experimentos de quase titulação com amprenavir foram ajustados na equação (1), permitindo a estimação da [Et] aparente e o calculo da constante catalítica aparente a partir da equação (4), para $10 \mu \mathrm{M}$ de substrato.

$$
\mathrm{k}_{\mathrm{cat}}=\mathrm{Vo} /[\mathrm{Et}]
$$

A constante de Michaelis-Menten $\left(\mathrm{K}_{\mathrm{M}}\right)$ das proteases foi determinada medindo a conversão do substrato em diferentes concentrações e fitando os dados na equação de Michaelis-Menten (5).

$$
\mathrm{V}=\mathrm{V} \max [\mathrm{S}] / \mathrm{K}_{\mathrm{M}}+[\mathrm{S}]
$$




\section{Resultados}

A seguir serão apresentados os resultados obtidos relacionados à produção heteróloga das proteases de HIV-1 e os ensaios enzimáticos realizados.

Somos nós que fazemos à vida, como der ou puder ou quiser. Sempre desejada por mais que esteja errada. Ninguém quer a morte só saúde e sorte. 


\section{1-Produção heteróloga das proteases Bwt, Bmut, Fwt e Fmut}

A construção dos plasmídeos contendo o gene das proteases em vetor de expressão, bem como a padronização dos protocolos relacionados à produção heteróloga das porteases foram feitas anteriormente a esse projeto pelo Dr. Mario Sanches (Sanches, 2004). Os plasmídios e foram utilizados na reação de transformação de células de E.coli BL21 e DH5- $\alpha$ competentes para expressão e propagação do DNA, respectivamente.

A produção heteróloga das proteases de HIV consistiu: da inserção no plasmídeo do gene codificante para cada protease; da reação de transformação dos mesmos em células bacterianas; da expressão em meio LB, purificação a partir de corpos de inclusão e finalmente reenovelamento das enzimas.

Iniciamos esse processo purificando os plasmídeos e digerindo-os com enzimas de restrição específicas, $N d e \mathrm{I}$ e $B a m \mathrm{HI}$, para confirmar a presença do gene da proteína de interesse. Em seguida, analisamos o produto da reação de digestão através de eletroforese em gel de agarose $1 \%$ para verificar a presença do inserto de $300 \mathrm{pb}$ correspondente ao gene da protease, figura 10.

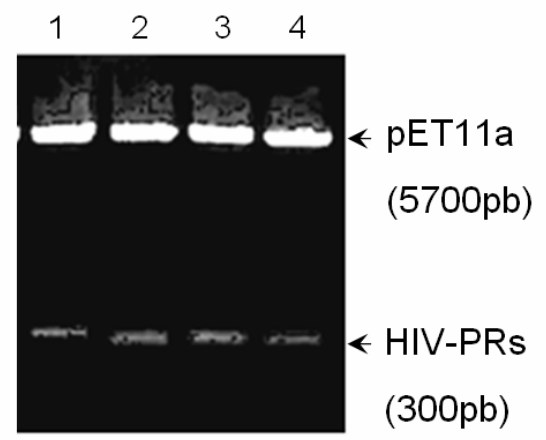

Figura 10: Digestão com enzima de restrição. O gel de agarose $1 \%$ mostra nas colunas 1-4 os DNAs plasmidiais purificados de Bwt, Bmut, Fwt, e Fmut respectivamente, após digestão com ambas as enzimas Nde I BamHI. O fragmento liberado de cerca de $300 \mathrm{pb}$ corresponde ao inserto codificador para a protease. A banda maior de cerca de 5700pb contém o vetor de expressão, pET-11a.). 
Os DNAs plasmidiais provenientes das amostras positivas foram então utilizados para a trasnfecção de células bacterianas imediatamente antes da realização dos experimentos de expressão.

A protease foi superexpressada em E. coli, cepa BL21 (DE3)..após indução com $1 \mathrm{mM}$ de IPTG por 4 horas. A presença de glicose durante a expressão da protease foi crucial para a manutenção de sua atividade após o reenovelamento. Como as proteases de HIV são expressas em corpos de inclusão, ou seja, na fração insolúvel, a estratégia adotada para sua purificação consistiu então de uma série de lavagens da fração insolúvel para a retirada do maior número de contaminantes possível. Alguns passos foram muito importantes para a recuperação da atividade após o reenovelamento, por exemplo: o procedimento de sonicação que está relacionado com a quebra de DNA; a suspensão das proteínas em tampão com triton; o cuidado com a total homogeneização da amostra; também foi observada a manutenção do ambiente antioxidante do tampão (obtido através do acréscimo de $\beta$-mercaptoetanol ou DTT); e a realização de todo o processo a baixa temperatura. Na figura 11 podemos observar a análise em SDS-PAGE dos passos de lavagens dos corpos de inclusão para a protease Fmut. Vale ressaltar que todas as proteases que trabalhamos mostraram o mesmo perfil de expressão e. purificação.

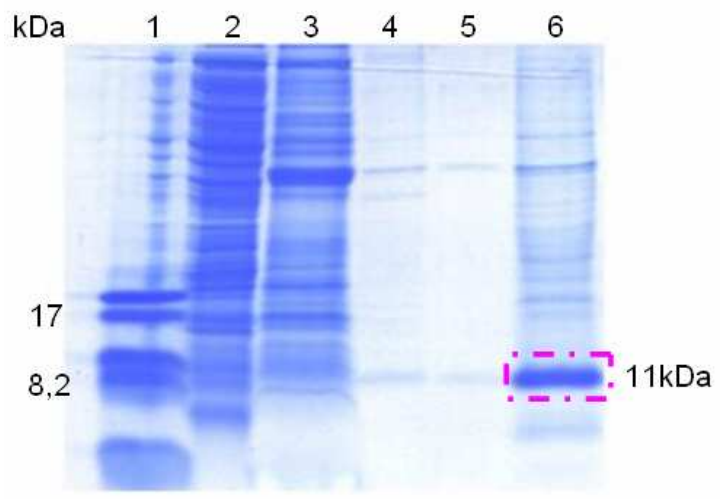

Figura 11: Gel SDS-Poliacrilamida $16 \%$. Coluna 1: PM - marcadores de pesos moleculares (17,0 e 8,2 KDa). Coluna 2-5: Sobrenadante proveniente das lavagem dos corpos de inclusão. Colunas 6: Amostra contendo a protease Fmut em corpúsculos de inclusão após o processo de lavagem . 
Antes do início dos experimentos cromatográficos a protease foi solubilizada em tampão com 8M de uréia, e nessa forma desnaturada a amostra foi injetada na coluna de troca aniônica (QHP), a qual foi seguida por cromatografia catiônica (SPHP). Os perfis cromatográficos do HPLC para as duas trocas iônicas foram utilizados na identificação das frações que continham a proteína recombinante, figuras 12 e 13. Ao término da purificação a pureza das amostras foi analisada através de gel de SDS-poliacrilamida como mostra a figura 14.

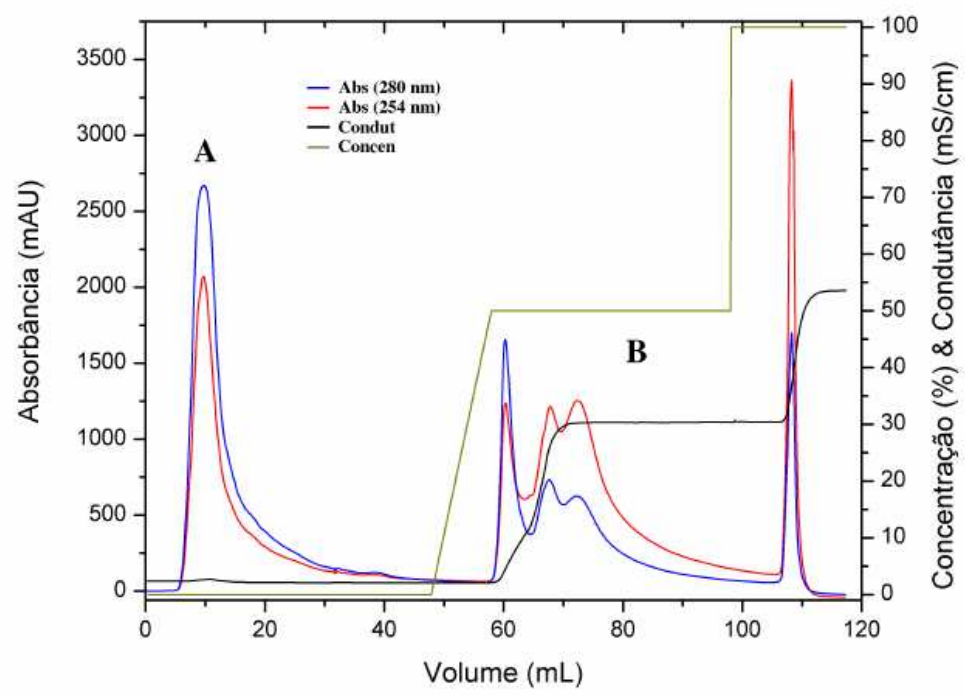

Figura 12:

Cromatograma da purificação da protease Fmut em coluna de troca aniônica - QHP. Nesse passo a proteína não se liga à coluna sendo eliminada nos $30 \mathrm{ml}$ iniciais de lavagem da coluna (pico A).

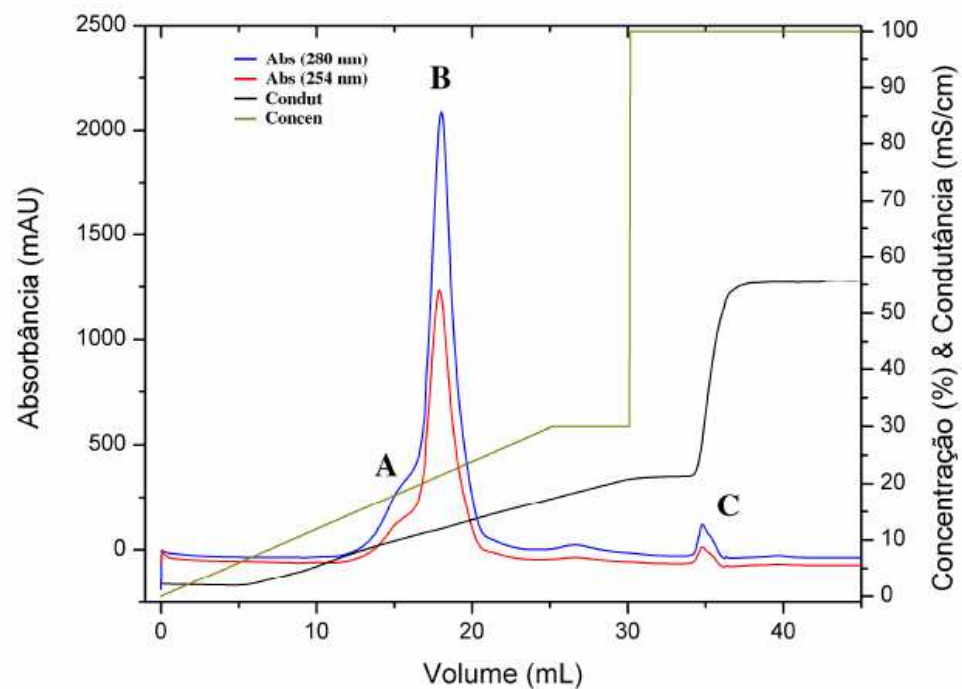

Figura 13:

Cromatograma da purificação da protease Fmut em coluna de troca catiônica SPHP. Nesse passo a proteína ligou-se à coluna, e foi retirada através de gradiente de $\mathrm{NaCl}$ (pico A), para eliminar os contaminantes observados na preparação proveniente da cromatografia por troca aniônica. 


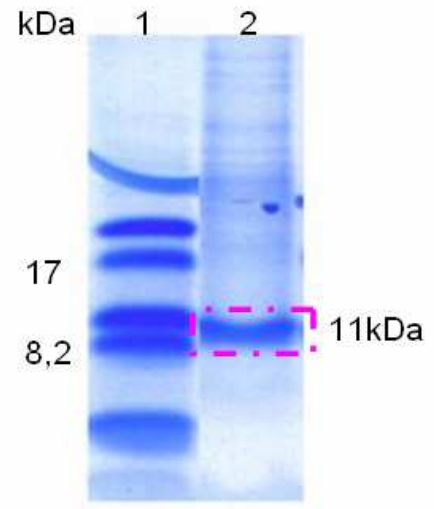

\section{2-Ensaios enzimáticos}

\section{1-Calibração com EDANS}

O gráfico abaixo (figura 15) representa a curva de calibração obtida em unidades de fluorescência relativa ou UFR, para as diferentes concentrações de EDANS em tampão de ensaio contendo o substrato. A inclinação da reta $\left(387.34 \mathrm{UFR} \times \mathrm{nM}^{-1}\right)$ foi obtida através de regressão linear e foi utilizada para converter os sinais de fluorescência URF em concentração de produto clivado (nM).

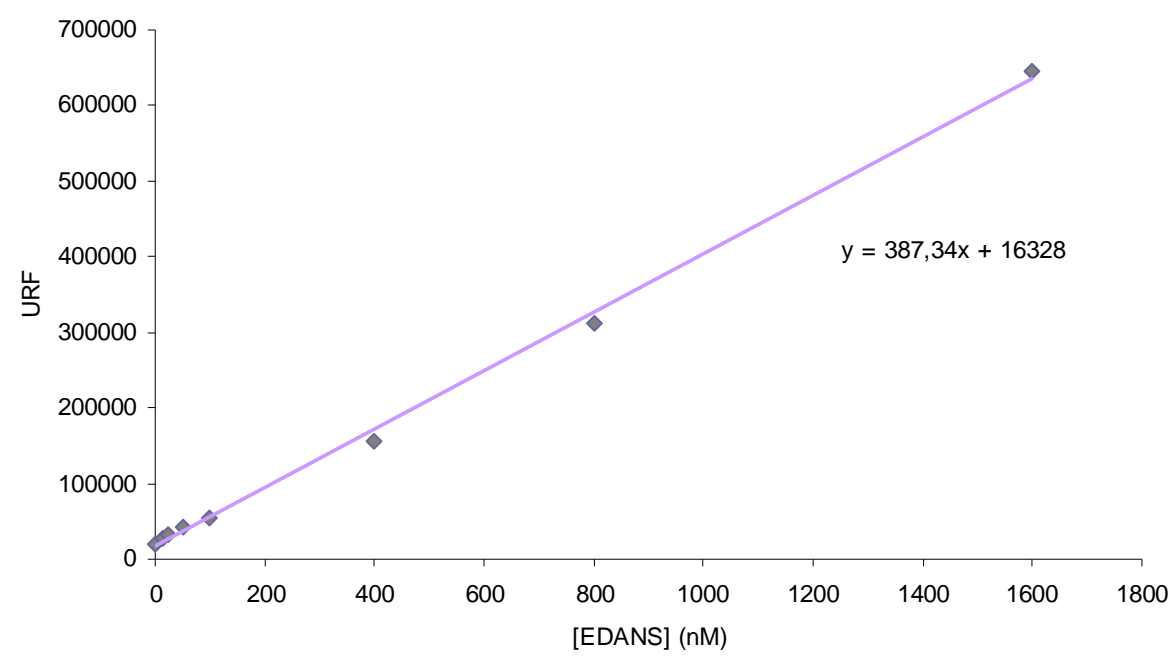

Figura 15: Gráfico da curva de calibração com EDANS. O ensaio com EDANS foi feito nas mesmas condições dos ensaios de atividade, Material e Métodos. 


\section{2-Ensaios de Inibição}

Os valores das constantes cinéticas obtidas para as proteases $B w t, F w t, B m u t$ e Fmut podem ser observados na tabela 1. As medidas realizadas com o subtipo B selvagem serviram como referência para a validação de nossos resultados, concordando com dados já apresentados na literatura para o mesmo substrato (Matayoshi, 1990; Velazquez-Campoy, 2001; Hoffman, 2003). As constantes de inibição foram obtidas experimentalmente para seis inibidores comerciais (amprenavir, nelfinavir, lopinavir, ritonavir, e saquinavir) e para 2 inibidores universais (TL-3 e pepstatina) das proteases aspárticas.

\begin{tabular}{ccccc}
\hline \multicolumn{5}{c}{ Tabela 1: Constantes de inibição para subtipos diferentes de HIV-1 proteases. } \\
\hline Inibidor & $\mathrm{K}_{\mathrm{i}}(\mathrm{nM})$ & $\mathrm{K}_{\mathrm{i}}(\mathrm{nM})$ & $\mathrm{K}_{\mathrm{i}}(\mathrm{nM})$ & $\mathrm{K}_{\mathrm{i}}(\mathrm{nM})$ \\
& $B w t$ & $F w t$ & Bmut & Fmut \\
APV & $0.16 \pm 0.05$ & $4.86 \pm 0.47$ & $6.14 \pm 0.59$ & $1422 \pm 271$ \\
IDV & $0.96 \pm 0.23$ & $106.27 \pm 26.05$ & $303.96 \pm 59.58$ & $3726 \pm 920$ \\
LPV & $0.48 \pm 0.27$ & $1.14 \pm 0.15$ & $11.81 \pm 1.51$ & $296 \pm 59$ \\
NFV & $1.05 \pm 0.23$ & $315.81 \pm 29.53$ & $124.05 \pm 15.78$ & $1313 \pm 286$ \\
RTV & $0.18 \pm 0.06$ & $32.94 \pm 4.55$ & $82.86 \pm 12.66$ & $1954 \pm 334$ \\
SQV & $0.52 \pm 0.22$ & $7.28 \pm 2.55$ & $102.45 \pm 23.61$ & $177 \pm 57$ \\
TL3 & $3.26 \pm 0.88$ & $23.81 \pm 8.48$ & $135.45 \pm 37.74$ & $180 \pm 29$ \\
PPT & $28.55 \pm 4.20$ & $59.61 \pm 8.44$ & $116.51 \pm 13.50$ & $2709 \pm 1078$ \\
\hline
\end{tabular}

Para entender melhor como esses valores foram obtidos, o ensaio de inibição da protease Bmut com amprenavir será utilizado como exemplo. Todos os gráficos e tabelas relativos aos ensaios com as outras proteases e os outros inibidores se encontram no anexo A. 
O ensaio começa com a medida da atividade da protease com o substrato sem a adição de inibidor, de onde tiramos o $\mathrm{V}_{0}$ da reação. A partir daí cada reação recebe uma concentração diferente de inibidor até que a atividade enzimática não seja mais observada, desses resultados observamos a $\mathrm{V}_{\mathrm{i}}$ para cada concentração de inibidor. Os valores de $\mathrm{V}_{0}$ e $\mathrm{V}_{\mathrm{i}}$ são obtidos graficamente através de regressão linear, sendo relativos ao valor de inclinação da reta. O gráfico representado na figura 16 mostra as curvas resultantes desse experimento.

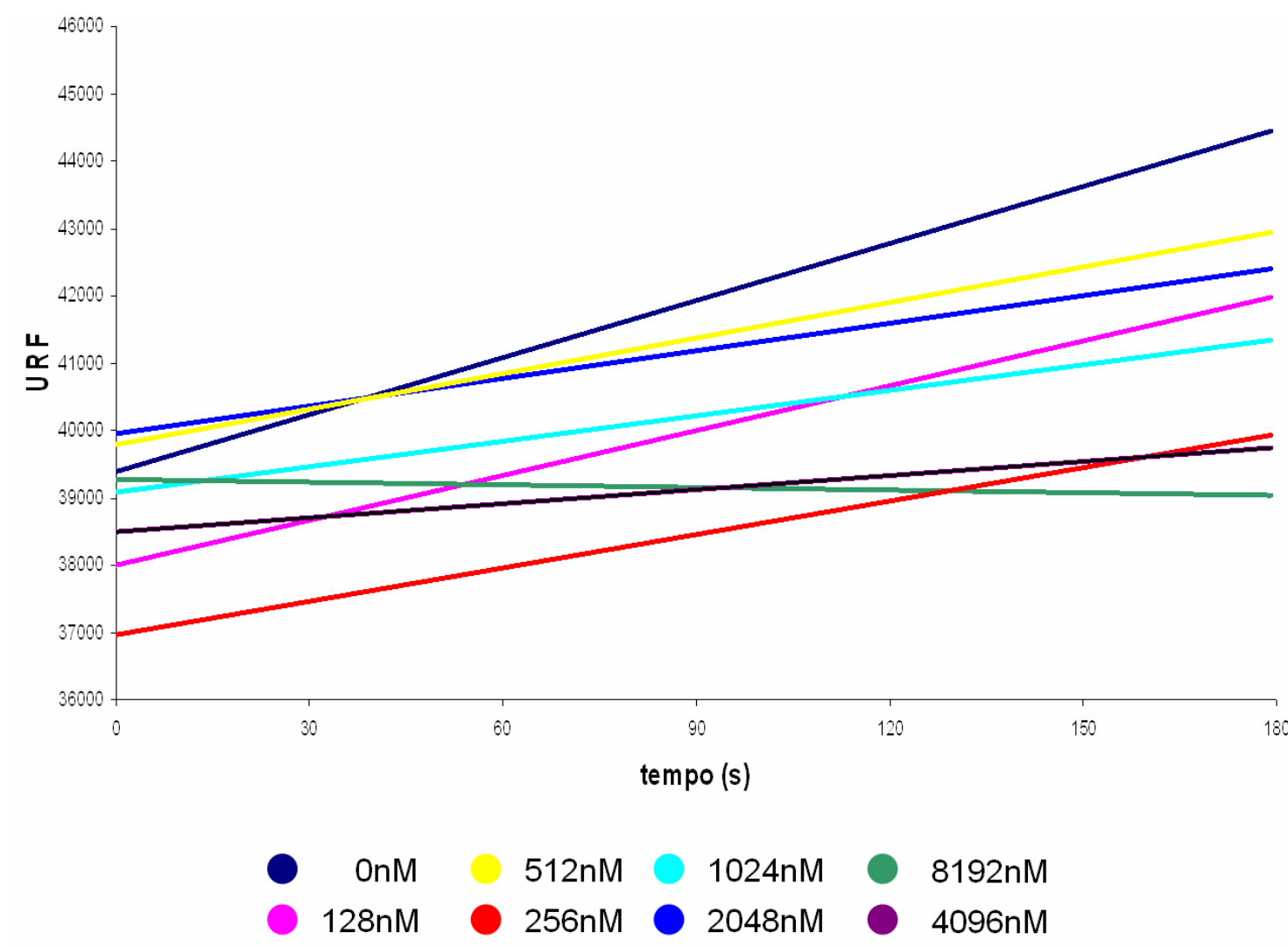

Figura 16: Gráfico de inibição da protease Bmut com o inibidor amprenavir. Com o aumento da concentração de inibidor observa-se o decaimento da atividade enzimática pela diminuição da inclinação da reta $\left(\mathrm{V}_{\mathrm{i}}\right)$.

Em seguida, os valores de $V_{i}$ foram divididos pelo valor de $V_{0}$ e plotados versus a concentração de inibidor, figura 17. A curva resultante desse gráfico foi fitada 
segundo a equação (1), descrita na seção Material e Métodos, quando obtivemos o valor da constante de inibição, que para esse caso foi de $6.14 \pm 0.59 \mathrm{nM}$.

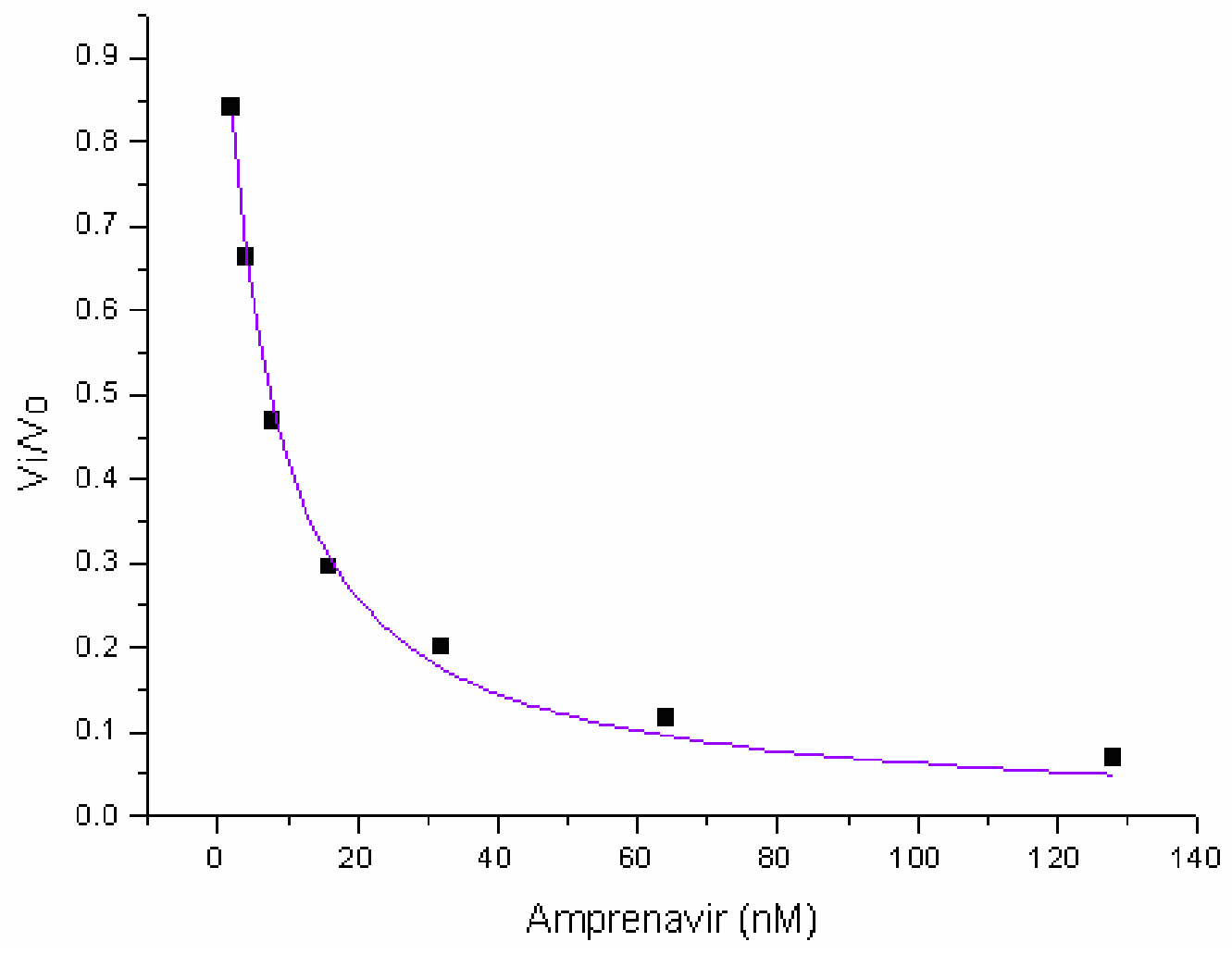

Figura 17: Gráfico Vi/Vo para Bmut versus concentração de amprenavir. Os dados foram ajustados através de regressão não linear, segundo a equação (1) de Material e Métodos (Morrison, 1969 e Bieth, 1995).

Os valores de $\mathrm{Ki}$ para todos os inibidores estudados foram maiores para o subtipo $\mathrm{F}$ e para as mutantes do subtipo $\mathrm{F}$ e $\mathrm{B}$ quando comparados aos valores encontrados para a protease $B w t$ para os quais os inibidores foram desenvolvidos.

Para a protease $F w t$ o Ki teve aumento de 2 vezes para lopinavir e pepstatina, 7 vezes para o TL-3, 14 vezes para saquinavir, 30 vezes para amprenavir, 111 vezes para indinavir, 183 vezes para ritonavir e 301 vezes maior para nelfinavir quando comparados com Bwt.

Para Bmut, os valores de Ki encontrados também foram maiores para todos os inibidores testados, sendo que 4 vezes maior para pepstatina, 25 vezes para lopinavir, 38 vezes para amprenavir, 42 vezes para TL-3, 118 vezes para nelfinavir, 197 vezes para 
saquinavir, 317 vezes para indinavir e 460 vezes maior para ritonavir, quando comparado aos valores encontrados para $B w t$.

No caso do mutante do subtipo F, todos inibidores demonstraram queda de potência, sendo que o ritonavir mostrou a mais baixa eficiência, com Ki 10856 vezes maior, seguido por amprenavir, (8888 vezes), indinavir (3881 vezes, nelfinavir (1250 vezes), lopinavir (617 vezes), saquinavir (340 vezes), pepstatina (95 vezes) e TL-3 (55 vezes).

A partir do $\mathrm{k}_{\mathrm{cat}}$ a concentração de proteína ativa nos experimentos de equilíbrio de inibição foi calculada e encontrou-se na faixa de $0,1-0,2 \mathrm{M}$ assim como as constantes de inibição, indicando a prevalência das condições de tight-binding.

\section{3-Eficiência catalítica}

As constantes catalíticas obtidas para as proteases estudadas estão sumarizadas na tabela 2. Para ilustrar como essas constantes foram obtidas, utilizaremos os dados relacionados à protease Bmut. Todos os gráficos relacionados às outras proteases estão no anexo B.

Tabela 2: Eficiência catalítica para subtipos diferentes de HIV-1 proteases.

\begin{tabular}{cccc}
\hline Subtipo & $\mathrm{k}_{\mathrm{cat}}\left(\mathrm{s}^{-1}\right)$ & $\mathrm{K}_{\mathrm{M}}(\mu \mathrm{M})$ & $\begin{array}{c}\mathrm{k}_{\mathrm{cat}} / \mathrm{K}_{\mathrm{M}} \\
\left(\mathrm{s}^{-1} \mu \mathrm{M}^{-1}\right)\end{array}$ \\
Bwt & $8.6 \pm 0.4$ & $61.2 \pm 12$ & $0.14 \pm 0.02$ \\
Fwt & $5.0 \pm 0.2$ & $12.3 \pm 3$ & $0.41 \pm 0.03$ \\
Bmut & $2.7 \pm 0.2$ & $15.4 \pm 4$ & $0.18 \pm 0.05$ \\
Fmut & $0.72 \pm 0.03$ & $24.7 \pm 3$ & $0.029 \pm 0.007$ \\
\hline
\end{tabular}


$\mathrm{O}$ cálculo da constante catalítica, $\mathrm{k}_{\mathrm{cat}}$, foi feito usando-se experimento de quasetitulação com o inibidor amprenavir, sendo que a $\mathrm{V}_{0}$ foi ajustada para a faixa de 100 200nM/min, o gráfico já representado na figura 17 é relativo aos dados de $V_{i} / V_{0}$ versus concentração de amprenavir para Bmut. A curva foi fitada segundo a equação (1) (Material e Métodos) (Morrison, 1969 e Bieth, 1995), que além de permitir o cálculo da constante de inibição também permite o cálculo da concentração da protease ativa na reação [Et]. A partir daí calculou-se a $\mathrm{k}_{\text {cat }}$ de acordo com a equação (4) (Material e Métodos), que nesse caso foi de $2,7 \pm 0.2 \mathrm{~s}^{-1}$.

As medidas de $\mathrm{K}_{\mathrm{M}}$ foram feitas medindo a conversão do substrato em diferentes concentrações e fitando os dados na equação de Michaelis-Menten (5) (Material e Métodos). O substrato foi pouco solúvel, impedindo medidas com concentrações acima de $60 \mu$ M. Para Fmut o valor de $\mathrm{K}_{\mathrm{M}}$ obtido foi de 24,7 \pm 3, figura 18.

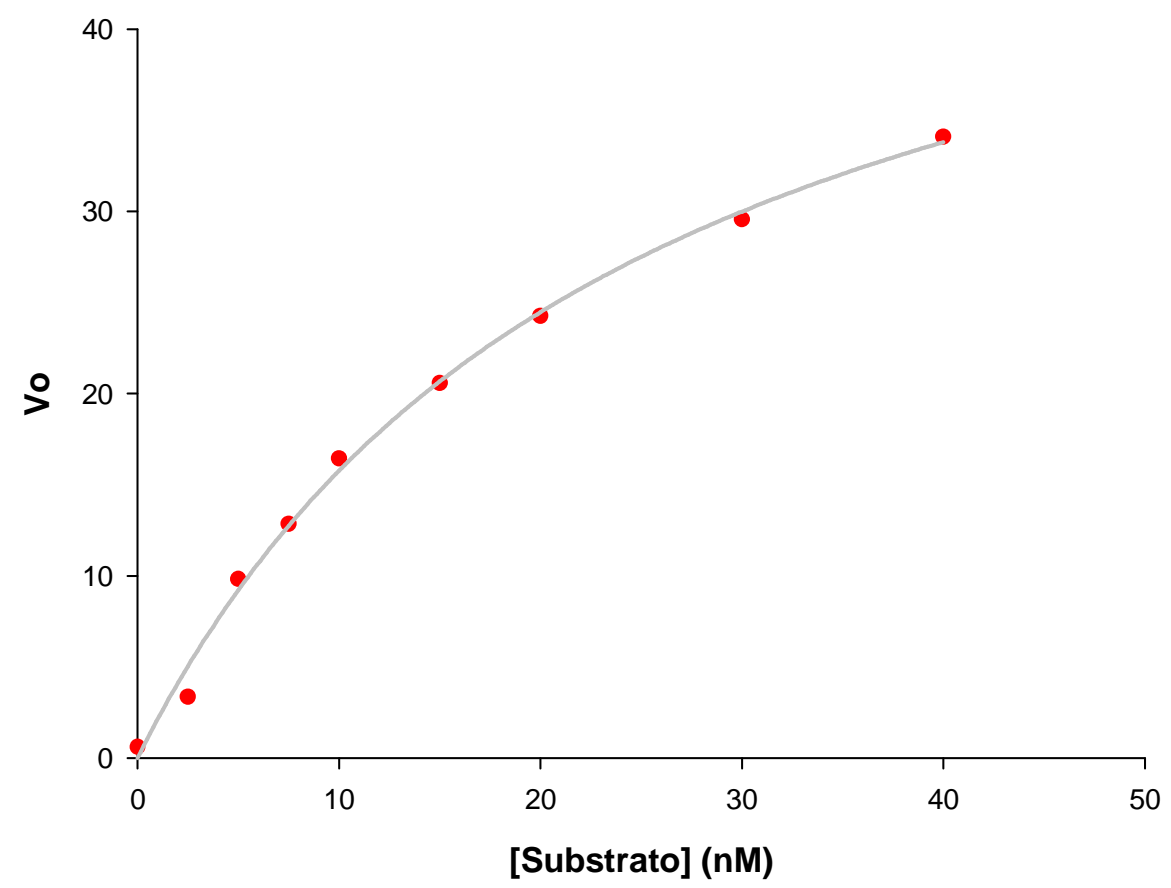

Figura 18: Gráfico de conversão do substrato para Fmut. Nesse experimento a concentração de proteína é constate e a velocidade de conversão é medida para diferentes concentrações de substrato. Os dados foram ajustados segundo a equação de Michaelis-Menten 
A constante catalítica, $\mathrm{k}_{\text {cat }}$, obtida para o subtipo $\mathrm{F}$ é 1,7 vezes menor que a obtida para o subtipo B. Para os mutantes dos subtipos B e F os valores encontrados ficam 3 e 17 vezes menores, respectivamente, quando comparados com o subtipo B selvagem.

Para os valores de $\mathrm{K}_{\mathrm{M}}$ o comportamento observado foi diferente, quando comparamos a $F w t$ com a $B w t$ observamos que o valor da constante é 5 vezes menor para o subtipo $\mathrm{F}$, já para os mutantes, Bmut apresenta $\mathrm{K}_{\mathrm{M}} 4$ vezes menor e $F m u t \mathrm{~K}_{\mathrm{M}}$ 2,5 vezes menor quando comparadas com Bwt. De acordo com esses resultados, a eficiência catalítica, definida como $\mathrm{k}_{\mathrm{cat}} / \mathrm{K}_{\mathrm{M}}$ para o subtipo $\mathrm{F}$ é 3 vezes maior que para $\mathrm{o}$ subtipo B, enquanto que para o mutante do subtipo B é 1.3 vezes, já para o mutante do subtipo $\mathrm{F}$ a eficiência catalítica é 4,8 vezes menor que para o subtipo B.

\section{4-Adaptação bioquímica ou vitalidade}

Para comparar as vantagens seletivas de diferentes mutações na presença de inibidores específicos, Gulnik, 1995, introduziu um parâmetro empírico chamado vitalidade, calculado a partir da seguinte equação:

$$
\text { vitalidade }=\left(\mathrm{Ki} \times \mathrm{k}_{\mathrm{cat}} / \mathrm{K}_{\mathrm{M}}\right)_{\text {mutante }} /\left(\mathrm{Ki} \times \mathrm{k}_{\mathrm{cat}} / \mathrm{K}_{\mathrm{M}}\right)_{\text {selvagem }}
$$

A vitalidade pode ser considerada como uma medida da adaptação enzimática de um mutante em particular na presença de um dado inibidor. Os valores de vitalidade obtidos para o subtipo F e para mutantes dos subtipos F e B na presença de amprenavir, indinavir, lopinavir, nelfinavir, ritonavir, squinavir, TL-3 e pepstatina estão mostrados na figura 19. Em geral a vitalidade para $F w t$ e Bmut é próxima e são maiores que as 
reportadas para mutações primárias de resistência (Gulnik, 1995). Foram encontradas apenas duas exceções para $F w t$ e Bmut. A vitalidade para $F w t$ é maior para nelfinavir e para Bmut a vitalidade é maior para saquinavir. Em alguns casos os valores de vitalidade estão próximos aos encontrados para $B w t,(F w t$ na presença de lopinavir, TL3 e pepstatina). Valores extremos foram observados para Fmut refletindo sua resistência para todos os inibidores comerciais. Amprenavir, ritonavir e indinavir foram os que apresentaram valores relativamente maiores de vitalidade.

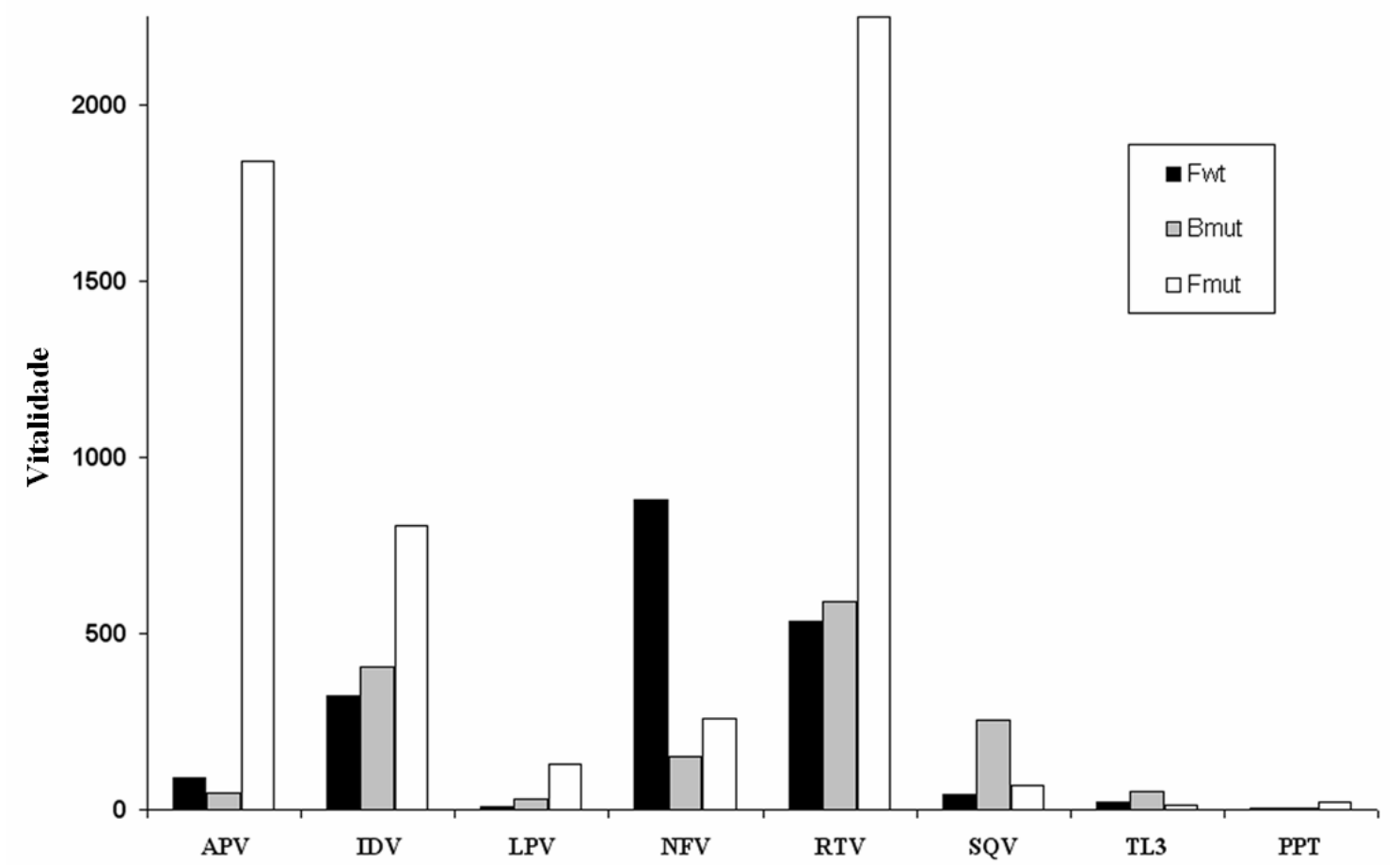

Figura 19: Gráfico de barras representando os valores de vitalidade. Os valores mais altos de vitalidade foram encontrados para Fmut na presença de amprenavir e ritonavir. 


\section{Discussão}

Eu sei que a vida devia ser bem melhor e será! Mas isso não impede que eu repita: É bonita, é bonita e é bonita! 
Mesmo com o grande número de estudos relacionados à proteases do subtipo $\mathrm{B} \mathrm{e}$ de como suas mutações podem interferir na estrutura, na resistência a inibidores e na eficiência catalítica da enzima, existe ainda uma lacuna de como as mudanças polimórficas de proteases de HIV de outros subtipos de HIV-1 interferem nesses fatores. Nesse contexto se insere esse trabalho, que utilizou proteases de HIV-1 isoladas de crianças brasileiras HIV-1 soropositivas verticalmente infectadas com o subtipo F, e outros dois mutantes, sendo que um do subtipo $\mathrm{F}$ e outro do subtipo B. Vale ressaltar que o subtipo F possui grande relevância para o perfil da infecção brasileira, já que, em números, é o segundo subtipo predominante.

Assim, as proteases Fwt, Fmut e Bmut estudadas aqui, carregam além de mutações polimórficas, outras semelhantes as já relatadas para o subtipo B, as quais vêm sendo associadas à resistência a inibidores. Portanto, é esperado que essas enzimas possuam modificações de aminoácidos que causam diferentes níveis de susceptibilidade a inibidores comercialmente disponíveis.

Inicialmente as proteases foram estudadas do ponto de vista estrutural, quando foram obtidas as estruturas tridimensionais para as proteases Bmut, Fwt e Fmut em complexo com o inibidor TL-3 (Sanches, 2007). A Figura 20 mostra os modelos tridimensionais obtidos anteriormente, destacando as posições das mutações observadas.

Uma dessas mudanças estruturais significativas ocorre na região de dobradiça do flap, que compreende os resíduos 33 a 42, e é caracterizada pelos grandes rearranjos entre enzimas ligadas e não ligadas a inibidores ou substratos (Figura 21). Essa região precisa ser flexível para permitir a entrada e saída de substrato e produto. Para a protease $B w t$ observou-se um total de 25 ligações entre a dobradiça e o restante da enzima, enquanto que para a $F w t$ foram observadas 30 ligações, o que implica em um aumento na estabilidade dessa região tornando-a menos flexível, e consequentemente 
aumentando a resistência a inibidores. $\mathrm{O}$ aumento da resistência a inibidores é marcante na mutação M36I, encontrada na $F$ wt e $F m u t$, onde observou-se o colapso dessa dobradiça, devido à substituição de um resíduo grande (metionina) por um resíduo pequeno (isoleucina) (Sanches, 2007).
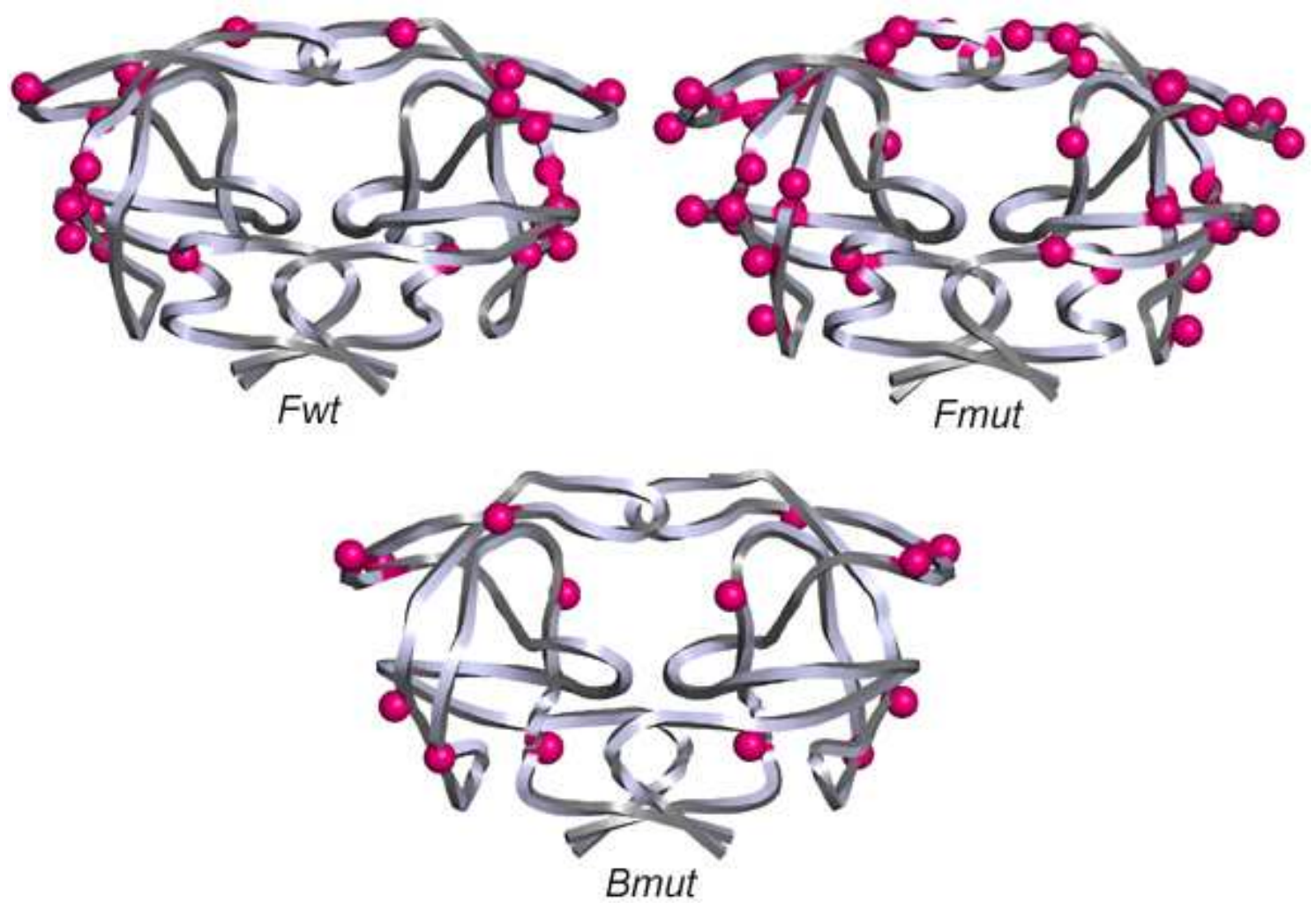

Figura 20: Representação da estrutura tridimendional das proteases de HIV-1. Destaque em vermelho para as mutações com relação a protease $B w t$.

Também foi observada a correspondência estrutural entra as mutações L90M e L89M, encontrada no subtipo F. Nesse caso, o resíduo de metionina faz mais interações de Van de Walls com os átomos da cadeia principal do sítio ativo, o que leva a uma diminuição do volume do sítio e compromete a flexibilidade estrutural do bolsão S1/S1'(Sanches, 2007) (Figura 22).

A mutação V82A presente em Bmut e Fmut apresentou mudanças interessantes semelhantes a outras já reportadas. Nesse caso, ocorreu a troca de um aminoácido 
grande (valina) por um pequeno (alanina) fazendo com que o bolsão P1 e S1

diminuísse, levando a redução da afinidade entre inibidor e protease (Figura 23)

(Sanches 2007).
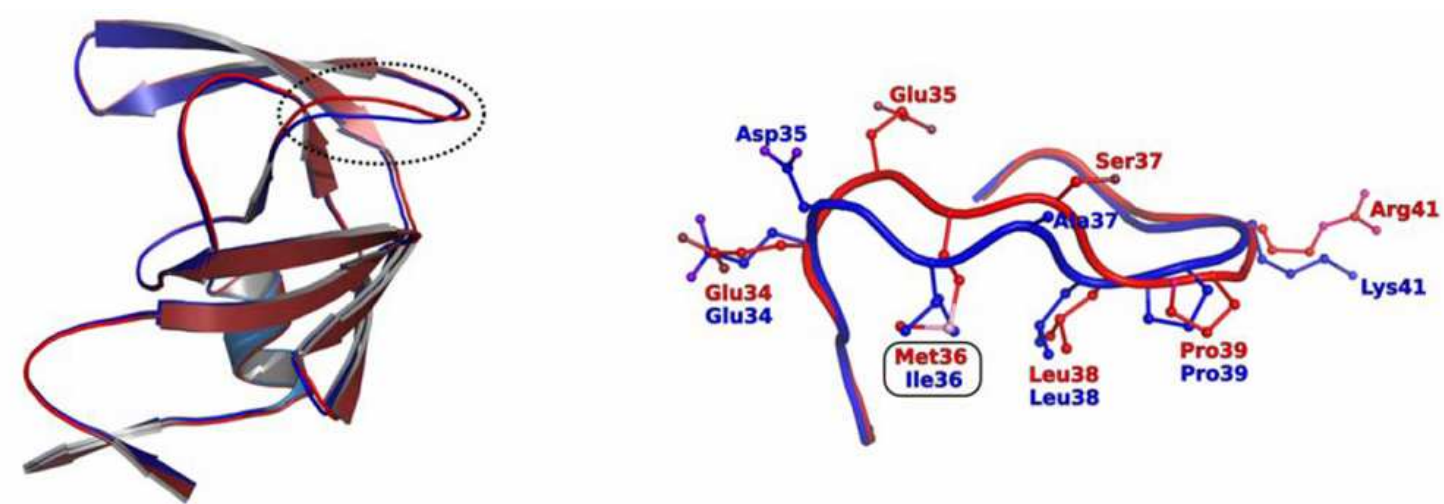

Figura 21: Mudanças conformacionais observadas na região do flap. Em vermelho $B w t$ e $F w t$ em azul Com a mutação M36I, observamos um rearranjo de toda a região, que se move em direção ao restante da proteína, para compensar a substituição de um aminoácido grande por um pequeno, aumentando assim o número de interações de van-der-Walls (Reproduzido de Sanches, 2007)
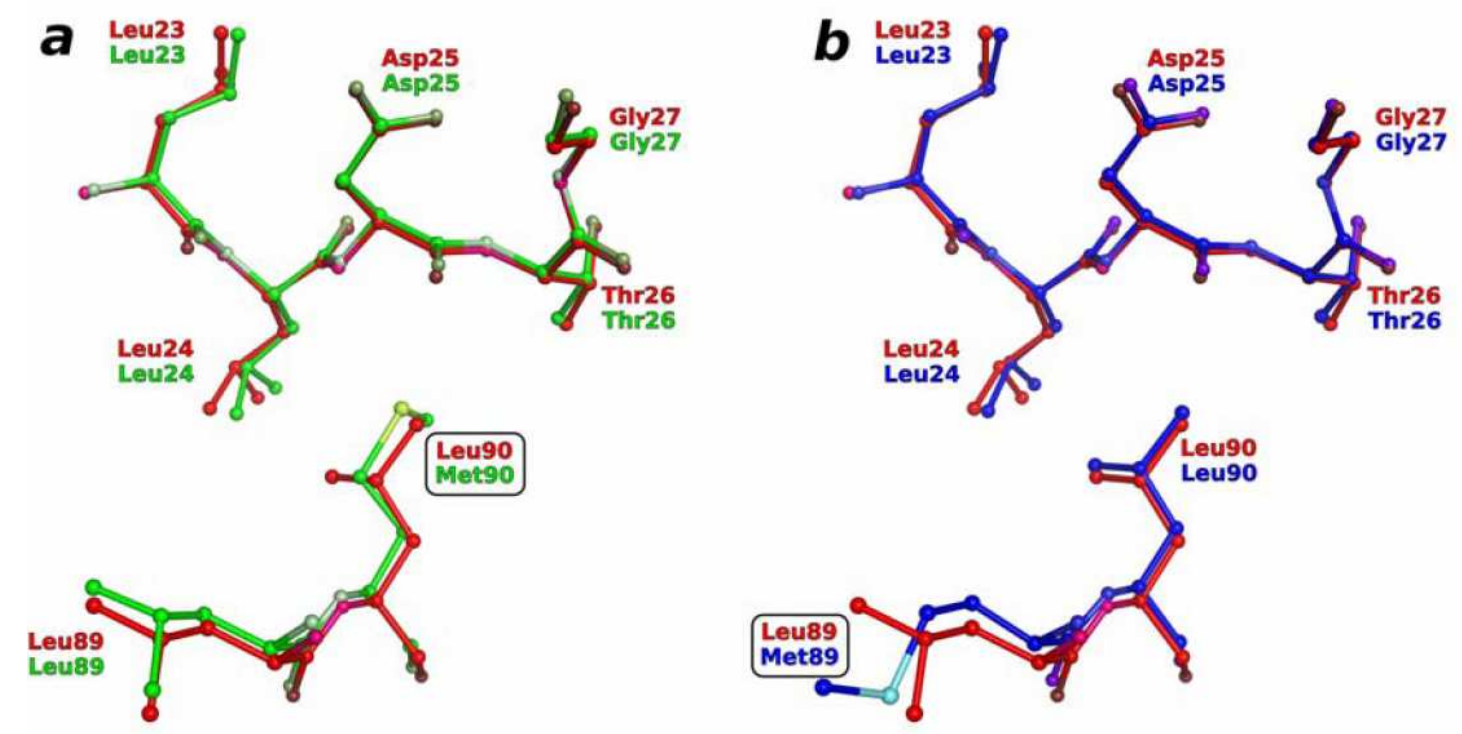

Figura 22: Correspondência estrutural entre L90M e L89M. A figura mostra a estrutura $B w t$ (em vermelho) alinhada com Bmut (em verde) e $F w t$ (em azul). Aparentemente a mutação L90M possui o mesmo efeito que a L89M. Ambas as mutações fazem com que essa região se mova em direção ao loop contendo o Asp 25 causando o aumento de interações van-de-Walls do resíduo 90 e o loop do sítio ativo. (Reproduzido de Sanches, 2007) 

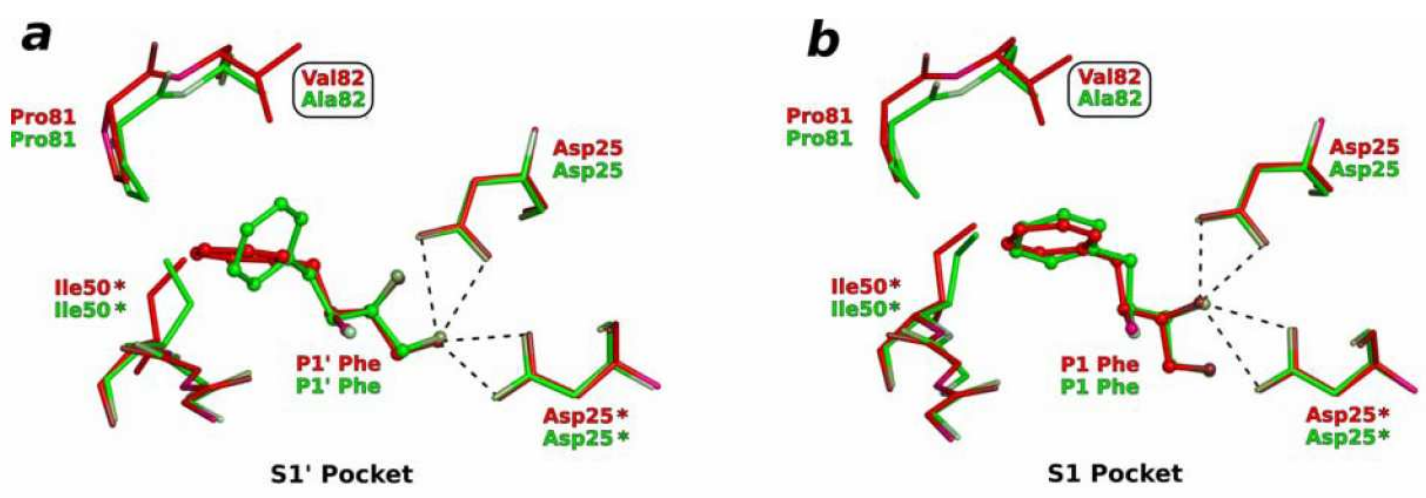

Figura 23: Mudanças conformacionais devido à mutação V82A. Alinhamento das estruturas $B w t$ (em vermelho) e Bmut (em verde). O subsítío P1/P1' do inbidor está mostrado em sticks enquanto o bolsão da protease S1/S1' está mostrado em linhas, os asteriscos representam os resíduos da cadeia vizinha e as linhas pontilhadas representam as ligações de hidrogênio. Enquanto não observamos muitas modificações no subsítio P1 (b) no P1' (a) observamos uma rotação do anel da Phe do inibidor devido à mutação. Essa rotação preserva o número de interações entre a cadeia lateral do inibidor e o bolsão, enquanto no bolsão S1, algumas interações são perdidas com o subsítio P1 devido à mutação. (Reproduzido de Sanches, 2007)

Mudanças na região do sítio ativo, como é o caso da V82A causam resistência devido à redução da afinidade da ligação entre o inibidor e a protease. A maioria dessas mutações levou a uma redução de $2-5$ vezes na susceptibilidade in vitro para um ou mais inibidores. Mutações em outras regiões da enzima ajudam na compensação do decaimento cinético causado por mutações no sítio ativo ou também levam a resistência causada pela alteração da catálise enzimática, da estabilidade do dímero, da cinética de ligação do inibidor ou do rearranjo do sítio ativo através de muitas perturbações estruturais (Erickson, 1999; Barbour, 2002; Muzammil, 2003).

Nesse contexto iniciamos a busca por informações relacionadas às constantes de inibição e a eficiência catalítica para essas proteases com o intuito de complementar o trabalho estrutural previamente realizado.

As constantes de inibição encontradas para TL-3, o inibidor utilizado na cocristalização das proteases, confirmam a hipótese de que as mudanças conformacionais observadas alteram a susceptibilidade pelo inibidor, já que tanto para a $F w t$ quanto Fmut 
e Bmut observou-se diferentes graus de resistência, sendo que quando comparados a $B w t$ os valores de $\mathrm{Ki}$ são aproximadamente três vezes maior para $B m u t$, sete vezes maior para $F w t$ e 54 vezes maior para Fmut.

Quanto às constantes de inibição, frente aos inibidores comerciais, era esperado de acordo com dados da literatura e análise das mutações (Figura 6), que as proteases do projeto apresentassem diminuição da susceptibilidade frente a praticamente todos os inibidores utilizados. Lembrando que os pacientes portadores da Fmut e Bmut estavam em tratamento com os inibidores para protease ritonavir e nelfinavir.

Mutações no gene da protease durante terapia intensa anti-AIDS geralmente ocorrem de forma ordenada: a mutação V82A associada com a perda inicial da atividade antiviral aparece primeiro, depois se desenvolvem as mutações I54V e A71V (Molla, 1996; Condra, 2000; Patick, 1998). Mais tarde aparecem proteases contendo I84V, K20R, M46I, L33F e L90M. Mutações essas que são encontradas nas proteases Bmut (V82A, A71V, L90M) e Fmut (I54V, V82A, K20R, M46I) e vale destacar que para a $F w t$ a mutação I54V ocorre naturalmente. Embora não exista um estudo clínico longo e sistemático para a eficácia dos inibidores atuais diante outros subtipos de HIV1, alguns estudos indicam a existência de polimorfismos relacionados à resistência a inibidores (Becker-Pergola, 2000; Cornelissen, 1997).

Por exemplo, as mutações polimórficas L10I/V/F e A71I/V/T estão associadas com resistência a indinavir, lopinavir e nelfinavir, L63P com indinavir e nelfinavir, K20I/M/R/T com lopinavir e nelfinavir, e M36I e V77I são freqüentemente observadas durante o tratamento com nelfinavir (Rhee et al., 2005). Recentemente sugeriu-se que a mutação polimórfica L89M, observada no subtipo F e em outros subtipos como A, C e G, como causa de resistência a inibidores mimetizando a mutação L90M (Calazans, 2005, Sanches, 2007). 
A variedade de mutações desenvolvidas durante o tratamento com amprenavir, indinavir, nelfinavir, ritonavir, e saquinavir têm sido bem documentadas (Condra, 1996; Molla, 1996; Craig, 1998; Patick, 1998; Atkinson, 2000; Maguire, 2002), porém poucos dados estão disponíveis para lopinavir (Masquelier, 2002; Romano, 2002a) e novos inibidores.

Para Bmut que possui oito mutações: S37N, R41K, K45R, I54V, L63P, A71V, V82A e L90M, em relação à $B w t$ ressaltamos a presença das mutações primárias V82A e L90M e da mutação secundária $\mathrm{I54V}$, frequentemente observadas em resposta a todos os inibidores terapêuticamente utilizados (Rhee et al., 2005). As mutações L63P e A71V estão associadas com a resistência a indinavir, nelfinavir, lopinavir e ritonavir. Os valores de vitalidade obtidos para Bmut refletem esses dados. A enzima possui os valores mais altos com respeito à ritonavir, indinavir, saquinavir e nelfinavir, respectivamente.

A protease do subtipo $\mathrm{F}$ possui naturalmente doze mutações polimórficas: $\mathrm{I} 15 \mathrm{~V}$, E35D, M36I, S37N, R41K, R57K, D60E, Q61N, I62V, L63S, I64L e L89M. É sabido que subtipos não-B não costumam desenvolver a mutação primária L90M, mesmo em indivíduos em tratamentos intensivos com inibidores de protease, enquanto que a substituição L89M é bastante freqüente entre subtipos não-B (Caride et al., 2001). Adicionalmente a dupla mutação L89M/L90M é muita rara em todos os subtipos. Os dados de inibição corroboram a hipótese de que a substituição L89M é correspondente a L90M, já que protease $F w t$ apresentou aumento na resistência para todos os inibidores testados. Além disso, estão presentes as mutações M36I que aparecem em resposta a terapia com nelfinavir e ritonavir e a mutação L63S, associada com a resistência a indinavir e nelfinavir. Isso reflete diretamente nos valores de vitalidade obtidos para a 
protease $F w t$. Os valores mais altos obtidos foram em reposta a nelfinavir, ritonavir e indinavir, respectivamente.

Fmut é a protease que carrega o maior número de mutações (polimórficas e de resistência). Dentre as mutações encontradas (L10I, I15V, G16E, K20R, E35D, M36I, S37N, P39S, R41K, M46I, G51R, I54V, R57K, D60E, Q61D, K70R, I72V, T74A, V82A e L89M), três (M46I, I54V e V82A) são comumente detectadas em resposta a terapia com amprenavir, quatro (L10I, M46I, I54V e V82A) com indinavir, cinco (L10I, K20R, M46I, I54V e V82A) com lopinavir, seis (L10I, K20R, M36I, M46I, I54V e V82A) com nelfinavir e três (M46I, I54V e V82A) com o tratamento com saquinavir (Rhee et al., 2005). O acúmulo dessas mutações leva a uma enzima com alto grau de resistência cruzada, possuindo grande diminuição da susceptibilidade para todos os inibidores testados, como é indicado pelas altas constantes de inibição e pelos valores de vitalidade.

O balanço entre a habilidade de ligação do substrato e a resistência a inibidores determina o sucesso ou o fracasso da função dessa protease mutante $\mathrm{e}$ consequentemente da viabilidade do vírus. Se a protease viral perder a habilidade de ligar o inibidor fortemente, o vírus pode tornar-se viável e sobreviver frente ao tratamento com esse determinado fármaco. Por outro lado, se a protease perder a habilidade de ligação e clivagem da poliproteína gag, o vírus poderá tornar-se incapaz de replicar-se corretamente.

As mutações nas proteases de HIV podem levar a diferentes efeitos nas propriedades catalíticas da enzima. Algumas mutações são cataliticamente deletérias enquanto outras compensam os efeitos catalíticos perdidos, promovendo o aumento da atividade catalítica. A presença das mutações M46I e I54V diminui a eficiência 
catalítica em 2 e 3 vezes, respectivamente, causando alto nível de resistência a inibidores e resistência cruzada (Clemente et al., 2004).

Nesse contexto a protease $F w t$, quando comparada com a $B w t$, demonstrou um aumento de aproximadamente 3 vezes na eficiência catalítica $\left(\mathrm{k}_{\mathrm{cat}} / \mathrm{K}_{\mathrm{M}}\right)$ causada principalmente pela diminuição de 5 vezes do $\mathrm{K}_{\mathrm{M}}$. Bmut, possui eficiência catalítica muito próxima a $B w t$ devido a diminuição simultânea de 3 vezes tanto no $\mathrm{k}_{\text {cat }}$ quanto $\mathrm{K}_{\mathrm{M}}$. Finalmente, Fmut, mostrou uma diminuição de aproximadamente 5 vezes na eficiência catalítica devido a diminuição de 12 vezes no $\mathrm{k}_{\text {cat }}$ e 2,5 vezes no $\mathrm{K}_{\mathrm{M}}$.

A falta de um efeito significante nas medidas de $\mathrm{k}_{\text {cat }}$ para $F w t$ provavelmente reflete o fato de as mutações não estarem no sítio ativo, assim o ambiente químico ao redor da díade aspártica permanece intacta. O mesmo não é verdade para os mutantes dos subtipos $\mathrm{B}$ e $\mathrm{F}$, os quais apresentam diminuição significante no $\mathrm{k}_{\text {cat }}$. Ambas possuem duas mutações primárias: V82A (região de cleft do substrato) e L90M(L89M) mais a mutação secundária I54V inserida na região do flap. Além disso, Fmut também possui a mutação M46I na região do flap.

Esses resultados revelam que os polimorfismos considerados nesse estudo afetam significantemente os valores de $\mathrm{K}_{\mathrm{M}}$ e $\mathrm{K}_{\mathrm{i}}$, mesmo essas mutações não estando localizadas no sítio ativo ou na região do flap. Em todos os casos o aumento nos valores de $\mathrm{K}_{\mathrm{i}}$, é acompanhado pela diminuição do $\mathrm{K}_{\mathrm{M}}$. $\mathrm{O}$ efeito contrário para as constantes $\mathrm{K}_{\mathrm{i}}$ e $\mathrm{K}_{\mathrm{M}}$ foi observado previamente para mutantes do subtipo B (Lin, 1995; Baldwin, 1995; Hong, 1996). Vale ressaltar que esses efeitos ocorrem quando as mutações não afetam a natureza química ou a polaridade do sítio ativo, mas são conhecidas pela modificação em sua geometria (Baldwin, 1995). Do ponto de vista termodinâmico a origem desses efeitos diferentes parece estar relacionada com dificuldades conformacionais dos 
inibidores em se adaptarem às distorções geométricas no sítio de ligação (Luque et al., 1998; Todd et al., 2000). 


\section{Conclusões}

\section{e Perspectivas}

Viver e não ter a vergonha de ser feliz, cantar... a beleza de ser um eterno aprendiz. 
A conclusão desse trabalho consolida mais uma etapa dentro do projeto envolvendo proteases de HIV, no Grupo de Cristalografia de Proteínas do Instituto de Física de São Carlos. Em trabalhos anteriores a produção heteróloga das proteases foi realizada com sucesso e deu origem a informações estruturais bastante relevantes. Nesse contexto essa dissertação vem acrescentar informações relacionadas à eficiência catalítica e susceptibilidade a inibidores para estruturas já resolvidas.

A metodologia relacionada a ensaios enzimáticos para protease de HIV foi estabelecida com sucesso e de maneira reprodutiva em nosso laboratório, abrindo possibilidades para que novos inibidores sejam testados.

Nossos resultados experimentais revelam que os seis inibidores comerciais estudados são significantemente menos ativos para o subtipo F quando comparados ao subtipo B. Além disso, o subtipo F é menos susceptível a inibição que os subtipos A e C (Velazquez-Campoy, at el, 2001). Vale ressaltar que na América Latina mais de 6\% das seqüências de HIV notificadas correspondem ao subtipo F, e se considerarmos que essa porcentagem é proporcional ao número de infecções teríamos em torno de 120 mil pessoas infectadas com esse subtipo e que provavelmente são mais propensas a apresentar falha terapêutica.

Nossos dados fornecem informações importantes que deveriam ser levados em conta durante a escolha do inibidor a ser utilizado para proteases do subtipo F. A protease $F w t$ foi a que apresentou melhor balanço entre resistência a inibidores e eficiência catalítica. Lembrando que a constante de inibição teve aumento de 2 vezes para lopinavir, 14 vezes para saquinavir, 30 vezes para amprenavir, 111 vezes para indinavir, 183 vezes para ritonavir e 301 vezes maior para nelfinavir e quando comparados com $B w t$, além disso a eficiência catalítica se mostrou três vezes maior para a consenso do subtipo F. 
Acredita-se que as diferenças polimórficas entre os subtipos B e F ampliam o efeito das mutações já relacionadas à resistência, fato observado na protease Fmut que apresentou baixa susceptibilidade a todos os inibidores testados.

Ainda relacionado a polimorfismo, a mutação M36I está presente em 95\% das linhagens do subtipo F, $98 \%$ no subtipo A, $80 \%$ no subtipo C, $62 \%$ no subtipo D e $100 \%$ no subtipo G e apenas $13 \%$ no subtipo B (Standford HIV Database), levando a conclusão de que subtipos não-B são mais passíveis de desenvolverem resistência.

Quando tratamos da mutação L89M, também observamos grande prevalência dessa mutação polimórfica entre subtipos não-B, $99 \%$ para o subtipo A, $85 \%$ para o subtipo C, $69 \%$ para o subtipo $\mathrm{F}$ e $98 \%$ para o subtipo $\mathrm{G}$, enquanto que para as proteases do subtipo B e D, observamos apenas $1 \%$ e $3 \%$ da substituição respectivamente. Novamente, baseado nos dados estruturais, e no aumento das constantes de inibição para as proteases do subtipo F com relação a todos os inibidores testados, indicam a correspondência entre essa mutação e a L90M.

Assim fica a necessidade de novos estudos para avaliar a eficiência dos inibidores de proteases disponíveis atualmente frente a outros subtipos de HIV, bem como a avaliação de outros inibidores frente aos subtipos já estudados. 


\section{Referências}

Eu fico com a pureza das respostas das crianças. É a vida, é bonita e é bonita!

(O que é que é? - Gonzaguinha) 
AIDS epidemic update (2006). Publicação conjunta UNAIDS/WHO (http://www.unaids.org)

Atkinson, B., Isaacson, J., Knowles, M., Mazabel, E. e Patick, A. K. (2000). Correlation between human immunodeficiency virus genotypic resistance and virologic response in patients receiving nelfinavir monotherapy or nelfinavir with lamivudine and zidovudine. J. Infect. Dis. 182, 420-427.

Baldwin, E. T., Bhat, T. N., Liu, B., Pattabiraman, N. e Erickson, J. W. (1995) Nat. Struct. Biol. 2, 244-249.

Barbour, J. D., Wrin, T., Grant, R. M., Martin, J. N., Segal, M. R., Petropoulos, C. J. e Deeks, S. G. (2002) Evolution of phenotypic drug susceptibility and viral replication capacity during long-term virologic failure of protease inhibitor therapy in human immunodeficiency virus-infected adults. J. Virol. 76, 11104-11112.

Barré-Sinousi, F., Chermann, J. C., Rey, F., Nugeyre, M. T., Chamaret, S., Gruest, J., Daughet, C., Axler-Blin, C., Vézinet-Brun, F., Rouzioux, C., Rozembaum, W e Montagnier, L. (1983). Isolation of a T-lymphotropic retrovirus from a patient at risk for acquired immune deficiency syndrome (AIDS). Science, 220, 868-871.

Becker-Pergola, G., Kataaha, P., Johnston-Dow, L., Fung, S., Jackson, J. B. e Eshleman, S. H. (2000) AIDS Res. Hum. Retroviruses 16, 807-813.

Boletim Epidemiológico AIDS.(2006) Ministério da Saúde — Secretaria Executiva Coordenação Nacional de DST e AIDS.

Benson, D. A., Boguski, M. S., Lipman, D. J., Ostell, J. e Francis, B. F. (1998) GenBank of HIV proteases. Nucleic Acids Res. 26, 1-7.

Bieth, J.G. (1995). Theoretical and practical aspects of proteinase inhibition kinetics. Methods Enzymol. 248, 59-84. 
Blundell, T., Lapatto, L. R., Wilderspin, A. F., Hemmings, A. M., Hobart, P. M, Danley, D. E. e Whittle P. J. (1990) The 3-D structure of HIV-1 proteinase and the design of antiviral agents for the treatment of AIDS. Trends in Biochemistry Sciences 15(11):425-430.

Brindeiro, P. A., Brindeiro, R. M., Mortensen, C., Hertogs, K., Vroey, V. D., Rubini, N. P. M., Sion, F. S., Sá, C. A. M., Machado, D. M., Succi, R. C. M. e Tarnuri, A. (2002). Testing genotypic and phenotypic resistance in Human Immunodeficiency Virus type 1 isolates of clade B and other clades from children failing antiretroviral therapy. Journal of Clinical Microbiology, 40(12), 4512-4519.

Calazans, A., Brindeiro, R., Brindeiro, P., Verli, H., Arruda, M. B., Gonzalez, L. M., et al. (2005) Low accumulation of L90M in protease from subtype F HIV-1 with resistance to protease inhibitors is caused by the L89M polymorphism. J Infect Dis 191, 1961-70.

Caride, E., Hertogs, K., Larder, B., Dehertogh, P., Brindeiro, R., Machado, E., de As, C. A., Eyer-Silva, W. A., Sion, F. S., Passioni, L. F., Menezes, J. A., Calazans, A. R. e Tanuri, A. (2001) Genotypic and phenotypic evidence of different drug-resistance mutation patterns between $B$ and non-B subtype isolates of human immunodeficiency virus type 1 found in Brazilian patients failing HAART. Virus Genes 23, 193-202.

Clemente, J. C., Moose, R. E., Hemrajani, R., Whitford, L.R., Govindasamy, L., Reutzel, R., McKenna, R., Agbandje-McKenna, M., Goodenow, M. M., e Dunn, B. M. (2004) Comparing the accumulation of active- and nonactive-site mutations in the HIV-1 protease. Biochem. 43(38), 12141-12151.

Condra, J. H., Petropoulos, C. J., Ziermann, R., Schleif, W. A., Shivaprakash, M. e Emini, E. A. (2000) Drug resistance and predicted virologic responses to human 
immunodeficiency virus type 1 protease inhibitor therapy. J. Infect. Dis. 182, 758765.

Cornelissen, M., van den Burg, R., Zorgdrager, F., Lukashov, V. e Goudsmit, J. (1997) Pol gene diversity of five human immunodeficiency virus type 1 subtypes: evidence for naturally ocurring mutations that contribute to drug resistance, limited recombination patterns, and common ancestry for subtypes B and D. J. Virol. 71, $6348-6358$.

Craig, C., Race, E., Sheldon, J., Whittaker, L., Gilbert, S., Moffatt, A., Rose, J., Dissanayeke, S., Chirn, G. W., Duncan, I.B. e Cammack N. (1998). HIV protease genotype and viral sensitivity to HIV protease inhibitors following saquinavir therapy. AIDS 12, 1611-1618.

Erickson, J. W. e Burt, S. K. (1996) Structural mechanisms of HIV drug resistance. Annu. Rev. Pharmacol. Toxicol. 36, 545-71.

Frankel, A. D. e Young, J. A. (1998) HIV-1: Fifteen Proteins and an RNA. Annu. Rev. Biochem. 67, 1-25.

Gallo, R. C., Slahuddin, S. Z., Popovic, M., Shearer, G. M., Kaplan, M., Haynes, B. F., Palker, T. J., Redfield, R., Oleske, J., Safai, B., White, G., Foster, P e Markham, P. D. (1984) Frequent detection and isolation of cytopathic retroviruses (HTLV-III) from patients with AIDS and risk for AIDS. Science, 224, 500-503.

Gulnik, S., Suvorov, L. I., Liu, B., Yu, B. Anderson, B., Mitsuya, H. e Erickson, J. W. (1995) Kinetic characterization and cross-resistance patterns of HIV protease mutants selected under drug pressure. Biochem. 34, 9282-9287.

Hazuda, D. J. P. Ferlock, M. Witmer, A. Wolfe, K. Stillmock, J. A. Grobler, A. Espeseth, L. Gabryelski, W. Schlelf C. Blau e M. D. Miller.(2000) Inhibitors of 
strand transfer that prevent integration and inhibit HIV-1 replication in cells. Science, 287:646-650.

Hoffmann, D., Assfalg-Machleidt, 3., Nitschko, H., von der Helm, K., Koszinowski, U. e Machleidt, W. (2003) Rapid Enzymatic Test for Phenotypic HIV Protease Drug Resistance. Biol. Chem. 384, p. 1109-17.

Hong, L., Treharne, A., Hartsuck, J. A., Foundling, S. e Tang, J. (1996) Crystal Structures of complexes of a peptidic inhibitor with wild type and two mutants HIV1 proteases. Biochem. 35, 10627-10633.

Kantor, R. e Katzenstein D.(2004). Drug resistance in non-subtype B HIV-1. Journal of Clinical Virology, 29: 152-159.

Kummerle D. R. e Earlywine V. (1996) An overview of HIV infection. Pharmacy Times, 68-73.

Li, M. G. M. Morris, T. Lee, G. S. Laco, C. Wong, A. J. Olson, J. H. Elder, A. Wlodawer e A. Gustchina. Structural studies of FIV and HIV-1 Proteases complexed wth an efficient inhibitor of FIV Protease. Proteins: Structure, Function and Genetics 38:29-40, 2000.

Lin, Y., Lin, X., Hong, L., Foundling, S., Heinrikson, R. L., Thaisrivongs, S., Leelamanit, W., Raterman, D., Shah, M., Dunn, B. D. e Tang, J. (1995). Effect of point mutations on the kinetics and the inhibition of human immunodeficiency virus type 1 protease. Biochem. 34, 1143-1152.

Luque, I., Todd, M. J., Gomez, J., Semo, N. e Freire, E. (1998). Molecular basis of resistance to HIV-1 protease inhibition: a plausible hypothesis. Biochem. 37, 57915797.

Maguire, M. F., Guinea, R., Griffin, P., Macmanus, S., Elston, R. C., Wolfram, J., Richards, N., Hanlon, M. H., Porter, D. J., Wrin, T., Parkin, N., Tisdale, M., Furfine, 
E., Petropoulos, C., Snowden, B. W. e Kleim, J. P. (2002). Changes in human immunodeficiency virus type $1 \mathrm{Gag}$ at positions L449 and P453 are linked to I50V protease mutants in vivo and cause reduction of sensitivity to amprenavir and improved viral fitness in vitro. J Virol 76:7398-7406.

Matayoshi, E.D., Wang, G.T., Kraft, G.A. e Erickson, J. (1990). Novel fluorogenic substrates for assaying retroviral proteases by resonance energy transfer. Science $\mathbf{2 4}$, 954-958.

Masquelier, B., Breilh, D., Neau, D., Lawson-Ayayi, S., Lavignolle, V., Ragnaud, J. M., Dupon, M., Morlat, P., Dabis, F. e Fleury, H. (2002). Human immunodeficiency virus type 1 genotypic and pharmacokinetic determinants of the virological response to lopinavir-ritonavir-containing therapy in protease inhibitor-experienced patients. Antimicrob Agents Chemother 46, 2926-2932.

Mildner AM, Rothrock DJ, Leone JW, Bannow CA, Lull JM, Reardon IM, Sarcich JL, Howe WJ, Tomich CS, Smith CW, et al. (1994) The HIV-1 protease as enzyme and substrate: mutagenesis of autolysis sites and generation of a stable mutant with retained kinetic properties. Biochem. 33(32), 9405-9413.

Miller, M., Schneider, J., Sathyanarayana, B. K., Toth, M. V., Marshall, G. R., Clawson, L., Selk, L., Kent, S. B. H. e Wlodawer, A. (1989) Structure of complex of synthetic HIV-1 protease with a substratebased inhibitor at $2.3-\AA ̊$ resolution. Science 246, 1149-1152.

Molla, A., Korneyeva, M., Gao, Q., Vasavanonda, S., Schipper, P. J., Mo, H. M., Markowitz, M., Chernyavskiy, T., Niu, P., Lyons, N., Hsu, A., Granneman, G. R., Ho, D. D., Boucher, C. A., Leonard, J. M., Norbeck, D. W. e Kempf, D. J. (1996) Ordered accumulation of mutations in HIV protease confers resistance to ritonavir. Nat. Med. 2, 760-766. 
Morrison, J.F. (1969). Kinetics of the reversible inhibition of enzyme catalysed reactions of tight-binding inhibitors. Biochim. Biophys. Acta 185, 269-285.

Muzammil, S., Ross, P. e Freire, E. (2003) A major role for a set of non-active site mutations in the development of HIV-1 protease drug resistance. Biochemistry 42 , 631-638.

Navia. M. A. P.M.D Fitzgerald, B. M. McKeever, C. T.Leu, J. C. Heimbach, W. K. Herber et al. (1989) Three Dimensional structure of aspartyl protease from human imunudeficiency virus HIV-1. Nature 737:615-620.

Patick, A. K., Duran, M., Cao, Y., Shugarts, D., Keller, M. R., Mazabel, E., Knowles, M., Chapman, S., Kuritzkes, D. R. e Markowitz, M. (1998) Genotypic and phenotypic characterization of human immunodeficiency virus type 1 variants isolated from patients treated with the protease inhibitor nelfinavir. Antimicrob. Agents Chemother. 42, 2637-2644.

Rhee, S. Y., Fessel, W. J., Zolopa, A. R., Hurley, L., Liu, T., Taylor, J., Nguyen, D. P., Slome, S., Klein, D., Horberg, M., Flamm, J., Follansbee, S., Schapiro, J. M. e Shafer, R. W. J. (2005) HIV drug resistance database. Infect. Dis. 192, 456-465 http://hivdb.stanford.edu/.

Roberts, N. A. J. A. Martin, D. Kinchington, A. V. Broadhurst, J. C. Craig, I. B Duncan, S. A Galpin, B. K Handa, J. Kay, A. Kröhn, R. W. Lambert, J. H Merrett, J. S Mills, K. E. B. Parkes, S. Redshaw, A. J. Ritchie, D. L. Taylor, G. J. Thomas e P. J. Machin.(1990) Rational design of peptide-based HIV proteinase inhibitors. Science, 248:358-361.

Robertson D. L. et al. (1999) HIV-1 nomenclature proposal. HIV Sequence Database hiv-web.lanl.gov. 
Romano, L., Peduzzi, C., Venturi, G., Di Pietro, M., Carli, T., Corsi, P., Gonnelli, A., Valensin, P. E. e Zazzi, M. (2002) Treatment with lopinavir/ritonavir in heavily pretreated subjects failing multiple antiretroviral regimens in clinical practice. $J$ Acquir Immune Defic Syndr 30, 533-535.

Rose, J. R., Salto, R. e Crik. C. S. (1993) Regulation of autoproteolysisof the HIV-1 e HIV-2 proteases whith engineered amino acid substitution. J. Biol. Chem, 268(16):11939-11945.

Sanches, M., Martins, N. H., Calazans, A., Brindeiro, R. M., Tanuri, A., Antunes, O. A. C. e Polikarpov, I. (2004) Crystallization of a non-B and a B mutant HIV protease. Acta Cryst. D60, 1625-1627.

Sanches, M., Krauchenco, S., Martins, N. H., Gustchina, A., Wlodawer, A. e Polikarpov, I (2007) Structural Characterization of B and non-B Subtypes of HIVProtease: Insights into the Natural Susceptibility to Drug Resistance Development. J. Mol. Biol. doi:10.1016/j.jmb.2007.03.049.

Shafer. R. W. (2004) Genotypic testing for HIV-1 drug resistance. HIV In site Knowledge Base chapter.

Sierra, S., Kupfer, B. e Kaiser, R. (2005) Basics of the virology of HIV-1 and its replication. J. Clin. Virol, 34, 233-244.

Todd, M. J., Luque, I., Velazquez-Campoy, A. e Freire, E. (2000) Thermodynamic basis of resistance to HIV-1 protease inhibition: calorimetric analysis of the V82F/I84V active site resistant mutant. Biochem. 39, 11876-11883.

Turner, B. G. e. Summers, M. F. (1999) Structural biology of HIV. Journal of Molecular Biology, 285:1-32.

Vaishnav Y. N. e Wong-Staal F. (1991).The biochemistry of aids. Annual Review of Biochemistry, 60:577-630. 
Velazquez-Campoy, A., Todd, M. J., Vega, S. e Freire, E. (2001) Catalytic efficiency and vitality of HIV-1 proteases from African viral subtypes. Proc. Natl. Acad. Sci. U.S.A. 98, 6062-6067.

Wiegers, K., Rutter, G., Kottler, H., Tessmer, U., Hohenberg, H. e Krausslich, H. G. (1998) Sequential steps in human immunodeficiency virus particle maturation revealed by alterations of individual Gag polyprotein cleavage sites. J. Virol. $\mathbf{7 2}$, 2846-2854.

Wlodawer, A., Miller, M., Jaskolski, M. K., Sathyanarayana, B., Baldwin, E. T., Weber, I. M., Selk, L., Clawson, L., Schneider, J. B. H. e Kent, S. (1989). Conserved folding in retroviral proteases: Crystal structure of a synthetic HIV-1 protease. Science, 245, 616-621.

Wlodawer, A. e Vondrasek, J. (1998) Inhibitors of HIV-1 protease: A major success of structure-assisted drug design. Annu. Rev. Biophys. Biomol. Struct. 27, 249-284. 


\section{Anexo A}

Gráficos de inibição para as proteases de HIV-1 - Vi/Vo versus concentração de inibidor. Os dados foram fitados através de regressão não linear, segundo a equação (1) de Material e Métodos. Os parâmetros P1 e P2 estão relacionados respectivamente com a concentração de proteína ativa e a constante de inibição. 


\section{1-Protease $B w t$}
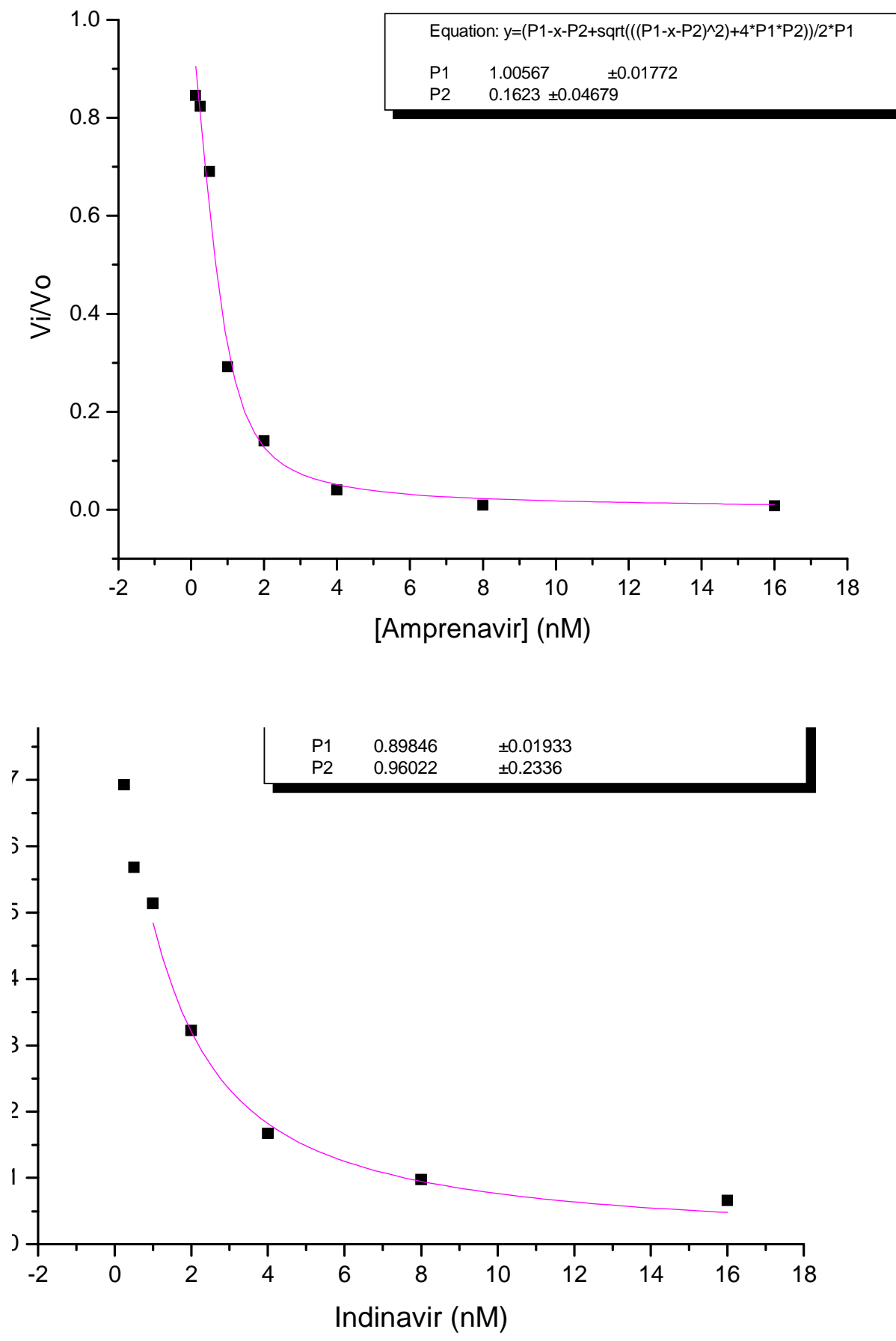

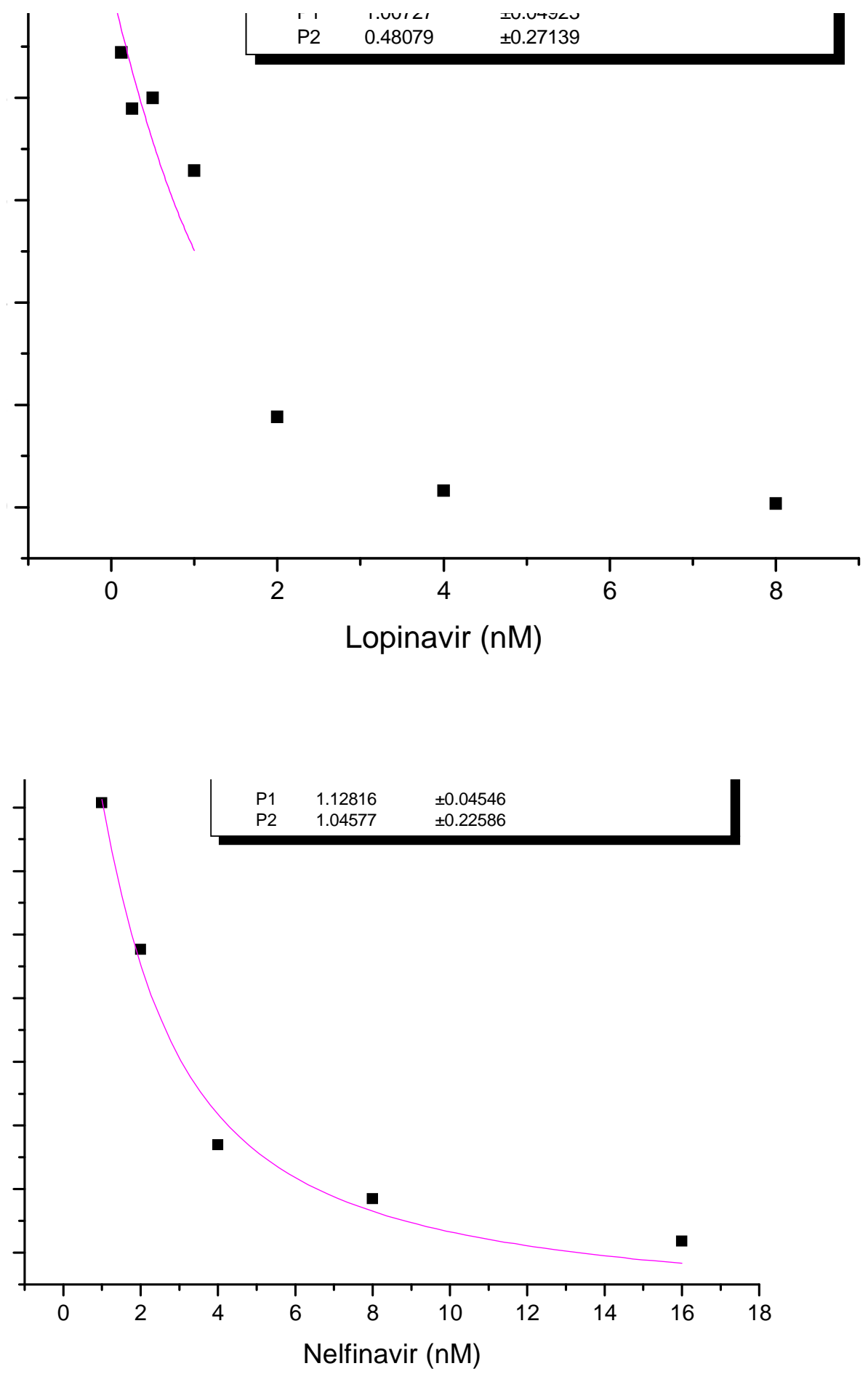

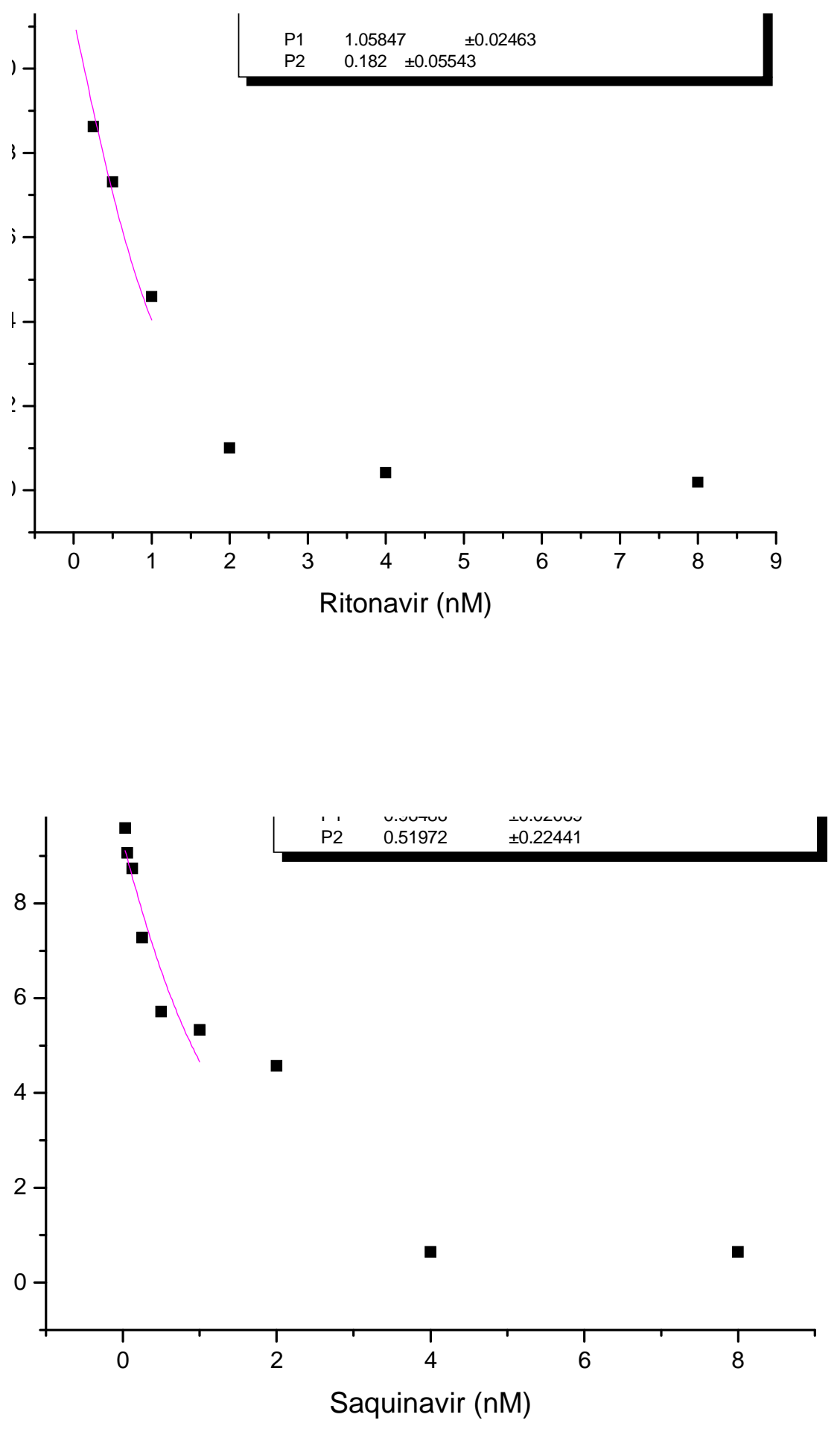


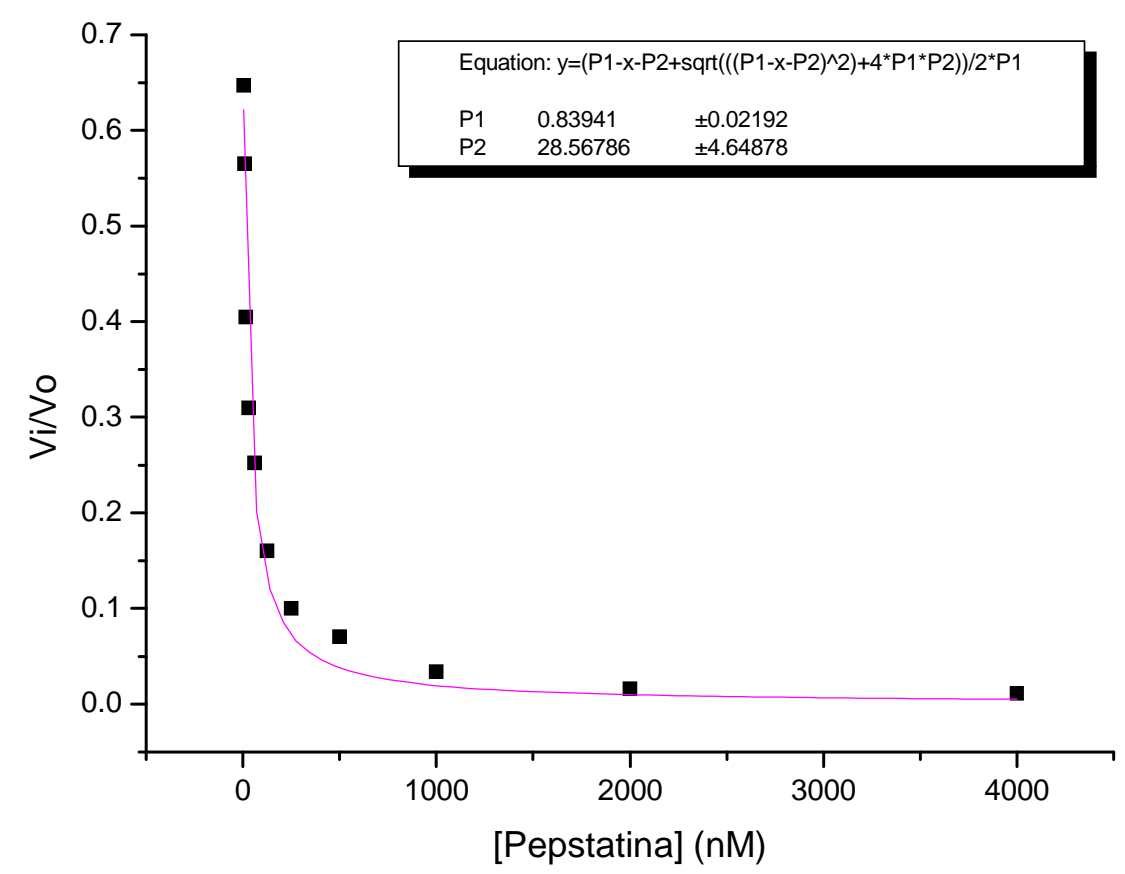



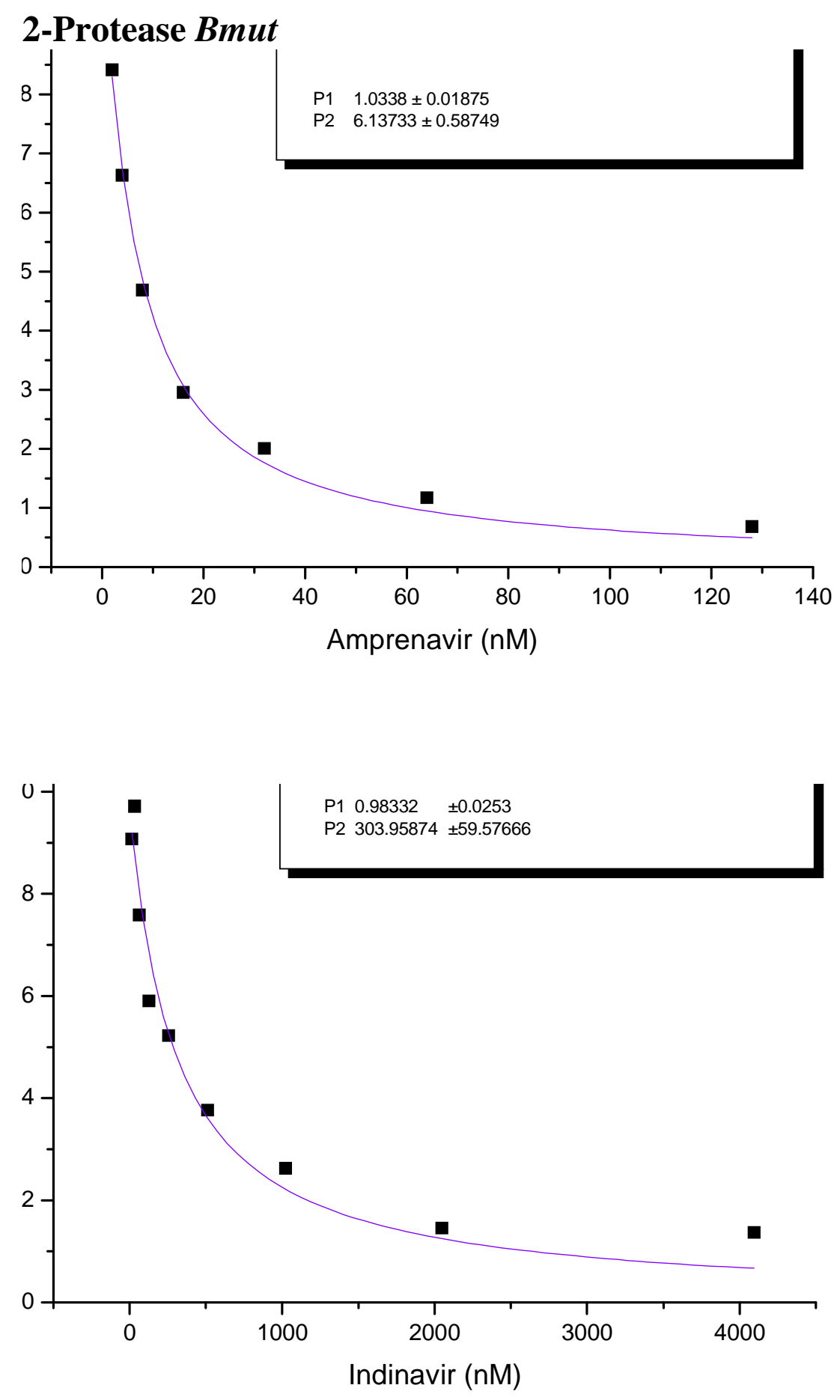

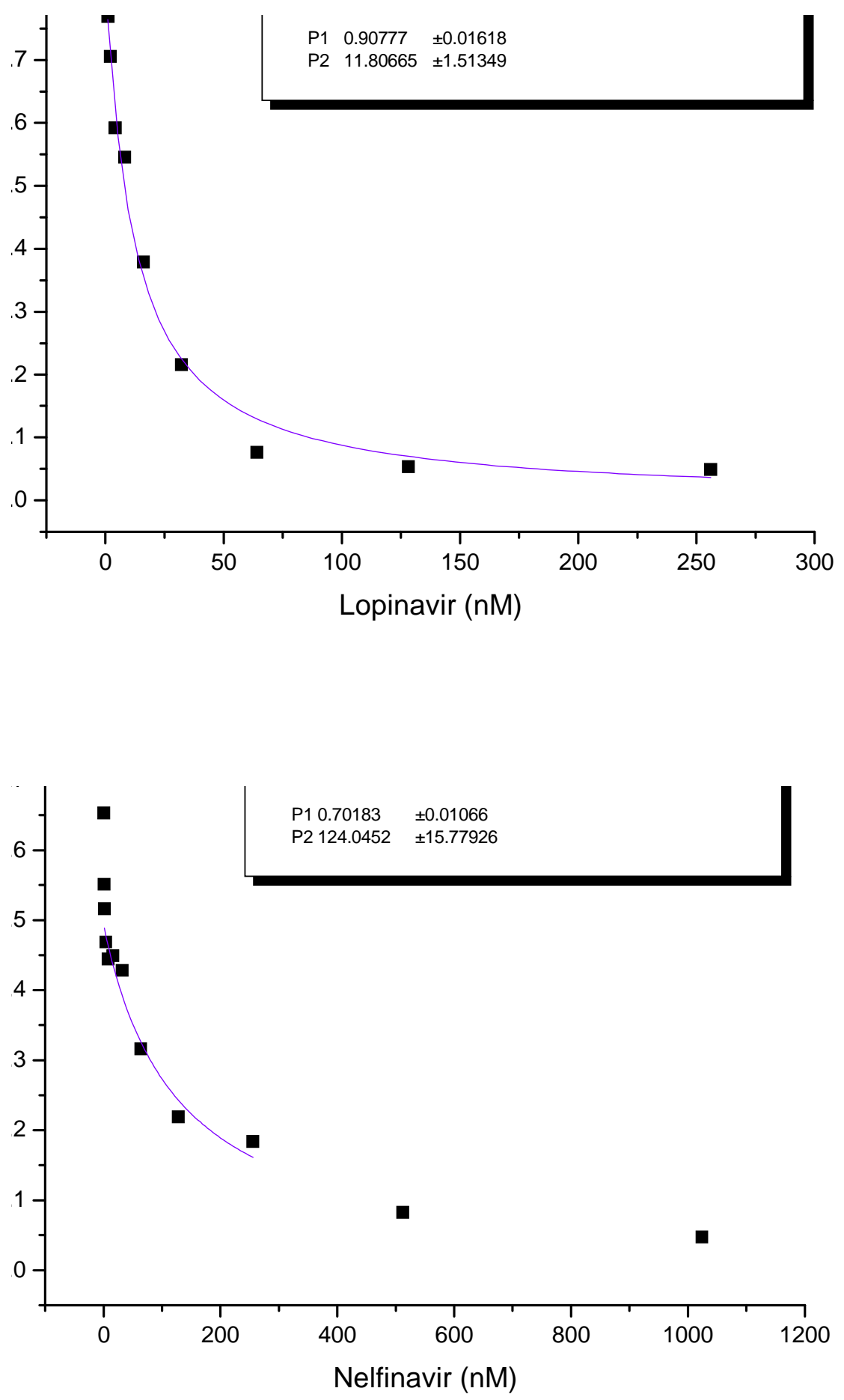


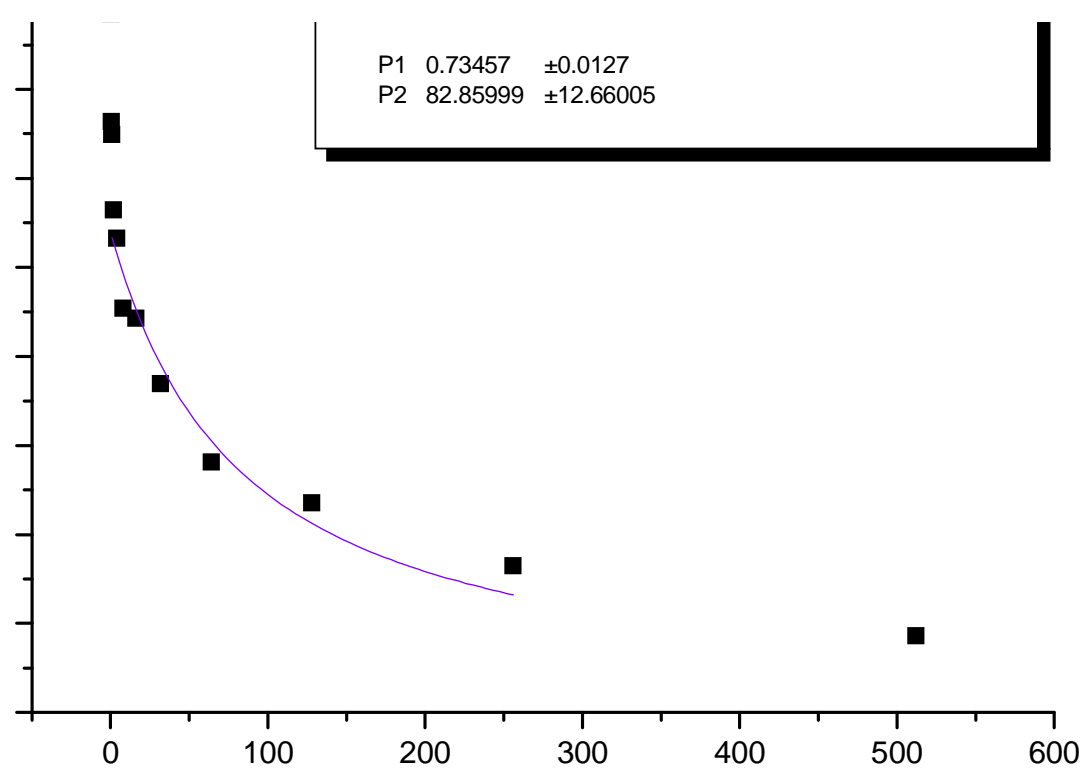

Ritonavir (nM)

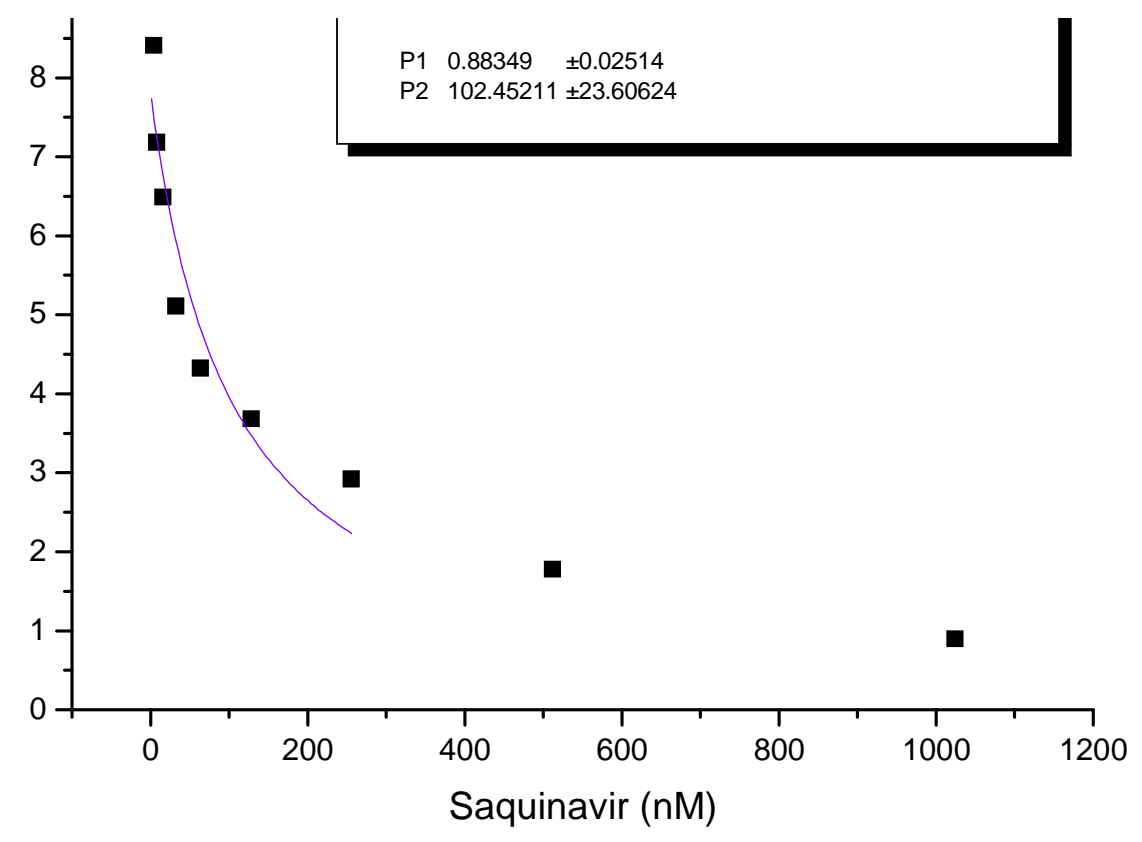



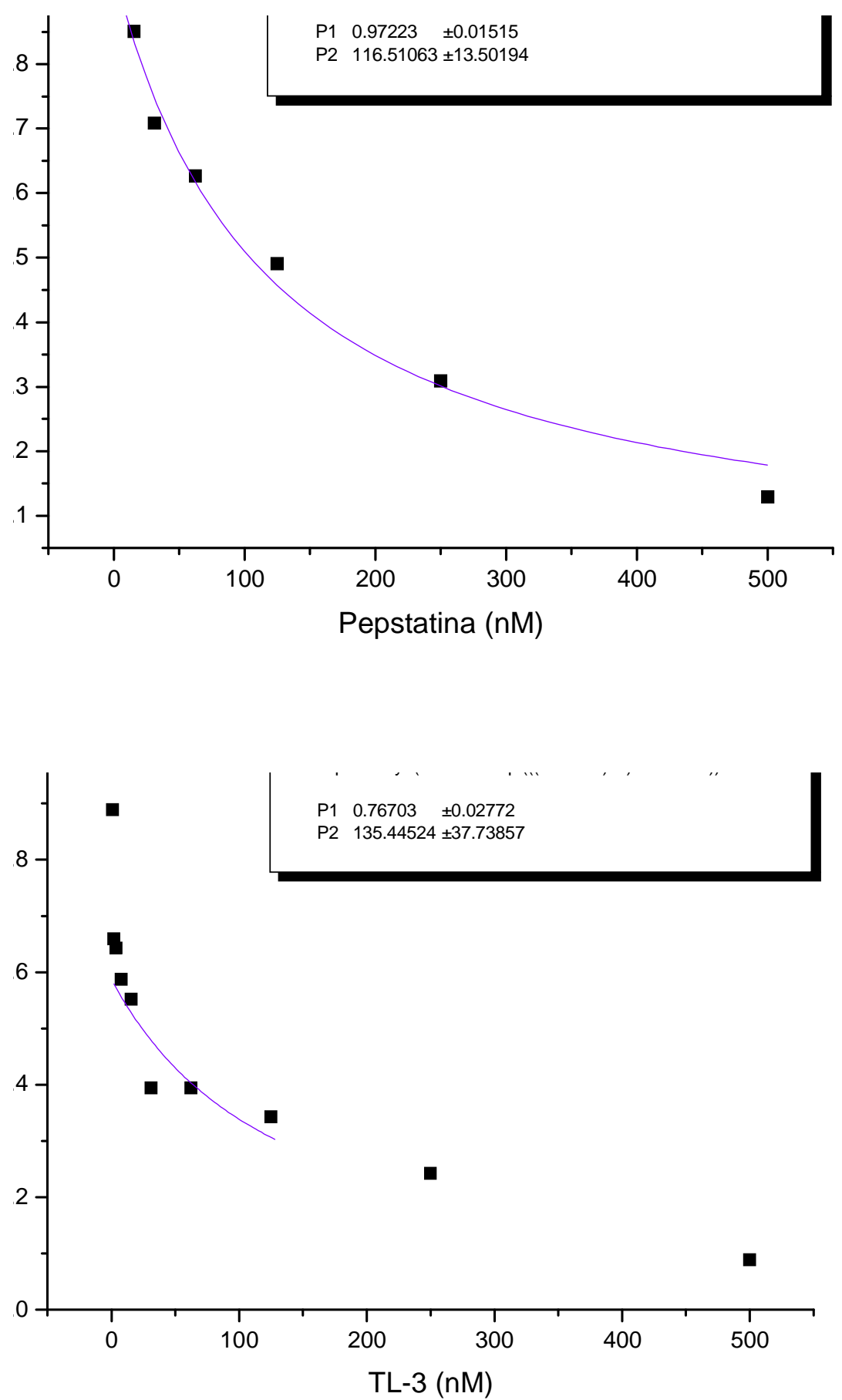


\section{3-Protease $\boldsymbol{F} w \boldsymbol{t}$}
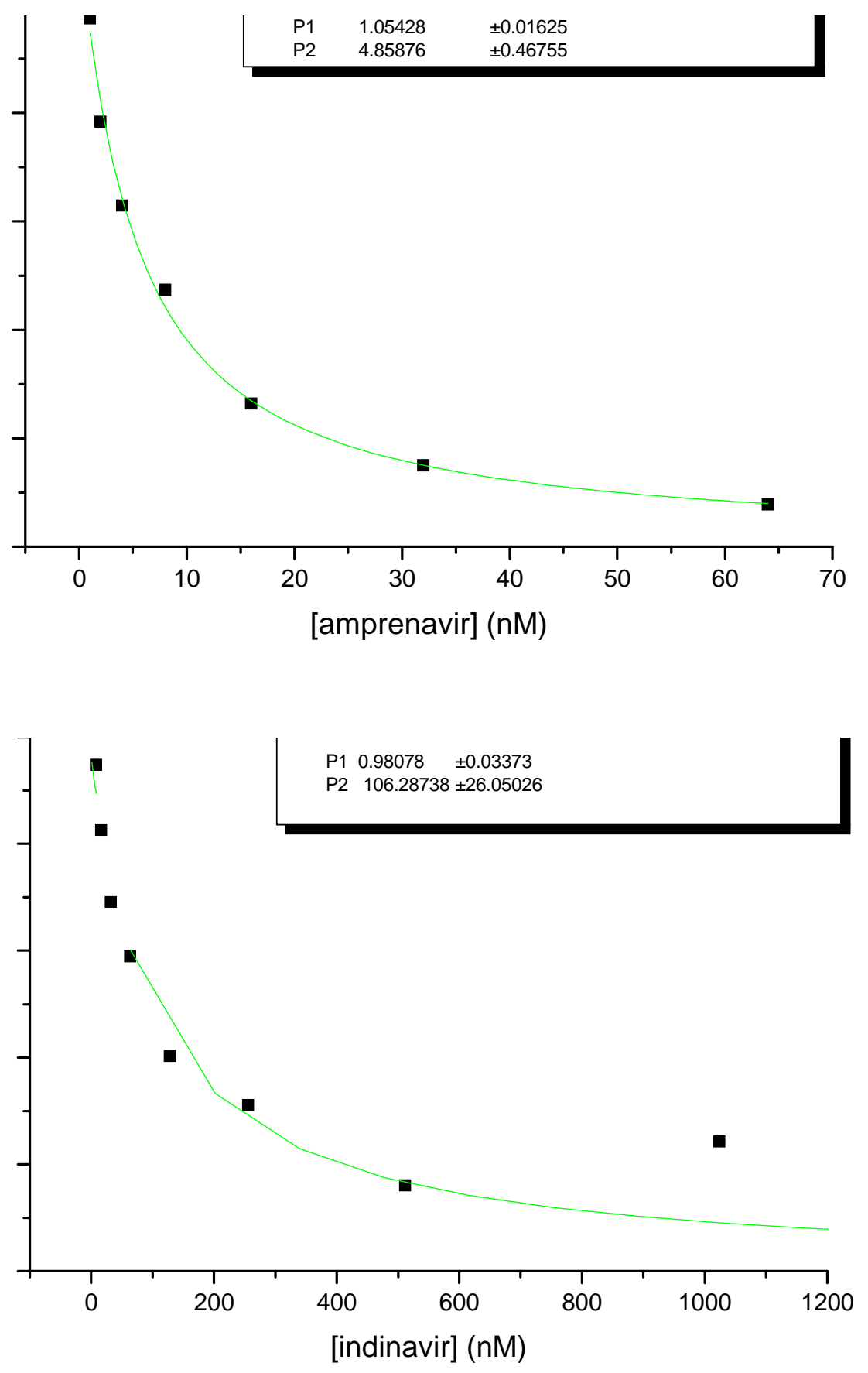

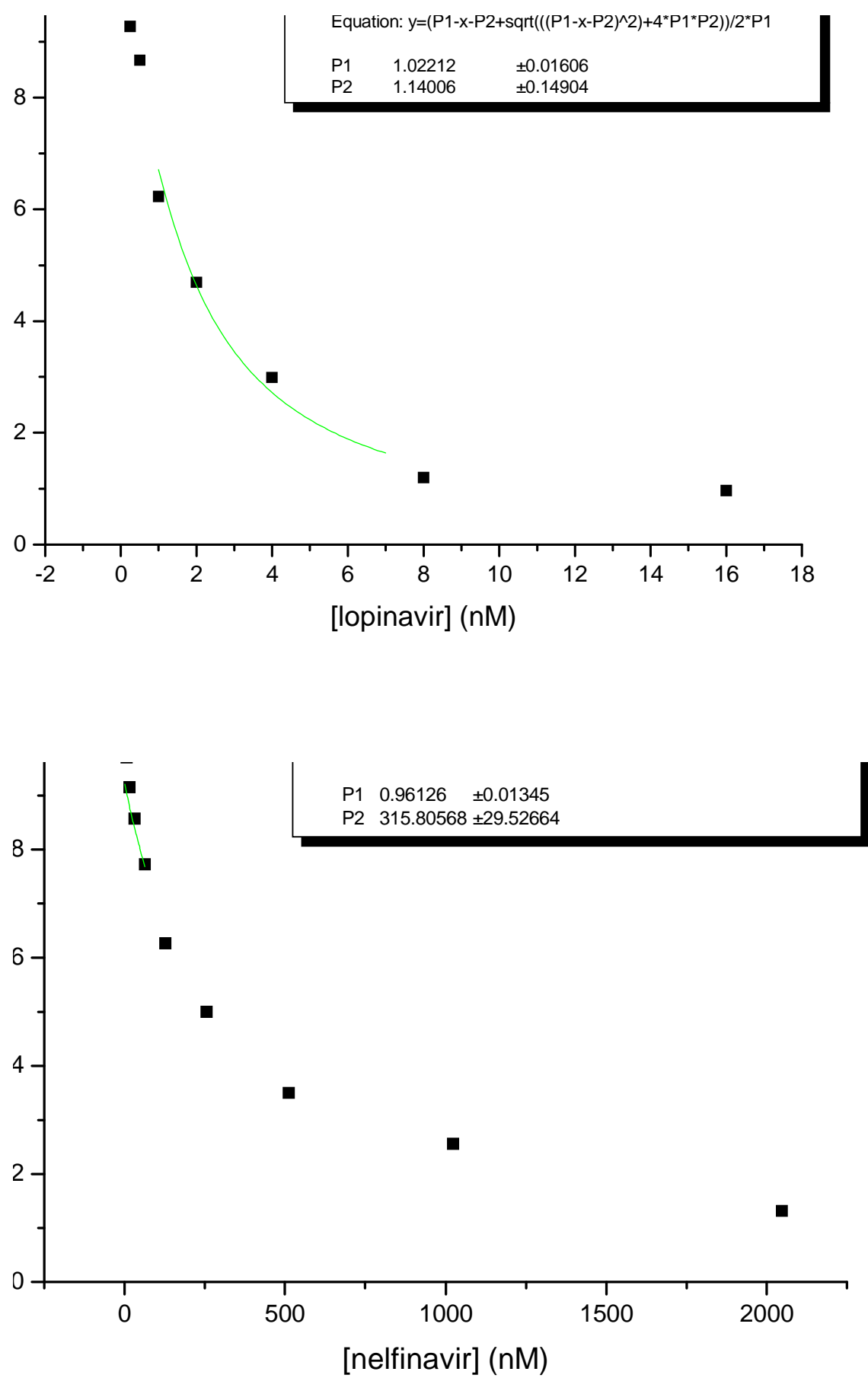

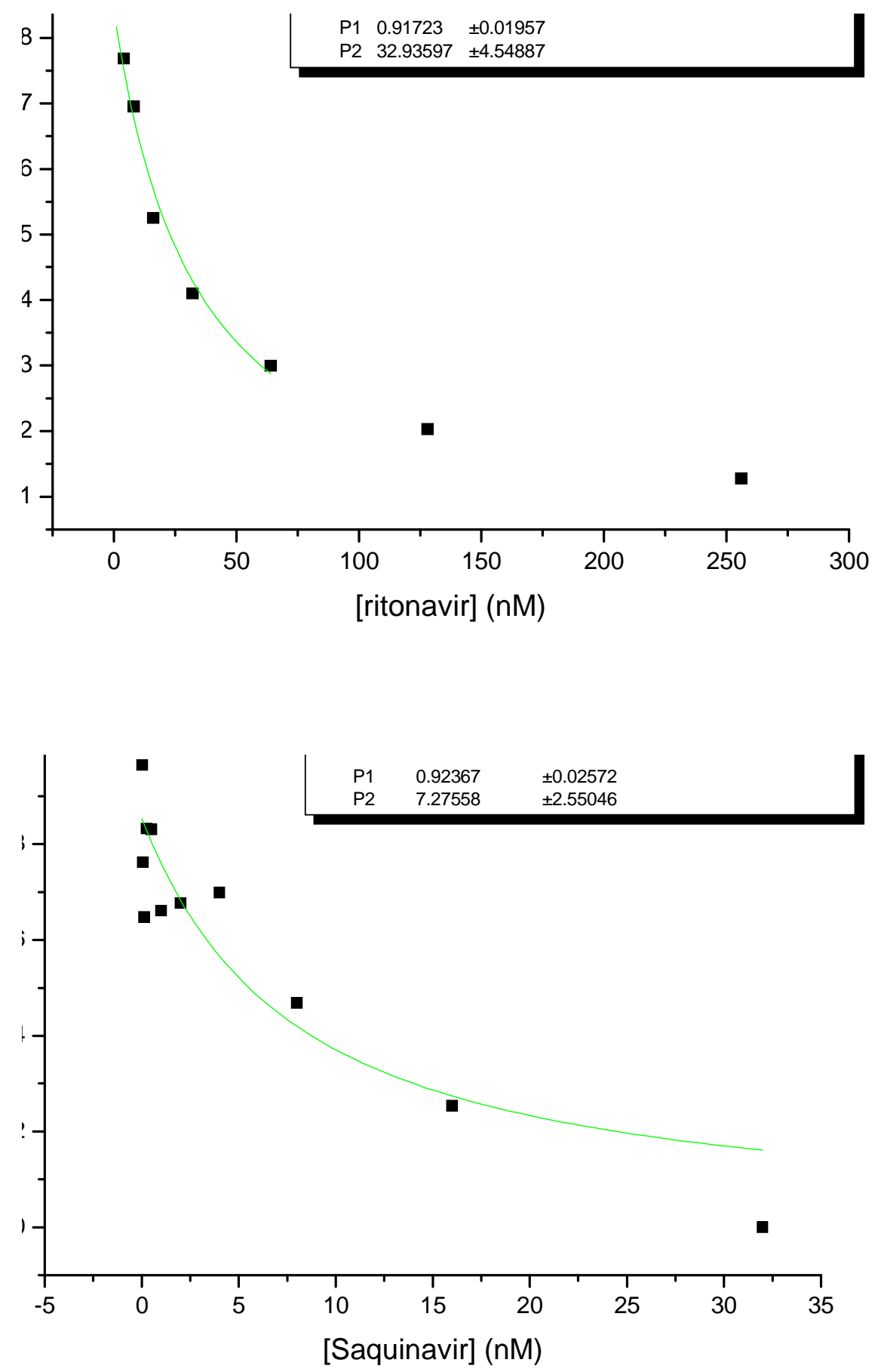

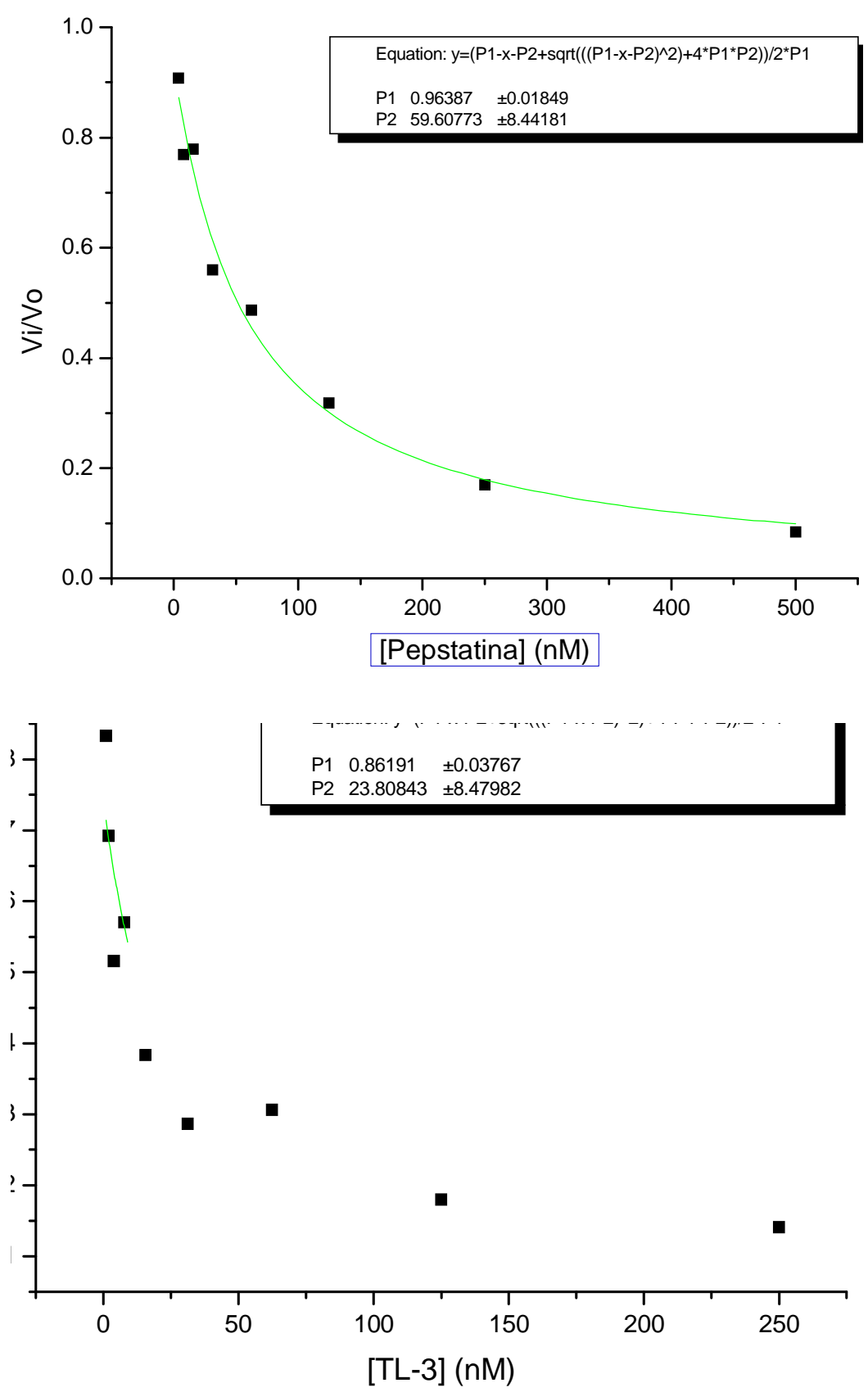


\section{4-Protease Fmut}
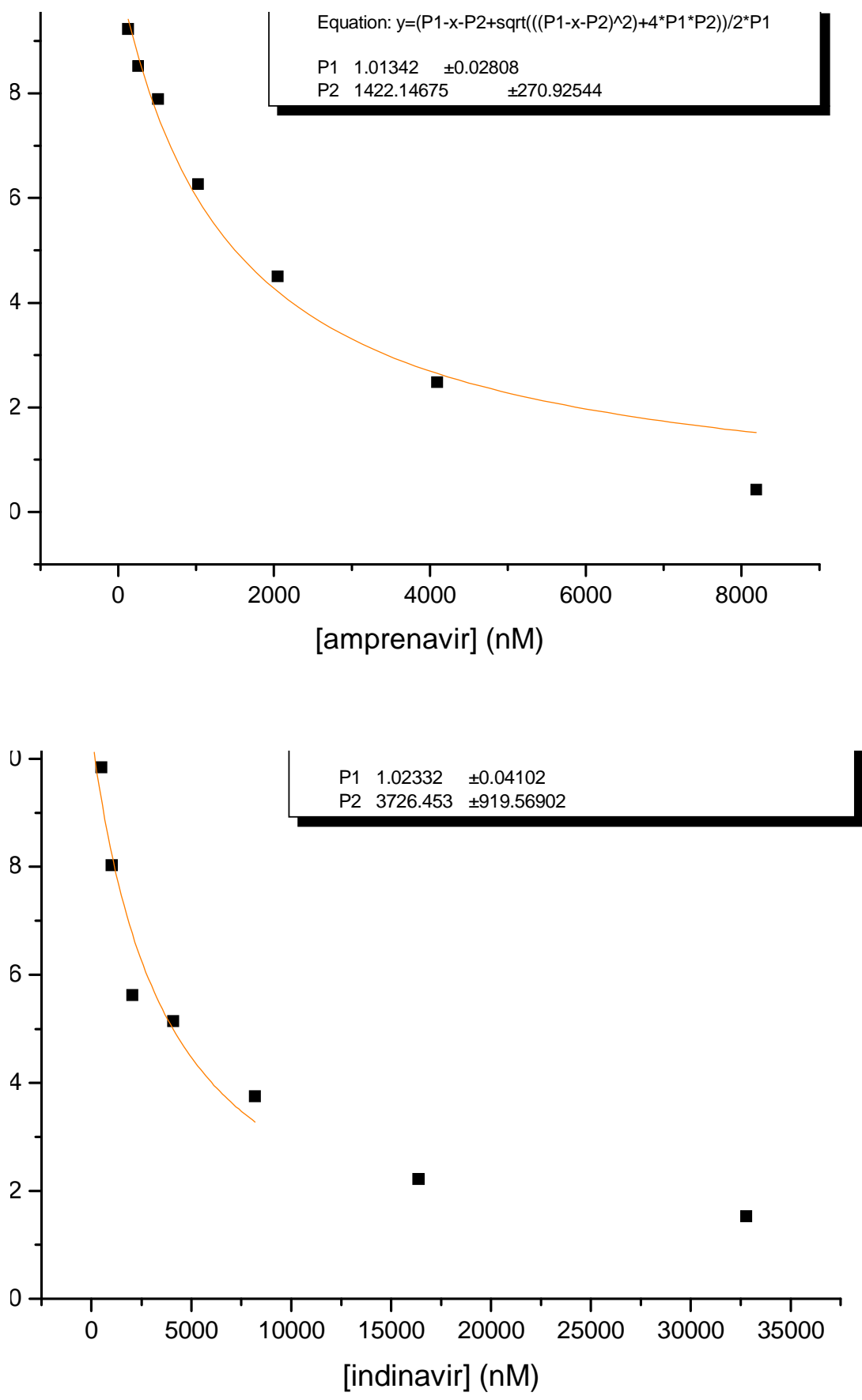

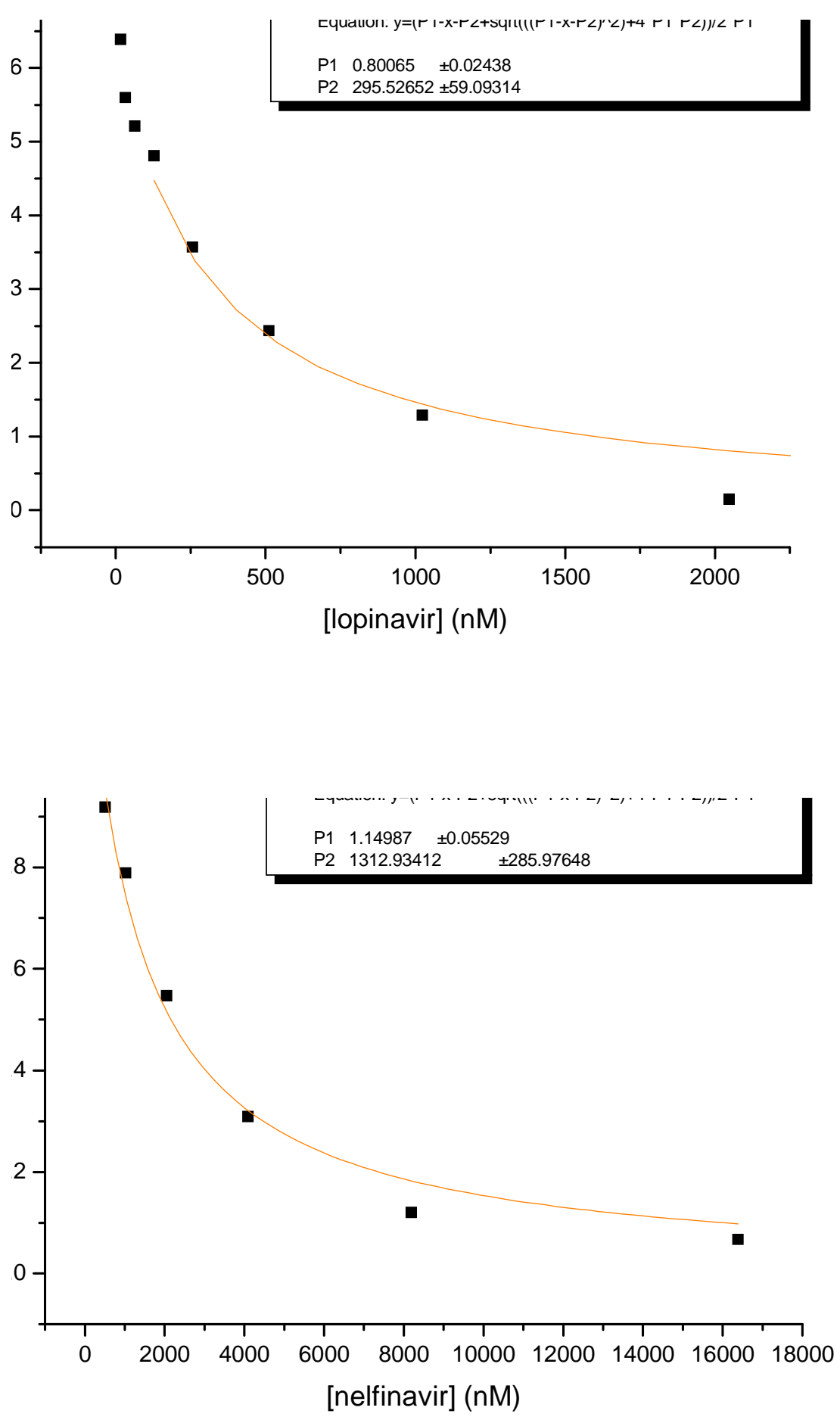

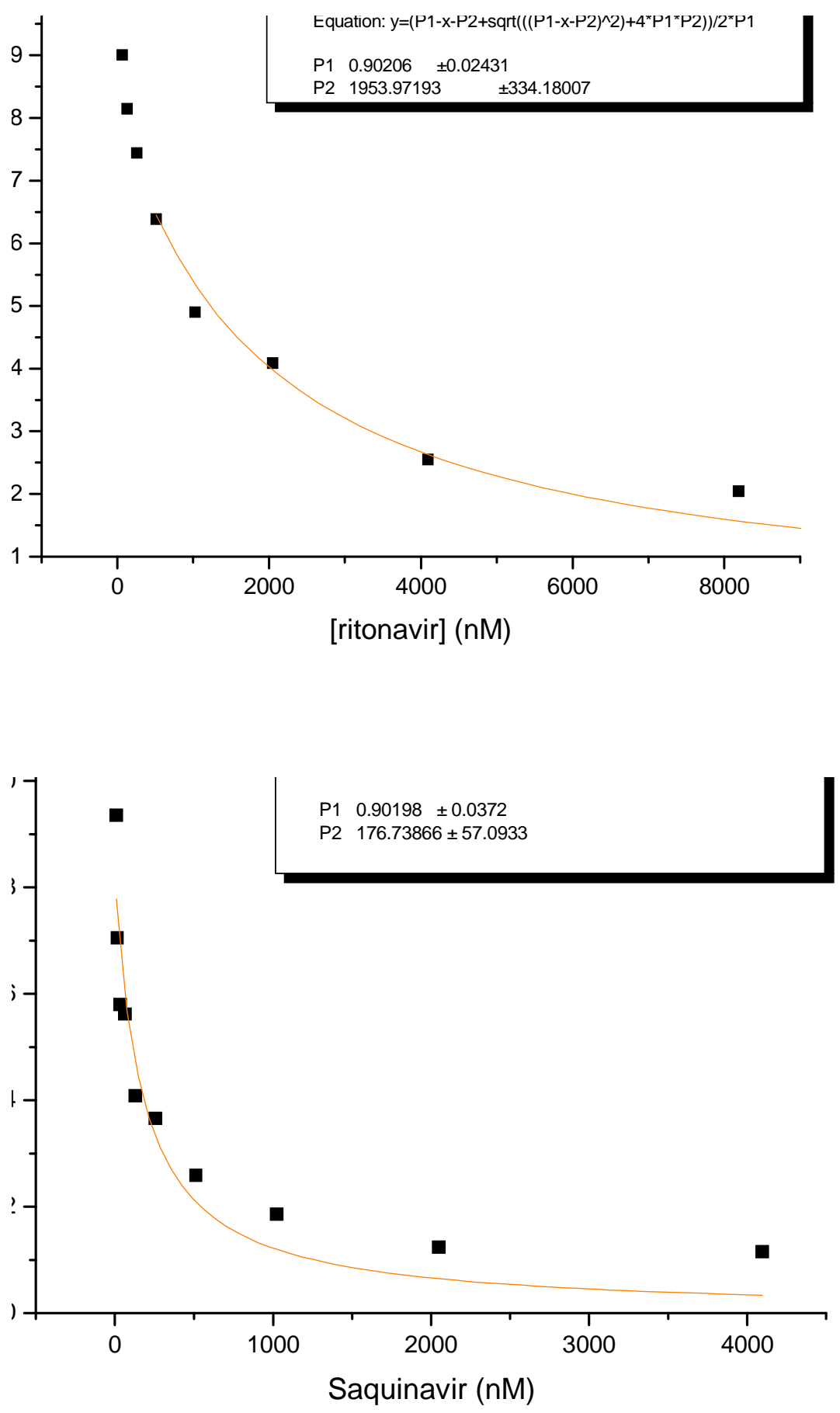

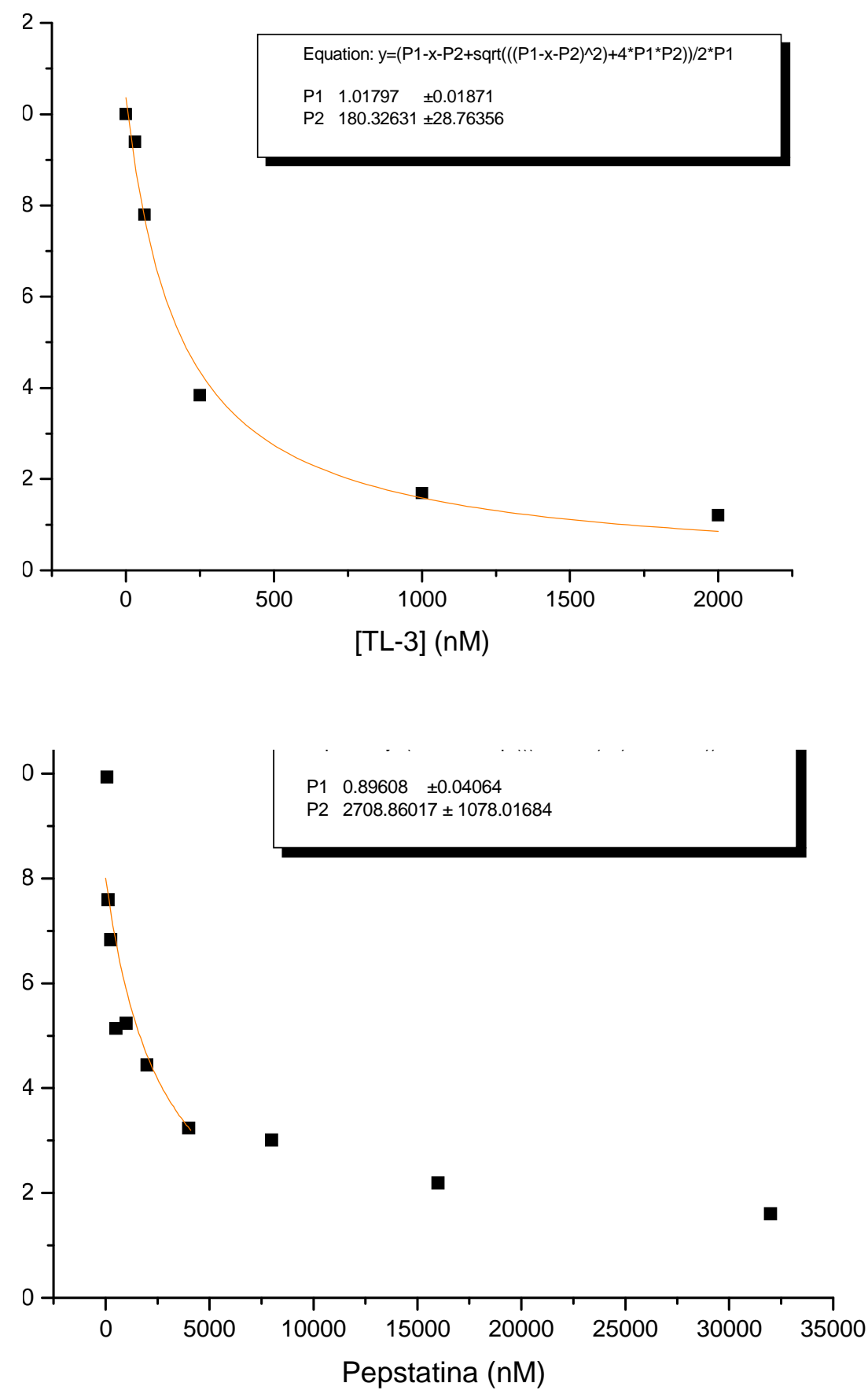


\section{Anexo B}

Gráficos de conversão do substrato para as proteases de HIV.

Nesses experimento a concentração de proteína é constate e a velocidade de conversão é medida para diferentes concentrações de substrato. Os dados foram fitados segundo a equação de Michaelis-Menten. 


\section{1-Protease Bwt}

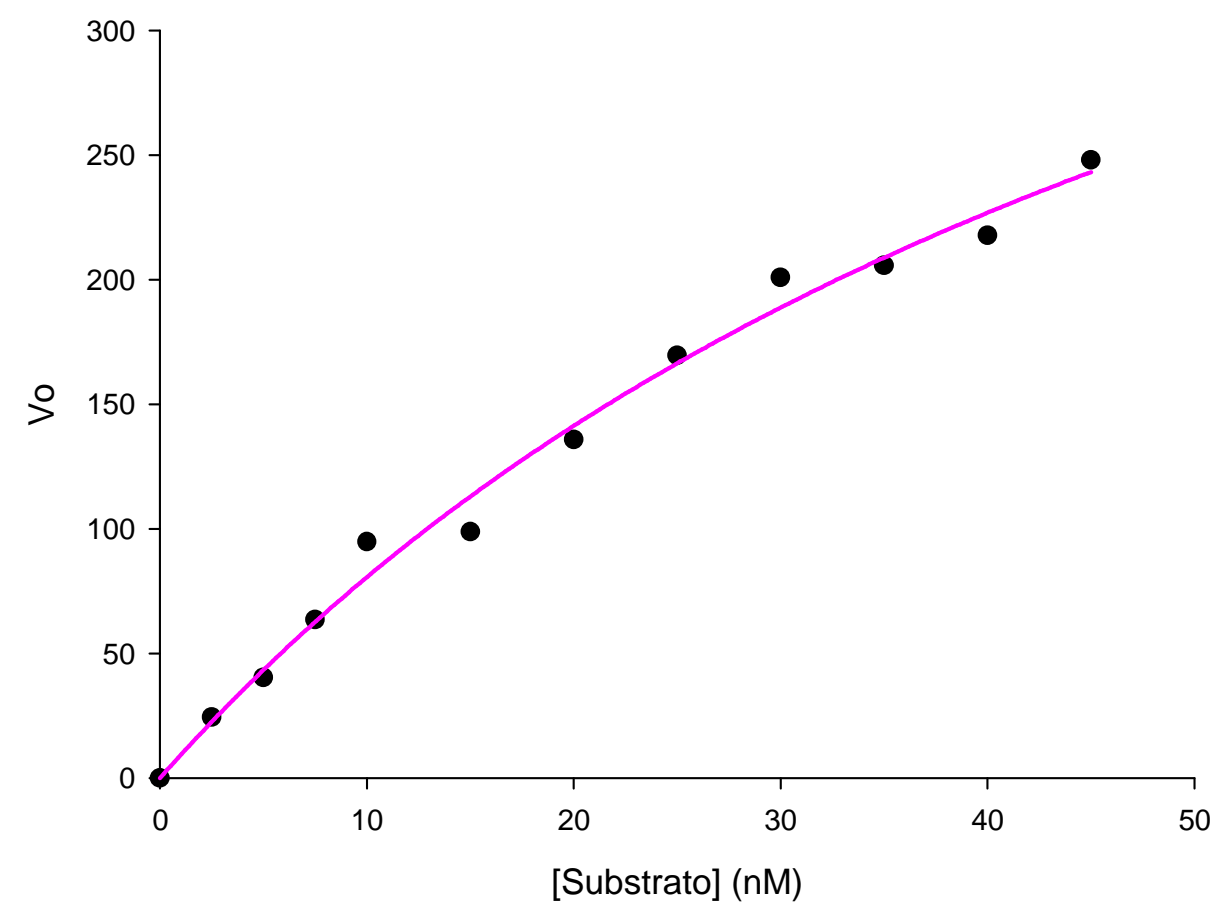

\section{2-Protease Bmut}

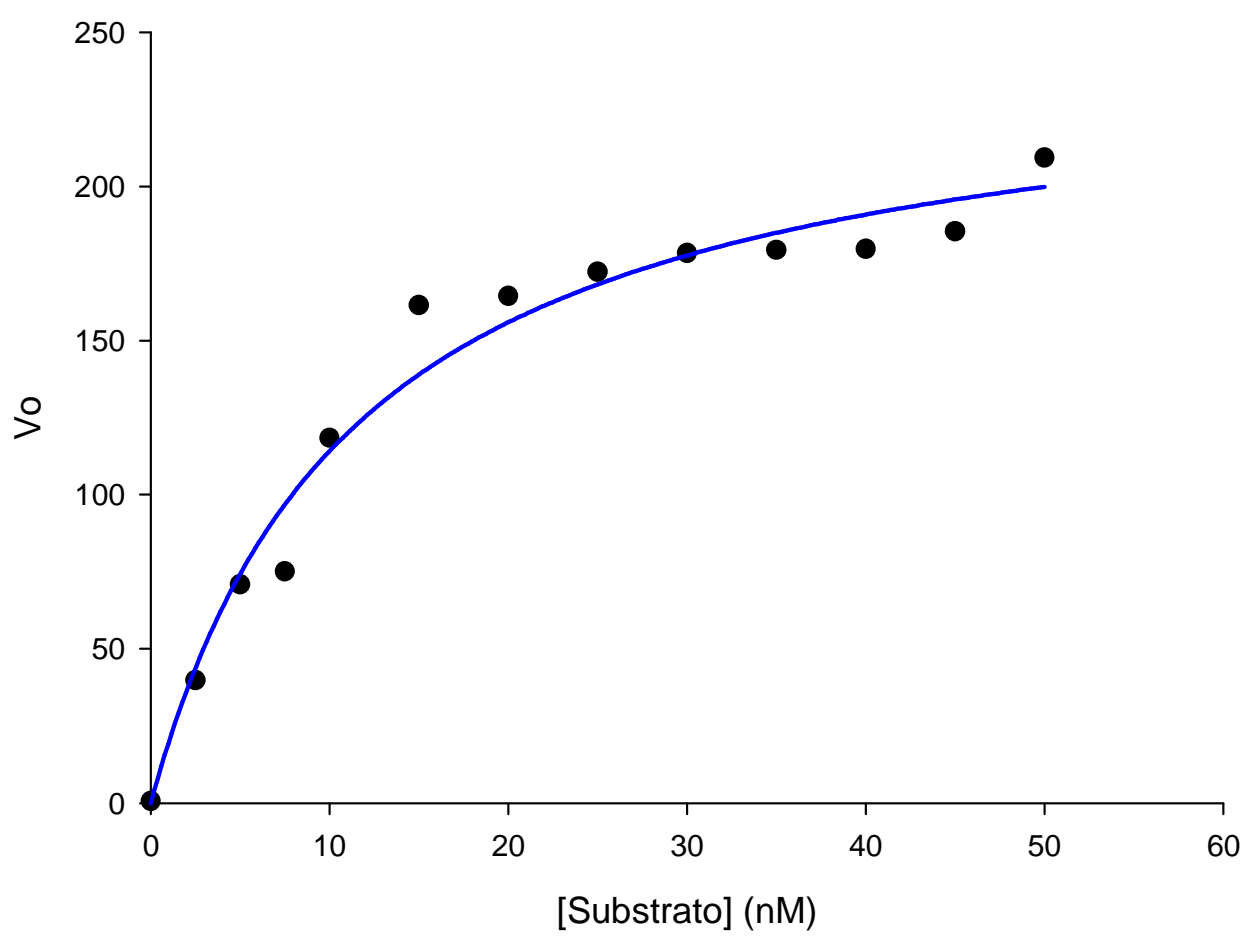




\section{3-Protease $F w t$}

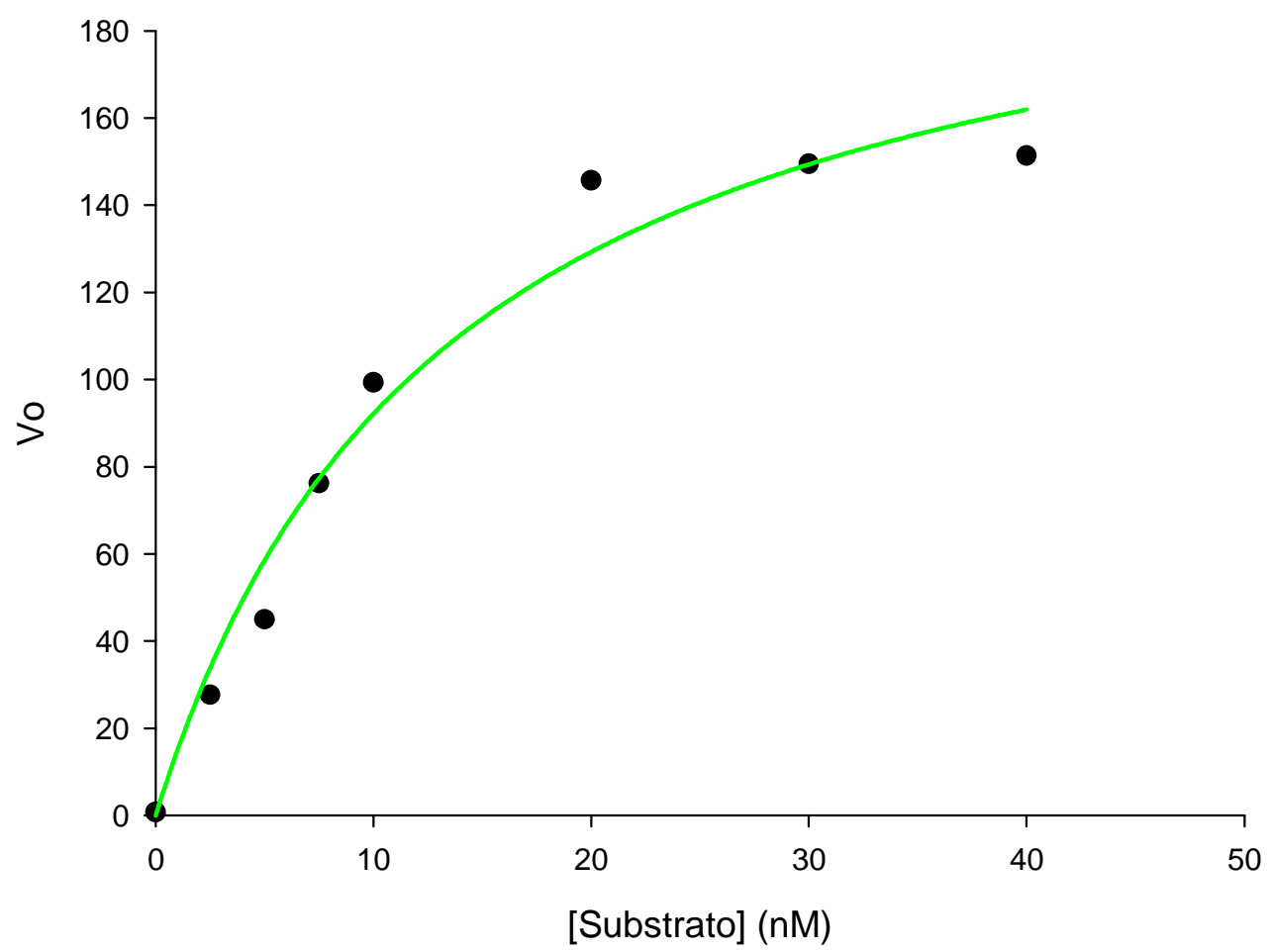

\section{4-Protease Fmut}

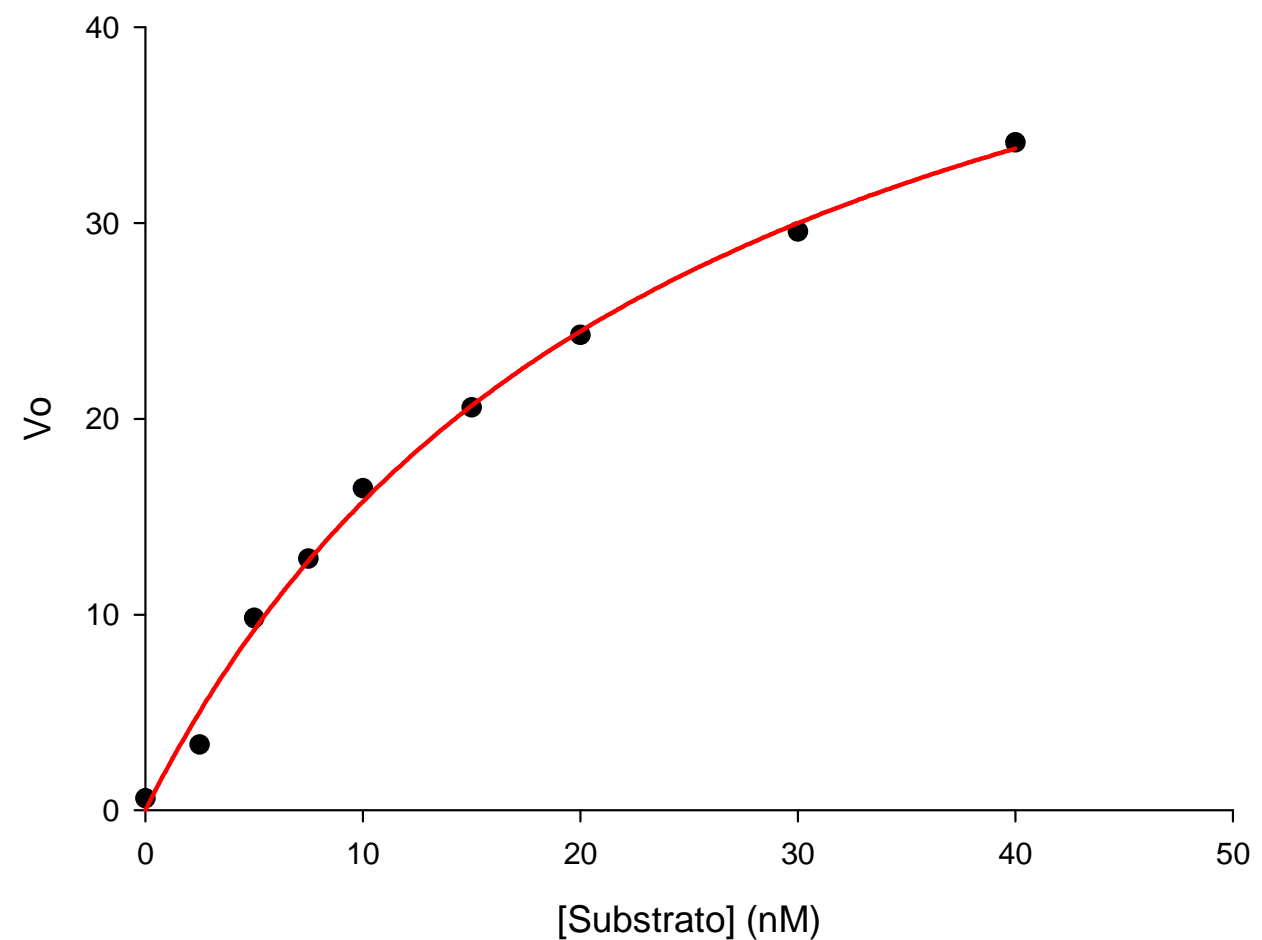




\section{Apêndice A}

Artigo em preparação

Effectiveness of Six FDA-Approved Inhibitors against Subtype F HIV-1 Protease and Two Drug-Resistant Mutants.

Sandra Krauchenco, Nádia H. Martins, Mario Sanches, and Igor Polikarpov 


\section{Effectiveness of Commercial Inhibitors against Subtype F HIV-1 Protease}

Sandra Krauchenco ${ }^{1}$, Nadia H. Martins ${ }^{1}$, Mario Sanches $^{2}$ and Igor Polikarpov ${ }^{1 *}$

1 Instituto de Física de São Carlos, Universidade de São Paulo, Av. Trabalhador Saocarlense, 400, CEP 13560-970, São Carlos, SP, Brazil. ${ }^{2}$ Laboratório Nacional de Luz Síncrotron, Caixa Postal 6192, CEP 13084-971, Campinas, SP, Brazil.

Running title: Effectiveness of commercial HIV protease inhibitors

* Correspondence should be addressed to

Prof. Igor Polikarpov,

IFSC/USP,

Av. Trabalhador Saocarlense, 400, CEP 13560-970, Brazil

Phone: $+55(16) 3373-9874$

Fax: +55(16)3373-9881

Email: ipolikarpov@if.sc.usp.br 


\section{ABSTRACT}

We have kinetically characterized subtype $\mathrm{F}$ wild type HIV protease using six commercial inhibitors (amprenavir, indinavir, lopinavir, nelfinavir, ritonavir and saquinavir) commonly used for HIV/AIDS treatment, as well as inhibitor TL-3 and pepstatin. We also obtained kinetic parameters for two multi-resistant proteases (one of subtype B and one of subtype F) harboring primary and secondary mutations selected by intensive treatment with ritonavir/nelfinavir. These newly obtained biochemical data show that all six studied commercially available protease inhibitors are significantly less effective against subtype F HIV proteases then against HIV proteases of subtype B, as judged by increased $\mathrm{K}_{\mathrm{i}}$ and biochemical fitness (vitality) values. Comparison with previously report kinetic values for subtype A and C HIV proteases show that subtype F wild type proteases are significantly less susceptible to inhibition. These results demonstrate that the accumulation of natural polymorphisms in subtype $\mathrm{F}$ proteases yields catalytically more active enzymes with a large degree of cross-resistance, which thus results in strong virus viability.

Keywords: non-B HIV protease, protease mutant, subtype F, inhibitor resistance, biochemical fitness, natural polymorphism. 


\section{INTRODUCTION}

Almost all studies on HIV-1 drug susceptibility have been performed in developed countries, where subtype B [1] dominates the epidemic, even though it is not a predominant HIV subtype worldwide. Given that, it is demanding that the effectiveness of existing anti-HIV drugs against non-B HIV-1 subtypes to be examined. For example, Latin American epidemic is characterized by multiple HIV-1 subtypes, primarily subtype B and subtype F [2]. Specifically, there are at least half-a-million people infected by subtype F HIV worldwide, out of which over a 100 thousands men and women in Latin America alone (http://www.hiv.lanl.gov/content/hivdb/mainpage.html). HIV-1 protease (HIV-PR) is a key enzyme in viral propagation [3] and its X-ray structure $[4,5,6]$ was crucial for anti-AIDS drug design.

The present work investigates the enzymatic behavior of one subtype F wildtype HIV-PR $(F w t)$ and its comparison with a wild-type B HIV-PR $(B w t)$ using six commercial inhibitors (amprenavir, indinavir, lopinavir, nelfinavir, ritonavir and saquinavir) commonly used for HIV/AIDS treatment. Differences between protease sequences of non-B and B subtypes of untreated persons are defined as subtype-specific polymorphism [7]. It is known that HIV-1 protease occurs in various mutant forms and that protease-targeted drug therapy leads to the selection of specific mutations in HIV-1 protease isolated from patients [8]. Some of the $F w t$ polymorphic mutations (Figure $1 a$ ) occur at sites that are accessory (non-active site) mutations selected by drug therapy in subtype B isolates.

We have also investigated the enzymatic features of two multi-resistant mutant HIV proteases obtained from patients receiving ritonavir/nelfinavir as PIs: one subtype B HIV-PR (Bmut) and one subtype F HIV-PR (Fmut). Both enzymes present primary and secondary mutation [9] associated with PI administration (Figure1a). The mutations 
can directly change the shape or character of the binding cavity, but also might indirectly influence inhibitor binding via long-range structural perturbations of the active site, or by changing the efficiency of catalysis and the stability of the enzyme [10-12]. Some non-active site mutations alone can increase catalytic efficiency and partially compensate for the reduction of catalytic efficiency caused by active site mutations [13]. Another study revealed that some non-active site mutations might also contribute significantly to destabilization of inhibitor binding [14].

Even though drug resistance mutations in the protease have been well studied, few data is currently available on the influence of polymorphic mutations on drug susceptibility. Preliminary data have indicated that the existence of polymorphic mutations can lead to early development of drug resistance in patients infected with non-B HIV subtypes [15]. However, only a limited number of biochemical data is available for non-B HIV proteases (see, for example, [16]), and none of these include subtype F HIV PR.

The aim of the present work is to access the biochemical differences between subtype $\mathrm{F}$ and $\mathrm{B}$, and to gain insight into the role of the polymorphic mutations in the development of drug resistance. For that we have determined catalytic parameters and inhibition constants for six inhibitors in clinical use (amprenavir, indinavir, lopinavir, nelfinavir, ritonavir and saquinavir) as well as two more universal HIV PR inhibitors (pepstatin and TL-3 [17]). Our results reveal that the $F w t$ protease is naturally more resistant to all the inhibitors assayed and has much higher vitality than the Bwt protease. In this sense, Fwt can be compared to Bmut, a multi-drug resistant protease. Furthermore, Fmut presents the highest $\mathrm{K}_{\mathrm{i}}$ values of all four proteases, with all eight inhibitors analyzed, even though it carries the same primary mutations seen in Bmut. 
Throughout the analysis, an effort was made to establish a correlation between the biochemical results and the available structural data.

MATERIAL AND METHODS

\section{Recombinant Production of HIV Proteases}

All of the proteases used in these studies carry the mutation Q7K, which eliminates the most significant autocatalytic site and enhances the stability of the preparations for biochemical and biophysical studies without any effect on its enzymatic activity [18]. The protease coding sequence from subtypes $\mathrm{B}$ mutant and both subtype $\mathrm{F}$ were obtained from HIV-1 vertically infected seropositive Brazilian children [19]. The protocol for the recombinant production of Brazilian HIV proteases had been previously reported [20].

\section{HIV proteases activity assay}

Enzymatic activity of HIV PR was studied using the quenched fluorogenic peptide substrate Arg-Glu(EDANS)-Ser-Gln-Asn-Tyr-Pro-Ile-Val-Gln-Lys(DABCYL)-Arg. Calculation of the reaction rates $\left(\mathrm{nM} \times \mathrm{min}^{-1}\right)$ from the progress curves was based on calibration with EDANS in the presence of substrate $(10 \mu \mathrm{M})$. The assays were performed at $37^{\circ} \mathrm{C}$ in $100 \mathrm{mM}$ sodium acetate, $\mathrm{pH}$ 4.7, $1 \mathrm{mM}$ EDTA, $1 \mathrm{mM}$ DTT, $1.0 \mathrm{M}$ $\mathrm{NaCl}, 10 \% \mathrm{v} / \mathrm{v}$ DMSO (similar to the buffer used in [21]) and $10 \mu \mathrm{M}$ of substrate. The 
fluorescence was monitored in semi-micro cuvettes containing a volume of $500 \mu \mathrm{l}$ by using a PC1 Photon Counting Spectrofluorometer (ISS) with excitation and emission wavelengths of $340 \mathrm{~nm}$ and $490 \mathrm{~nm}$, respectively.

\section{Measurement of Proteases Inhibition by Commercial PIs}

The inhibition experiments were performed with the following six therapeutically used protease inhibitors (PIs): amprenavir (APV), indinavir (IDV), lopinavir (LPV), nelfinavir (NFV), ritonavir (RTV) and saquinavir (SQV), and with the universal inhibitors pepstatin (PPT) and TL-3. The initial reaction rate of HIV PR was adjusted to $10-20 \mathrm{nM} \times \mathrm{min}^{-1}$ by addition of the proper amount of enzyme solution. Different concentrations of PI were added and the reaction was followed for 15-30 min afterward. Ten initial concentrations of each of the six commercially available PIs (typically $0.0625,0.125,0.25,0.5,1,2,4,8,16$ and $32 \mathrm{nM})$ were measured in duplicate. For precise $\mathrm{K}_{\mathrm{i}}$ determination the PI concentration was adjusted for the sample been measured.

\section{Evaluation of Inhibition Data}

The ratio between inhibited $\left(\mathrm{V}_{\mathrm{i}}\right)$ and uninhibited $\left(\mathrm{V}_{0}\right)$ initial rates was determined using the general equation for competitive tight-binding inhibitors [22,23]:

$$
\mathrm{V}_{\mathrm{i}} / \mathrm{V}_{0}=\left([\mathrm{Et}]-[\mathrm{It}]-\mathrm{K}_{\mathrm{i}, \mathrm{app}}+\left\{\left([\mathrm{Et}]-[\mathrm{It}]-\mathrm{K}_{\mathrm{i}, \text { app }}\right)^{2}+4[\mathrm{Et}] \mathrm{K}_{\mathrm{i}, \text { app }}\right\}^{1 / 2}\right) / 2[\mathrm{Et}]
$$

where [Et] is the total concentration of the enzyme (free and bound); [It] is the total concentration of the inhibitor (free and bound); $\mathrm{K}_{\mathrm{i} \text {,app }}$ is the apparent dissociation 
constant of the enzyme-inhibitor complex at a given substrate concentration. Since under our experimental conditions $[\mathrm{S}]<\mathrm{K}_{\mathrm{M}}$, thus $\mathrm{K}_{\mathrm{i}, \text { app }}$ and $\mathrm{K}_{\mathrm{i}}$ are similar and the competition of the inhibitor with the substrate is negligible. From $\mathrm{k}_{\text {cat }}$ the active PR concentrations in the corresponding equilibrium inhibition experiments were calculated and were found to be in the same range $(0.1-0.2 \mathrm{nM})$ as the inhibition constants for wild-type PR, indicating the prevalence of tight-binding conditions. The MichaelisMenten constant $\left(\mathrm{K}_{\mathrm{M}}\right)$ of WT PR was determined by measuring the substrate turnover at different substrate concentrations and fitting the data to the Michaelis-Menten equation. The poor solubility of substrate prevented the use of concentrations higher than $60 \mu \mathrm{M}$.

\section{RESULTS AND DISCUSSION}

\section{Wild type F subtype protease $(F w t)$}

The measurements of catalytic efficiencies with subtype $B w t$ were performed as a reference and are in good agreement with the published data $[21,24,25]$. The $F w t$ catalytic efficiency $\left(\mathrm{k}_{\mathrm{cat}} / \mathrm{K}_{\mathrm{M}}\right)$, when compared to $B w t$, demonstrated an increase of about 3 times, mainly caused by a 5 -fold decrease in $\mathrm{K}_{\mathrm{M}}$, besides a slightly decrease of 1.7 fold in $\mathrm{k}_{\text {cat }}$ (Table 1). Moreover, there was an increase of at least an order of magnitude

in $\mathrm{K}_{\mathrm{i}}$ (Table 2) for all the tested PIs (Figure2), with a highest increase of 301-fold for nelfinavir.

These results reveal that the subtype-specific aminoacid polymorphisms for $F w t$ are able to significantly affect both the $\mathrm{K}_{\mathrm{M}}$ and the $\mathrm{K}_{\mathrm{i}}$ values, even though none of those mutations are located in the binding site or in the flaps (Figure1-b). In all cases, an increase in the $\mathrm{K}_{\mathrm{i}}$ values, accompanied by decrease in the $\mathrm{K}_{\mathrm{M}}$ values, is observed 
(Tables 1 and 2). This opposite effect on $K_{i}$ and $K_{M}$ has been previously described for inhibitor resistant mutants of the B subtype [11,26,27]. Notably, this effect occurs even for mutations that do not change the chemical nature or polarity of the binding site but are known to change its geometry [11].

The Fwt carries twelve naturally occurring polymorphic mutations (Figure1a). The increased values observed for the $F w t \mathrm{~K}_{\mathrm{i}}$ are characteristic of subtype B proteases harboring primary mutations. It is known that the non-B subtypes HIV PR do not usually develop the primary mutation L90M, while the L89M substitution is very frequent among the non-B subtypes isolates $[28,18]$. In addition, the double mutation L89M/L90M is very rare in all subtypes of HIV PRs. Our previous crystallographic studies of Fwt, Bwt and Bmut proteases [29] revealed that the L89M imposes the same structural effects observed for the L90M mutation. The later is associated with resistance against all therapeutically used PIs, explaining its pronounced effect in $\mathrm{K}_{\mathrm{i}}$.

We also calculated the biochemical fitness, or vitality [30], for Fwt, Bmut and Fmut using Bwt as comparison (Table 3). Fwt vitality is particularly high for nelfinavir (Figure3), an inhibitor for which L90M mutation is considered primary. The mutation to a bulkier side chain displaces this residue (at position 89 or 90) toward the active site loop, which slightly compresses the substrate/inhibitor binding cavity, leading to a reduction in both volume and flexibility of the active site. At the thermodynamic level, the origin of the differential effect appears to be related to the difficulties of conformationally constrained inhibitors to adapt to distortions in the geometry of the binding site [31,32]. Another polymorphic mutation, M36I, is commonly seen in response to nelfinavir and ritonavir therapy and is considered a secondary mutation for subtype B proteases [33]. Structurally, this mutation causes a hardening of the flap hinges [29], which could be the cause of the slightly lower value of $k_{\text {cat }}$ (Table 1). Most 
of the other polymorphic mutations do not cause detectable structural discrepancies and are away from the active site. Their effect on the $K_{i}$ values, if any, must reside at the dynamic level. The polymorphisms directly reflect in the vitality values (Figure3) obtained for $F w t$ protease. The highest vitalities were observed as a response to nelfinavir, ritonavir and indinavir, respectively. Moreover, $F w t$ enzyme is about 3 times more catalytically efficient than Bwt. These results demonstrate that the accumulation of PIs secondary resistant mutations in $F w t$, due to natural polymorphism, yields a catalytically more active protease with a large degree of cross-resistance, which thus results in strong virus viability.

\section{Mutant B subtype protease (Bmut)}

The B subtype mutant protease, Bmut, carries eight mutations with respect to $B w t$ (Figure $1 b$ ). Its catalytic efficiency is very close to that of $B w t$ due to a 3 -fold simultaneous decrease in both $\mathrm{k}_{\text {cat }}$ and $\mathrm{K}_{\mathrm{M}}$, indicative of a highly viable virus. The primary mutations V82A and L90M, most probably selected by the long term administration of ritonavir and nelfinavir to the patient, are commonly observed in response to all therapeutically used PIs [34]. The mutation V82A reshapes the S1/S1' binding pocket, causing a collapse of the crevice formed between the flap and the loop containing the residue Pro81. This reshaping forces the inhibitor to change its conformation, specially the ones with phenyl groups in both P1 and P1' [11,29], leading to a loss of interactions with the binding pocket. This effect is particularly pronounced with TL-3 (Figure2), with an increase of two orders of magnitude in $\mathrm{K}_{\mathrm{i}}$ when compared to $B w t$, and one order of magnitude to $F w t$ (Table 2). It has been proposed that a bulkier group in P1 could lead to an inhibitor less susceptible to V82A mutation [11]. That is 
verified for nelfinavir (Figure2) which contains a bicyclical group in that position and shows an increase in $K_{i}$ which is about 3 times lower than the increase observed for Fwt, which does not contain V82A. The contrary effect is seen with saquinavir, which contains a small amide group in P1 (Figure2), which reflects in pronounced differences between the vitalities of Bmut and Fwt (Figure3). The secondary mutation I54V was probably selected due to ritonavir administration [33]. Since no significant structural differences caused by this mutation could be detected [29], its presumably affects inhibitor binding dynamically by altering the flexibility of the flaps [35]. Additional secondary mutations are $\mathrm{L} 63 \mathrm{P}$ and $\mathrm{A} 71 \mathrm{~V}$, associated with resistance to therapy with indinavir, nelfinavir, lopinavir and ritonavir.

\section{Mutant F subtype protease (Fmut)}

Out of the clinically identified enzymes studied here, the Fmut is the one that carries the largest number of mutations, both polymorphic and selected by treatment (Figure $1 b$ ). It showed a decrease of about 5 times in catalytic efficiency because of a 12-fold decrease in $\mathrm{k}_{\text {cat }}$ and a 2.5 -fold decrease in $\mathrm{K}_{\mathrm{M}}$ (Table 1). Among the mutations encountered in Fmut, V82A is the primary mutation generated by treatment, while L90M does not arise due to the presence of the polymorphic L89M. The structural effects of V82A/L89M mutations in the structure of Fmut are the same observed for Bmut [29]. It also contains the important secondary mutation M46I, arising in response to almost all approved inhibitors, except for saquinavir [33]. Additionally, I54V is commonly detected in response to amprenavir, indinavir, lopinavir, nelfinavir and saquinavir therapy, L10I to indinavir, lopinavir and nelfinavir and K20R to lopinavir and nelfinavir [34]. The accumulation of these mutations yields a highly cross-resistant 
enzyme, which has the highest decrease in susceptibility to all the tested inhibitors (Table 2), as indicated by the high values of its inhibition constants and vitality (Table 3 and Figure3). On the other hand, Fmut displays the lowest catalytic efficiency against the substrate used in the experimental procedures. This loss of efficiency, which still renders a viable virus, could be explained by a concomitant mutation in the natural substrate of the protease, reestablishing the activity of the mutant protease.

\section{Implications to HIV/AIDS Treatment}

Our experimental results reveal that all the six commercially available PIs evaluated are significantly less effective against subtype F HIV-PR then against HIVPR of subtype B. Furthermore, Fwt is also much less susceptible to PI inhibition as compared to available data for subtypes A and C HIV-PRs [24]. A long term study may be necessary to evaluate the susceptibility of each variant to the inhibitors studied. Nevertheless, our biochemical data can serve as an indication for the treatment of individuals infected with subtype $\mathrm{F}$ protease. To this end, nelfinavir presents the worst vitality for $F w t$ and should be avoided in the treatment. In the other hand, lopinavir, followed by saquinavir, sustain only minor effects from the polymorphisms present in Fwt, and the mutations of Fmut, and should probably be elected as the first choice therapies for subtype F infected individuals.

\section{ACKNOWLEDGEMENTS}

We thank to FAPESP for grants 99/03387-4, 04/11890-8, 04/12201-1 and 06/00182-8 and to CNPq. Authors thank to Dr. Jordan J. Tang (Oklahoma Medical 
Research Foundation, USA) for a kind gift of a plasmid of artificial HIV PR subtype B gene and Dr. Amilcar Tanuri (UFRJ, Brasil) for cDNAs of HIV Bmut, Fwt and Fmut. 


\section{REFERENCES}

1. C. Kuiken, B. Foley, E, Freed, B. Hahn, P. Marx, F. McCutchan, L. Mellors, B. Korber, Editors, (2002). HIV sequence compendium 2002. Published by Theoretical Biology and Biophysics Group Los Alamos National Laboratory, LA-UR n 033564.

2. S. Osmanov, C. Pattou, N. Walker, B. Schwardlander, J. Esparza, Estimated global distribution and regional spread of HIV-1 genetic subtypes in the year 2000, J. Acquir.Immune Defic. Syndr. 29 (2002) 184-190.

3. A. D. Frankel, J. A. Young, HIV-1: Fifteen Proteins and a RNA, Annu. Rev. Biochem. 67 (1998) 1-25.

4. A. Wlodawer, M. Miller, M. K. Jaskolski, B. Sathyanarayana, E. T. Baldwin, et al., Conserved folding in retroviral proteases: Crystal structure of a synthetic HIV-1 protease, Science 245 (1989) 616-621.

5. M. Miller, J. Schneider, B. K. Sathyanarayana, M. V. Toth, G. R. Marshall, et al., Structure of complex of synthetic HIV-1 protease with a substrate based inhibitor at 2.3-Å resolution., Science 246 (1989) 1149-1152.

6. R. Lapatto, T. Blundell, A. Hemmings, J. Overington, A. Wilderspin, et al., X-ray analysis of HIV-1 proteinase at $2.7 \AA$ resolution confirms structural homology among retroviral enzymes, Nature 342 (1989) 299-302.

7. R. Kantor, D. A. Katzenstein, B. Efron, A. P. Carvalho, B. Wynhoven, et al., Impact of HIV-1 subtype and antiretroviral therapy on protease and reverse transcriptase genotype: results of a global collaboration, PLoS Medicine 2 (2005) 325-337.

8. S. Y. Rhee, W. J. Fessel, A. R. Zolopa, L. Hurley, T. Liu, et al., HIV drug resistance database, Infect. Dis. 192 (2005) 456-465. 
9. V. A. Johnson, F. Brun-Vézinet, B. Clotet, H. F. Günthard, D. R. Kuritzkes, et al., Update of the Drug Resistance Mutations in HIV-1: 2007, Topics in HIV Medicine 15 (2007) 119-125.

10. J. W. Erickson, S. K. Burt, Structural mechanisms of HIV drug resistance, Аnnu. Rev. Pharmacol. Toxicol. 36 (1996) 545-71.

11. E. T. Baldwin, T. N. Bhat, B. Liu, N. Pattabiraman, J. W. Erickson, Structural basis of drug resistance for the V82A mutant of HIV-1 proteinase, Nat. Struct. Biol. 2 (1995) 244-249.

12. S. Muzammil, P. Ross, E. Freire, A major role for a set of non-active site mutations in the development of HIV-1 protease drug resistance, Biochemistry 42 (2003) 631638.

13. H. B. Schock, V. M. Garsky, L. C. Kuo, Mutational anatomy of an HIV-1 protease variant conferring cross-resistance to protease inhibitors in clinical trials. Compensatory modulations of binding and activity, J. Biol. Chem. 271 (1996) 31957-31963.

14. D. B. Olsen, M. W. Stahlhut, C. A. Rutkowski, H. B. Schock, A. L. van Olden, L. Kuo, Non-active site changes elicit broad-based cross-resistance of the HIV-1 protease to inhibitors, J. Biol. Chem. 274 (1999) 23699-23701.

15. C. F. Perno, A. Cozzi-Lepri, C. Balotta, F. Forbici, M. Violin, et al., Secondary mutations in the protease region of human immunodeficiency virus and virologic failure in drug-naïve patients treated with protease inhibitor-based therapy, J. Infec. Dis. 184 (2001) 983-991.

16. A. Velázquez-Campoy, S. Vega, E. Fleming, U. Bacha, Y. Sayed, et al., Protease Inhibition in African subtypes of HIV-1, AIDS 5 (2003) 165-171. 
17. T. Lee, V.-D. Le, D. Lim, Y.-C. Lin, G. M. Morris, et al., Development of a new type of protease inhibitors, efficacious against FIV and HIV variants, J. Am. Chem. Soc. 121 (1999) 1145-1155.

18. A. M Mildner, D. J. Rothrock, J. W. Leone, C. A. Bannow, J. M. Lull, et al., The HIV-1 protease as enzyme and substrate: mutagenesis of autolysis sites and generation of a stable mutant with retained kinetic properties, Biochemistry 33 (1994) 9405-9413.

19. P. A. Brindeiro, R. M. Brindeiro, C. Mortensen, K. Hertogs, V. D. Vroey, et al., Testing genotypic and phenotypic resistance in Human Immunodeficiency Virus type 1 isolates of clade $\mathrm{B}$ and other clades from children failing antiretroviral therapy, J. Clin. Microbiol. 40 (2002) 4512-4519.

20. M. Sanches, N. H. Martins, A. Calazans, R. M. Brindeiro, A. Tanuri, et al., Crystallization of a non-B and a B mutant HIV protease, Acta Crystallogr. D60 (2004) 1625-1627.

21. E. D. Matayoshi, G. T. Wang, G. A. Kraft, J. Erickson, Novel fluorogenic substrates for assaying retroviral proteases by resonance energy transfer, Science 24 (1990) 954-958.

22. J. F. Morrison, Kinetics of the reversible inhibition of enzyme catalysed reactions of tight-binding inhibitors, Biochim. Biophys. Acta 185 (1969) 269-285.

23. J. G. Bieth, Theoretical and practical aspects of proteinase inhibition kinetics, Methods Enzymol. 248 (1995) 59-84.

24. A. Velázquez-Campoy, M. J. Todd, S. Vega, E. Freire, Catalytic efficiency and vitality of HIV-1 proteases from African viral subtypes, Proc. Natl. Acad. Sci. U.S.A. 98 (2001) 6062-6067. 
25. D. Hoffmann, I. Assfalg-Machleidt, H. Nitschko, K. K. von der Helm, U. Koszinowski, et al., Rapid Enzymatic Test for Phenotypic HIV Protease Drug Resistance, Biol. Chem. 384 (2003) 1109-17.

26. Y. Lin, X. Lin, L. Hong, S. Foundling, R. L. Heinrikson, et al., Effect of point mutations on the kinetics and the inhibition of human immunodeficiency virus type 1 protease: relationship to drug resistance, Biochemistry. 34 (1995) 1143-1152.

27. L. Hong, A. Treharne, J. A. Hartsuck, S. Foundling, J. Tang, Crystal structures of complexes of a peptidic inhibitor with wild-type and two mutant HIV-1 proteases, Biochemistry 35 (1996) 10627-10633.

28. A. Calazans, R. Brindeiro, P. Brindeiro, H. Verli, M. B. Arruda, et al., Low accumulation of L90M in protease from subtype F HIV-1 with resistance to protease inhibitors is caused by the L89M polymorphism, J. Infect. Dis. 191 (2005) 1961-70.

29. M. Sanches, S. Krauchenco, N. H. Martins, A. Gustchina, A. Wlodawer, et al., Structural characterization of B and non B subtypes of HIV-protease: Insights into natural susceptibility to drug resistance development, J. Mol. Biol. 369 (2007) 10291040.

30. S. Gulnik, L. I. Suvorov, B. Liu, B. Yu, B. Anderson, et al., Kinetic characterization and cross-resistance patterns of HIV protease mutants selected under drug pressure, Biochemistry 34 (1995) 9282-9287.

31. I. Luque, M. J. Todd, J. Gomez, N. Semo, E. Freire, Molecular basis of resistance to HIV-1 protease inhibition: a plausible hypothesis, Biochemistry 37 (1998) 57915797.

32. M. J. Todd, I. Luque, A. Velazquez-Campoy, E. Freire, Thermodynamic basis of resistance to HIV-1 protease inhibition: calorimetric analysis of the V82F/I84V active site resistant mutant, Biochemistry 39 (2000) 11876-11883. 
33. V. A. Johnson, F. Brun-Vézinet, B. Clotet, H. F. Günthard, D. R. Kuritzkes, et al., Update of the Drug Resistance Mutations in HIV-1: 2007, Topics in HIV Medicine 15 (2007) 119-125.

34. S. Y. Rhee, W. J. Fessel, A. R. Zolopa, L. Hurley, T. Liu, et al., HIV drug resistance database, Infect. Dis. 192 (2005) 456-465.

35. J. C. Clemente, R. E. Moose, R. Hemrajani, L. R. Whitford, L. Govindasamy, et al., Comparing the accumulation of active- and nonactive-site mutations in the HIV-1 protease, Biochemistry 43 (2004) 12141-12151. 


\section{FIGURE LEGENDS}

Figure 1. Studied HIV-PRs and their mutations. (a) Amino acid sequence alignment of the four HIV-PR. The mutations, either polymorphic or arisen from treatment, are marked [9]: primary in black and secondary in grey. (b) Crystallographic structures of the proteases $F w t$ (PDB code 3P3C), Bmut (PDB code 2P3A) and Fmut (PDB code 2P3D) [29]. Primary mutations are represented by black spheres, secondary by grey spheres, and other differences in white spheres.

Figure 2. Chemical structures of the six FDA-approved HIV PR inhibitors used in present study. Schematic representations of APV, amprenavir; IDV, indinavir, LPV, lopinavir, NFV, nelfinavir, RTV, ritonavir; SQV, saquinavir; PPT, pepstatin and TL-3 are given.

Figure 3. HIV PRs vitality bar plot for all eight protease inhibitors studied for Fwt, Bmut and Fmut proteases (Bwt as reference). The highest vitality values are observed for Fmut in response to amprenavir, ritonavir and indinavir; and for $F w t$ in the presence of nelfinavir and ritonavir. 


\section{TABLES}

Table 1: Catalytic efficiency for all four studied HIV-1 proteases.

\begin{tabular}{lllll}
\hline & Subtype & $\mathrm{k}_{\text {cat }}\left(\mathrm{s}^{-1}\right)$ & $\mathrm{K}_{\mathrm{M}}(\mu \mathrm{M})$ & $\begin{array}{c}\mathrm{k}_{\mathrm{cat}} / \mathrm{K}_{\mathrm{M}} \\
\left(\mathrm{s}^{-1} \mu \mathrm{M}^{-1}\right)\end{array}$ \\
Wild type & $\mathrm{B}$ & $8.6 \pm 0.4$ & $61.2 \pm 12$ & $0.14 \pm 0.02$ \\
& $\mathrm{~F}$ & $5.0 \pm 0.2$ & $12.3 \pm 3$ & $0.41 \pm 0.03$ \\
Mutant & $\mathrm{B}$ & $2.7 \pm 0.2$ & $15.4 \pm 4$ & $0.18 \pm 0.05$ \\
& F & $0.72 \pm 0.03$ & $24.7 \pm 3$ & $0.029 \pm 0.007$ \\
& & & &
\end{tabular}

Table 2: Inhibition constants $\left(\mathrm{K}_{\mathrm{i}}\right)$ for studied HIV-1 proteases.

\begin{tabular}{lllll}
\hline Inhibitor & $\mathrm{K}_{\mathrm{i}}(\mathrm{nM})$ & $\mathrm{K}_{\mathrm{i}}(\mathrm{nM})$ & $\mathrm{K}_{\mathrm{i}}(\mathrm{nM})$ & $\mathrm{K}_{\mathrm{i}}(\mathrm{nM})$ \\
& subtype $\mathrm{B}_{\mathrm{wt}}$ & subtype $\mathrm{F}_{\mathrm{wt}}$ & subtype $\mathrm{B}_{\mathrm{mut}}$ & subtype $\mathrm{F}_{\mathrm{mut}}$ \\
APV & $0.16 \pm 0.05$ & $4.86 \pm 0.47$ & $6.14 \pm 0.59$ & $1422 \pm 271$ \\
IDV & $0.96 \pm 0.23$ & $106.27 \pm 26.05$ & $303.96 \pm 59.58$ & $3726 \pm 920$ \\
LPV & $0.48 \pm 0.27$ & $1.14 \pm 0.15$ & $11.81 \pm 1.51$ & $296 \pm 59$ \\
NFV & $1.05 \pm 0.23$ & $315.81 \pm 29.53$ & $124.05 \pm 15.78$ & $1313 \pm 286$ \\
RTV & $0.18 \pm 0.06$ & $32.94 \pm 4.55$ & $82.86 \pm 12.66$ & $1954 \pm 334$ \\
SQV & $0.52 \pm 0.22$ & $7.28 \pm 2.55$ & $102.45 \pm 23.61$ & $177 \pm 57$ \\
TL3 & $3.26 \pm 0.88$ & $23.81 \pm 8.48$ & $135.45 \pm 37.74$ & $180 \pm 29$ \\
PPT & $28.55 \pm 4.20$ & $59.61 \pm 8.44$ & $116.51 \pm 13.50$ & $2709 \pm 1078$ \\
\hline
\end{tabular}

Table 3: Vitality values for subtype B and F HIV proteases. 


\begin{tabular}{c|c|c|c}
\hline Inhibitor & Fwt & Bmut & Fmut \\
APV & 88.95 & 49.33 & 1840.98 \\
IDV & 324.18 & 407.08 & 803.97 \\
LPV & 6.95 & 31.63 & 127.73 \\
NFV & 880.83 & 151.89 & 259.02 \\
RTV & 535.92 & 591.85 & 2248.65 \\
SQV & 41 & 253.31 & 70.50 \\
TL3 & 21.38 & 53.42 & 11.43 \\
PPT & 6.11 & 5.24 & 19.65 \\
\hline
\end{tabular}




\section{FIGURES}

$\boldsymbol{a}$

\begin{tabular}{|c|c|c|c|c|c|c|}
\hline & 10 & 20 & 30 & 40 & 50 & \\
\hline & . & . & . & . & . & \\
\hline Bwt & PQITLWKRPL & VTIKIGGQLK & EALLDTGADD & TVLEEMSLPG & RWKPKMIGGI & 50 \\
\hline Bmut & PQITLWKRPL & VTIKIGGQLK & EALLDTGADD & TVLEEMALPG & KWKPRMIGGI & 50 \\
\hline Fwt & PQITLWKRPL & VTIKVGGQLK & EALLDTGADD & TVLEDIALPG & KWKPKMIGGI & 50 \\
\hline Fmut & PQITLWKRPI & VTIKVEGQLR & EALLDTGADD & TVLEDINLSG & KWKPKIIGGI & 50 \\
\hline Consensus & 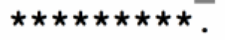 & $\star \star \star \star . \quad \star \star \star$. & 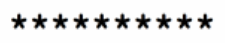 & $\star \star \star \star \ldots \ldots . \star \star$ & 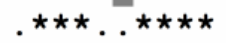 & \\
\hline
\end{tabular}

60

Bwt

Bmut

Fwt

Fmut

Consensus
GGFIKVROYD OILIEICGHK GGFVKVRQYD QIPIEICGHK GGFIKVKQY NVSIEICGHK RGFVKVKQY DILIEICGHR $\star \star . \star \star . \star \star$.
80

AIGTVLVGPT VIGTVLVGPT AIGTVLVGPT AVGAVLVGPT

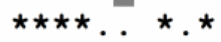

90

PVNIIGRNLL TQIGCTLNF PANIIGRNLY TQIGCTLNF PVNIIGRNML TQIGCTLNF PANNIIGRNML TQIGCTLNF

b

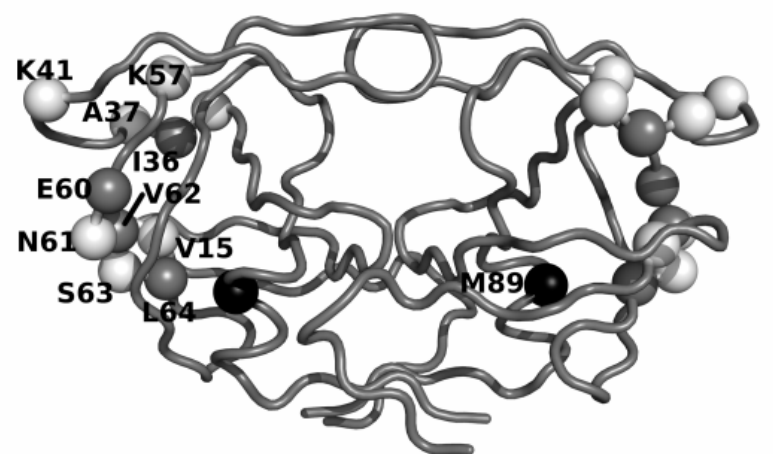

Fwt

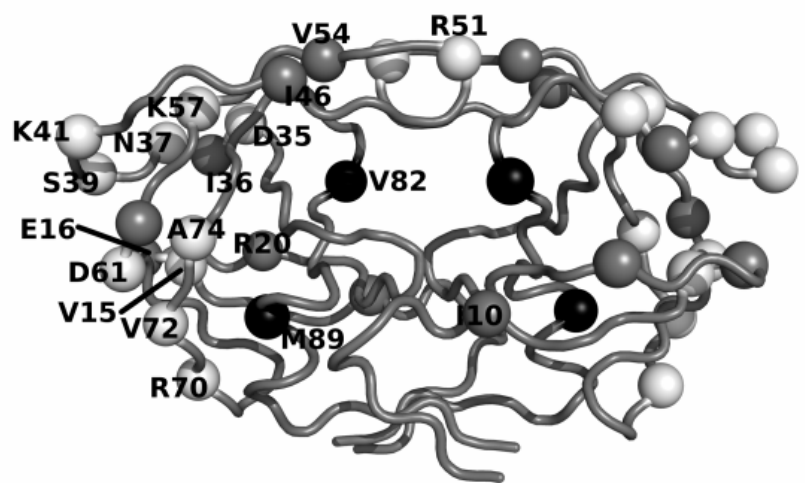

Fmut

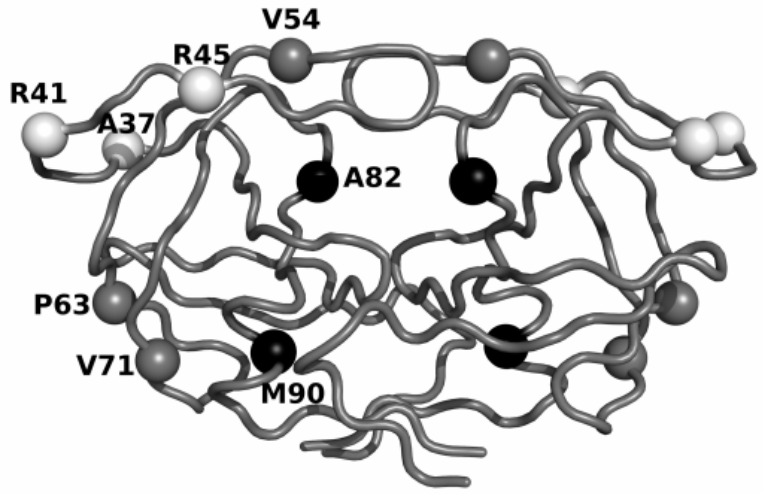

Bmut

Figure 1 
<smiles>CC(C)CN(C[C@H](O)[C@H](Cc1ccccc1)NC(=O)O[C@H]1CCOC1)S(=O)(=O)c1ccccc1</smiles>

Amprenavir<smiles>CC(C)(C)CC(=O)C1CN(Cc2cccnc2)CCN1C[C@H](O)C[C@H](Cc1ccccc1)C(=O)N[C@H]1c2ccccc2C[C@H]1O</smiles>

Indinavir

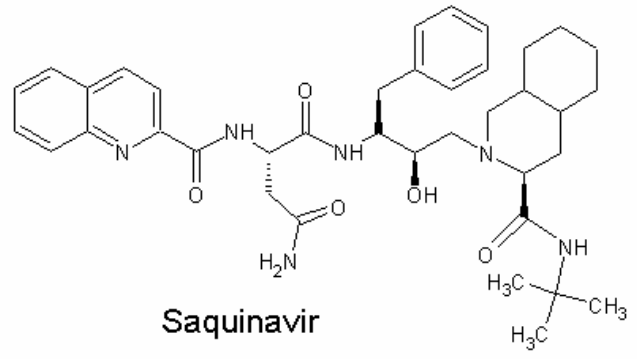

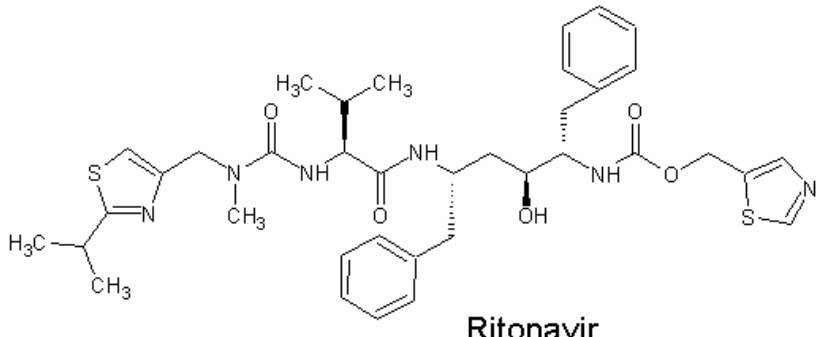

Ritonavir

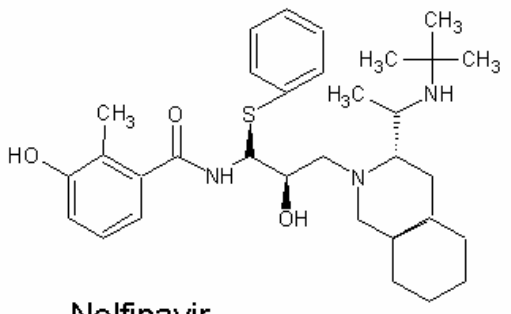

Nelfinavir

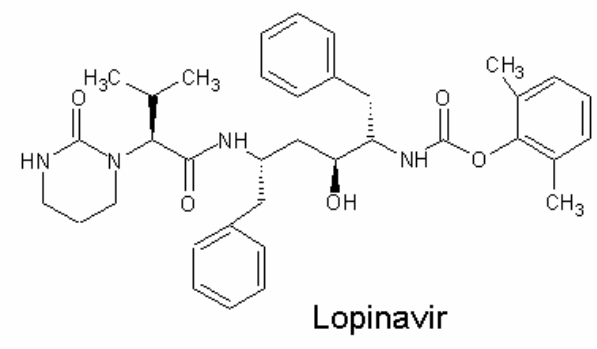

Lopinavir<smiles>CC(C)[C@H](NC(=O)CNC(=O)OCc1ccccc1)C(=O)N[C@H](Cc1ccccc1)[C@@H](O)[C@H](O)[C@H](Cc1ccccc1)NC(=O)[C@H](NC(=O)CNC(=O)OCc1ccccc1)C(C)C</smiles><smiles>CC(=O)NC(C(=O)NC(C(=O)NC(CC(C)C)C(O)CC(=O)NCC(=O)NC(CC(C)C)C(O)CC(=O)O)C(C)C)C(C)C</smiles>

\section{Pepstatin}

Figure 2 


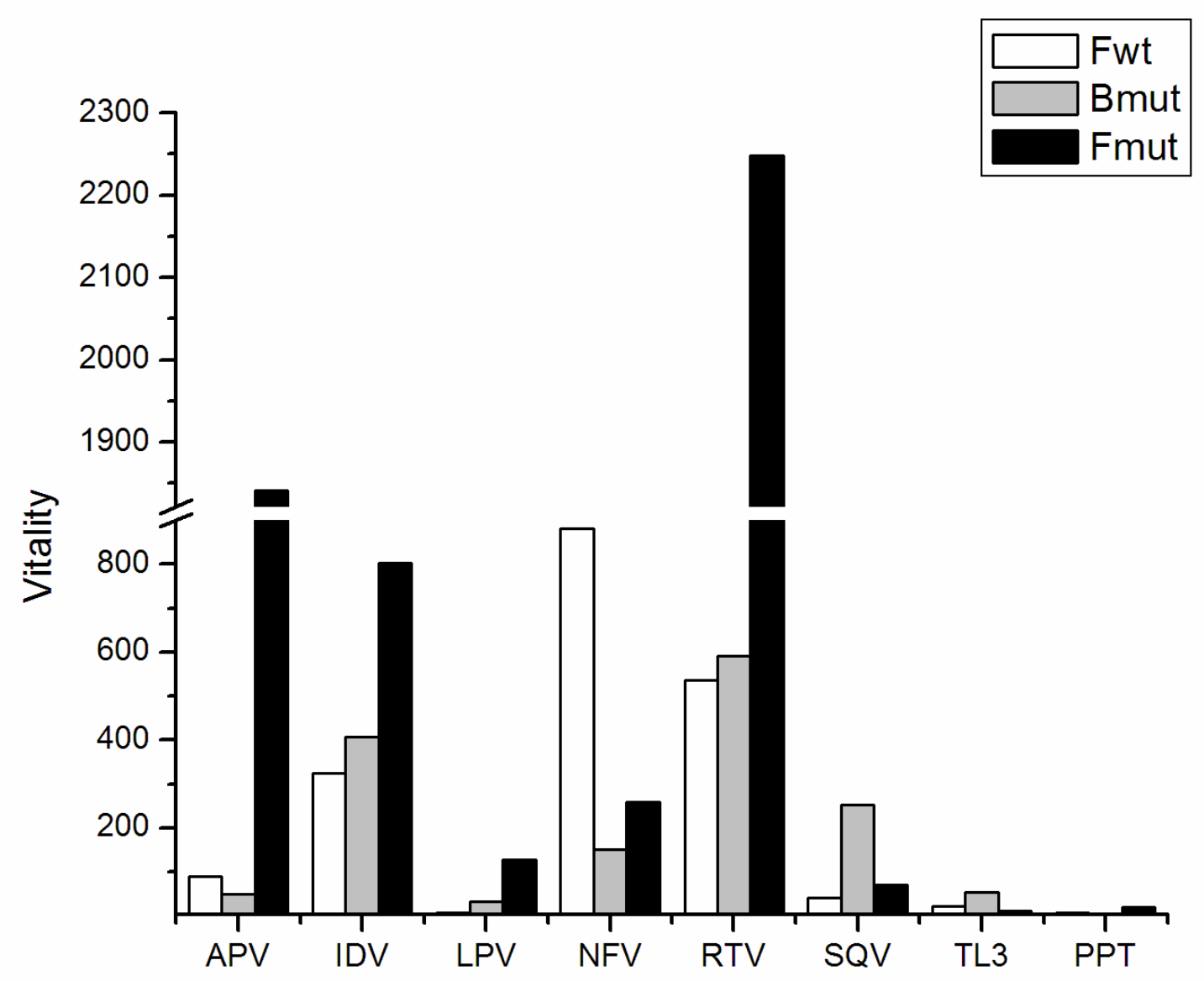

Figure 3 